\title{
WestVirginiaUniversity
}

THE RESEARCH REPOSITORY @ WVU

Graduate Theses, Dissertations, and Problem Reports

2000

\section{Individual differences and suggestibility of children's eyewitness memory reports}

\author{
Robin Myers Bartlett \\ West Virginia University
}

Follow this and additional works at: https://researchrepository.wvu.edu/etd

\section{Recommended Citation}

Bartlett, Robin Myers, "Individual differences and suggestibility of children's eyewitness memory reports" (2000). Graduate Theses, Dissertations, and Problem Reports. 1180.

https://researchrepository.wvu.edu/etd/1180

This Dissertation is protected by copyright and/or related rights. It has been brought to you by the The Research Repository @ WVU with permission from the rights-holder(s). You are free to use this Dissertation in any way that is permitted by the copyright and related rights legislation that applies to your use. For other uses you must obtain permission from the rights-holder(s) directly, unless additional rights are indicated by a Creative Commons license in the record and/ or on the work itself. This Dissertation has been accepted for inclusion in WVU Graduate Theses, Dissertations, and Problem Reports collection by an authorized administrator of The Research Repository @ WVU.

For more information, please contact researchrepository@mail.wvu.edu. 


\title{
Individual Differences and Suggestibility of Children's Eyewitness Memory Reports
}

\section{Robin Myers Bartlett}

\author{
Dissertation submitted to the \\ Eberly College of Arts and Sciences \\ at West Virginia University \\ in partial fulfillment of the requirements \\ for the degree of
}
Doctor of Philosophy
in Psychology

\author{
Tracy L. Morris, Ph.D., Chair \\ Wanda K. Franz, Ph.D. \\ Kevin T. Larkin, Ph.D. \\ Hayne W. Reese, Ph.D. \\ Anne C. Watson, Ph.D. \\ Department of Psychology
}

\section{Morgantown, WV 2000}

Keywords: individual differences, children's eyewitness memory Copyright 2000 Robin Myers Bartlett 


\author{
ABSTRACT \\ Individual Differences and Suggestibility of Children's \\ Eyewitness Memory Reports
}

Robin Myers Bartlett

A significant amount of recent research in the area of children's eyewitness memory has been aimed at examining children's vulnerability to suggestion. Numerous experimental factors have been found to impact children's suggestibility including the use of leading questions. However, research in this area has yet to investigate whether characteristics of the child play a role in susceptibility to suggestion. Accordingly, the present study was designed to combine the experimental and individual differences approaches to research to achieve a better understanding of children's susceptibility to suggestive questioning techniques. Ninety-six 9-12-year-old children and a parent participated in the study. Children viewed a brief videotaped anger scenario between male and female adult actors. Following a 20-minute delay, children were interviewed by a male or female research assistant regarding their recollections of the adult interaction. This interview included a: (1) free recall task, (2) series of prompted, open-ended questions, and (3) series of specific non-leading or leading questions. In addition, children and parents completed several questionnaires designed to assess attention, social anxiety, aspects of temperament, and assertiveness. Results indicated that while children provided limited amounts of information in response to the free and prompted recall interviews, their reports were highly accurate. Furthermore, children's free and prompted recall reports were more accurate for certain types of information including the statements made by the actors. Exposure to incorrectly leading questions had a negative impact on accuracy of recall, thereby supporting the notion that the inclusion of leading questions leads to suggestibility. Attention, assertiveness, and social anxiety were not found to be significant predictors of suggestibility. Taken together, the results emphasize the importance of employing non-suggestive questions when interviewing children about witnessed events. 


\section{Acknowledgments}

First and foremost, I want to express my sincere appreciation to my committee members, Dr. Tracy Morris, chair, and Drs. Wanda Franz, Kevin Larkin, Hayne Reese, and Anne Watson. I am extremely grateful for the time and effort each member contributed as well as the patience each displayed throughout the course of this project. A very special thank you is extended to Tracy and Hayne for their invaluable guidance and assistance on many aspects of the project. Their encouragement and willingness to help greatly facilitated my work on this project.

I am indebted to Keri Cunningham, Lisa Rizzuto, Kristen Mumaw, Sharon Ritz, Mike Weakland, and Eric Miller for their assistance during the data collection and coding phases of this project. These individuals were all great research assistants and their genuine dedication to the completion of this project will not be forgotten.

This project would not have been possible without financial support provided by the American Psychology-Law Society, West Virginia University's Office of Academic Affairs and Research, and West Virginia University's Department of Psychology Alumni Fund. The financial contributions made by each of these organizations is greatly appreciated.

Finally, I want to thank my friends and family. Special thanks to Staci Heindel, Pat Davies, Nicole Guajardo, Lisa Laumann, and Cathy Massey for being such dear and caring friends and providing me with a significant amount of support and encouragement throughout my graduate school experience. Thanks to my parents and family who never gave up on me or my quest for higher education. Your continued care and support as I embark upon a new phase in my life will be needed and welcomed. 
And last, but certainly not least, I want to acknowledge and thank my husband, Stacy, who has been with me from the beginning of this educational journey. I thank him for his support, encouragement, patience, and most of all, his love. While this chapter of our lives is coming to an end, a new one is just beginning and I look forward to sharing many new adventures, good and bad, with you. 


\section{TABLE OF CONTENTS}

Page

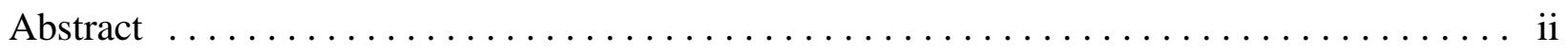

Acknowledgments $\ldots \ldots \ldots \ldots \ldots \ldots \ldots \ldots \ldots \ldots \ldots \ldots \ldots \ldots \ldots \ldots \ldots \ldots$ ii

List of Tables $\ldots \ldots \ldots \ldots \ldots \ldots \ldots \ldots \ldots \ldots \ldots \ldots \ldots \ldots \ldots \ldots \ldots \ldots \ldots \ldots$

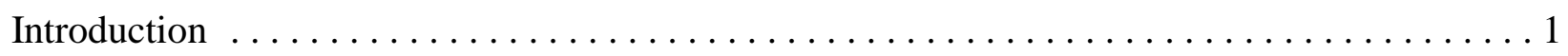

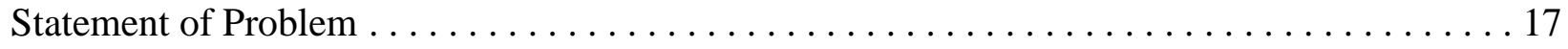

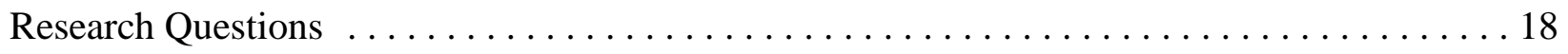

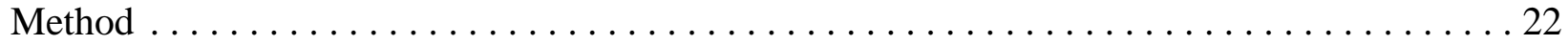

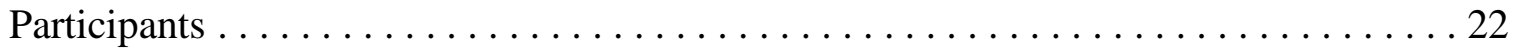

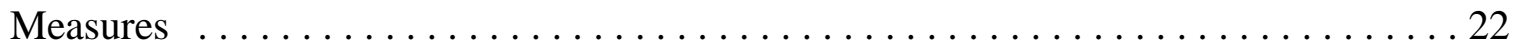

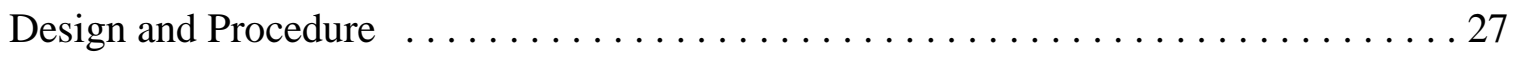

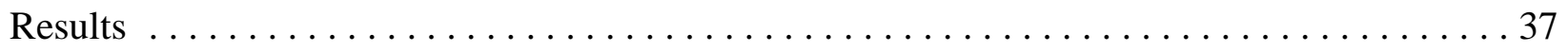

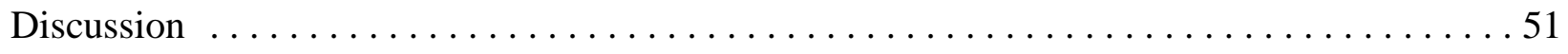

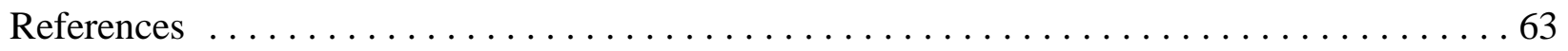

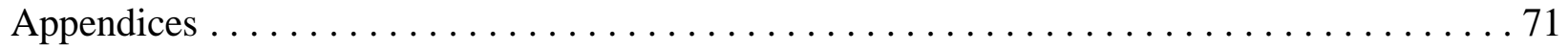

A. Demographic Background Questionnaire $\ldots \ldots \ldots \ldots \ldots \ldots \ldots \ldots \ldots$

B. Script for Simulated Conflict Scenario $\ldots \ldots \ldots \ldots \ldots \ldots \ldots \ldots \ldots$

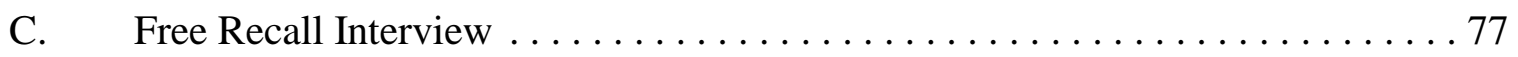

D. Prompted Recall Interview . . . . . . . . . . . . . . . . . . . . 79

E. Non-Leading and Leading Interviews $\ldots \ldots \ldots \ldots \ldots \ldots \ldots \ldots \ldots \ldots \ldots \ldots$

F. Free and Prompted Recall Accuracy Coding Sheets $\ldots \ldots \ldots \ldots \ldots \ldots 7$ 


\section{TABLE OF CONTENTS (CONTINUED)}

Page

G. Free and Prompted Recall Inaccuracy Coding Sheets . . . . . . . . . . . 96

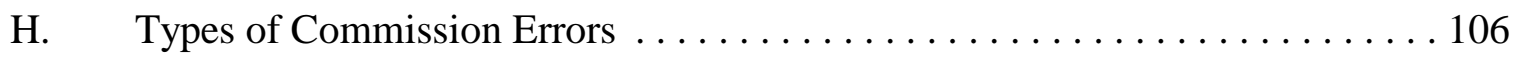

Tables ......................................... 110 


\section{LIST OF TABLES}

Table

Page

1 Mean Proportions (and Standard Deviations) of Accurate Information Reported for Free

Recall: Initial vs. Follow-up Responses . . . . . . . . . . . . . . . . 110

2 Mean Proportions (and Standard Deviations) of Accurate Information Reported for

Prompted Recall: Initial vs. Follow-up Responses $\ldots \ldots \ldots \ldots \ldots \ldots \ldots \ldots \ldots$

3 Mean Proportions (and Standard Deviations) of Accurate Information Reported for Free

Recall: Initial vs. Total (Initial + Follow-up) Responses . . . . . . . . . . . . 112

4 Mean Proportions (and Standard Deviations) of Accurate Information Reported for

Prompted Recall: Initial vs. Total (Initial + Follow-up) Responses . . . . . . . . . 113

5 Means (and Standard Deviations) of "Factually-Incorrect" Errors Reported for Free

Recall: Initial vs. Follow-up Responses . . . . . . . . . . . . . . . . 114

6 Means (and Standard Deviations) of "Factually-Incorrect" Errors Reported for Prompted

Recall: Initial vs. Follow-up Responses $\ldots \ldots \ldots \ldots \ldots \ldots \ldots \ldots \ldots \ldots \ldots \ldots \ldots$

7 Means (and Standard Deviations) of “Intrusion” Errors Reported for Free Recall: Initial

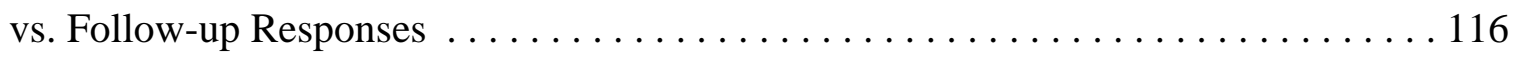

8 Means (and Standard Deviations) of "Intrusion" Errors Reported for Prompted Recall:

Initial vs. Follow-up Responses $\ldots \ldots \ldots \ldots \ldots \ldots \ldots \ldots \ldots \ldots \ldots \ldots \ldots \ldots \ldots$

9 Means (and Standard Deviations) of "Factually-Incorrect" Errors Reported for Free

Recall: Initial vs. Total (Initial + Follow-up) Responses . . . . . . . . . . . . . 118

10 Means (and Standard Deviations) of "Factually-Incorrect" Errors Reported for Prompted

Recall: Initial vs. Total (Initial + Follow-up) Responses . . . . . . . . . . . . . . . . 119 


\section{LIST OF TABLES (CONTINUED)}

Table

11 Means (and Standard Deviations) of "Intrusion" Errors Reported for Free Recall: Initial

vs. Total (Initial + Follow-up) Responses . . . . . . . . . . . . . . . . . 120

12 Means (and Standard Deviations) of "Intrusion" Errors Reported for Prompted Recall:

Initial vs. Total (Initial + Follow-up) Responses $\ldots \ldots \ldots \ldots \ldots \ldots \ldots \ldots \ldots \ldots \ldots$

13 Mean Proportions and Standard Deviations of Accurate Gender-specific Information as a

Function of Type of Information: Free Recall $\ldots \ldots \ldots \ldots \ldots \ldots \ldots \ldots \ldots \ldots \ldots \ldots$

14 Mean Proportions and Standard Deviations of Accurate Gender-specific Information as a

Function of Child Gender: Prompted Recall . . . . . . . . . . . . . . 123

15 Means (and Standard Deviations) of Inaccurate General Information (Raw Scores) as a

Function of Type of Error: Free and Prompted Recall . . . . . . . . . . . . . 124

16 Means (and Standard Deviations) of Inaccurate Gender-Specific Information (Raw

Scores) as a Function of Type of Error: Free Recall $\ldots \ldots \ldots \ldots \ldots \ldots \ldots \ldots \ldots$

17 Means (and Standard Deviations) of Inaccurate Gender-Specific Information (Raw

Scores) as a Function of Type of Error: Prompted Recall . . . . . . . . . . 126

18 Mean Proportions and Standard Deviations of Omission Errors for Gender-specific

Information as a Function of Type of Information: Free Recall $\ldots \ldots \ldots \ldots \ldots \ldots 127$

19 Mean Proportions and Standard Deviations of Omission Errors for Gender-specific Information as a Function of Child Gender: Prompted Recall $\ldots \ldots \ldots \ldots \ldots \ldots .128$

20 Non-Leading and Leading Interview Specific Questions . . . . . . . . . . . . . . 129

viii 


\section{LIST OF TABLES (CONTINUED)}

Table

Page

21 Mean Proportions (and Standard Deviations) of Accurate Responses as a Function of Type of Interview and Type of Question: Specific Questions . . . . . . . . . 131

22 Mean Proportions (and Standard Deviations) of Leading Interview Responses as a Function of Type of Question, Type of Response, and Type of Information . . . . . 132

23 Mean Proportions (and Standard Deviations) of "Don't Know/Remember" Responses as a Function of Type of Question, Type of Interview, and Type of Information: Specific

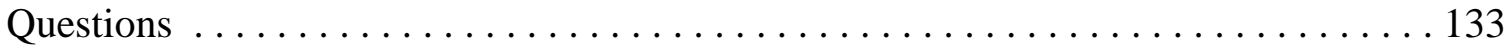

24 Means and Standard Deviations for Parent- and Child-Report Measures of Individual Difference Variables ................................ 134

25 Interrelations Between Parent-Report Assessments of Individual Difference Variables 135

26 Interrelations Between Child-Report Assessments of Individual Difference Variables 136

27 Interrelations Between Parent- and Child-Report Assessments of Individual Difference Variables ....................................... 137

28 Factor Analysis of Parent-and Child-Report Assessments of Individual Difference

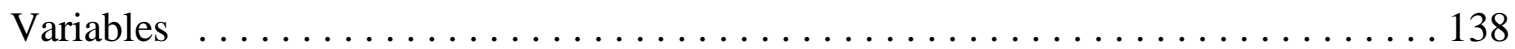

29 Interrelations among Variables included in the Standard Multiple Regression . . . . . 139

30 Standard Multiple Regression for Individual Difference Variables Predicting Accuracy:

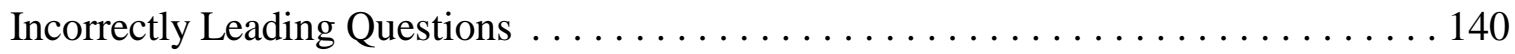


Individual Differences and Suggestibility of Children's

Eyewitness Memory Reports

Introduction

Historically, the use of children as eyewitnesses in civil and criminal legal proceedings

has been a controversial issue. As witnesses, children of all ages often are viewed as unreliable due to the assumption that they are highly susceptible to suggestion (Bruck, Ceci, \& Melnyk, 1997; Ceci \& Bruck, 1993; Ceci, Ross, \& Toglia, 1987; Loftus \& Doyle, 1992). Nevertheless, increased awareness of the effects of child physical and sexual abuse has increased the frequency with which children serve as witnesses, and also mandated changes in the laws governing their testimony in court cases. For example, given the private nature of sexual abuse events, the corroboration of evidence requirements for child victims have been dropped in all fifty states (Ceci \& Bruck, 1993). Consequently, such changes have heightened the importance of research aimed at determining the reliability (i.e., accuracy) of child witnesses.

\section{Definitions of Suggestibility and Approaches to Research}

Traditionally, definitions of suggestibility have emphasized the acceptance and incorporation of post-event information into memory (Powers, Andriks, \& Loftus, 1979; Ward \& Loftus, 1985). Consistent with this definition, early studies of children's suggestibility typically introduced post-event information via the use of leading questions which Hilgard and Loftus (1979) defined as a question “...that, either by its form or content, suggests to the witness what answer is desired or leads him to the desired answer" (p. 351). Results of such research indicated that, in general, children of all ages (i.e., preschoolers to adolescents) are more suggestible than adults (Bruck, Ceci, \& Hembrooke, 1998; Ceci \& Bruck, 1993). Recent work, however, has 
shown that children's recollections also are influenced by a variety of other factors including preevent information (e.g., stereotypes) (Leichtman \& Ceci, 1995), the age of the interviewer (e.g., child vs. adult) (Ceci et al., 1987), and the emotional tone of the interview (Saywitz, Geiselman, \& Bornstein, 1992). Accordingly, Ceci and Bruck (1993) extended the definition of suggestibility to include "the degree to which children's encoding, storage, retrieval, and reporting of events can be influenced by a range of social and psychological factors" (p. 404).

A significant amount of research in this area has focused on examining the conditions under which children are most susceptible to suggestion (Ceci \& Bruck, 1993). This "experimental approach" to research, as termed by Schooler and Loftus (1986), has yielded a vast amount of information regarding factors that increase children's suggestibility. For example, children are more susceptible to suggestive questions following long delays between witnessing and recalling an event (Oates \& Shrimpton, 1991). Exposure to repeated questioning about an event also negatively impacts children's eyewitness performance (Poole \& White, 1991).

While the experimental approach to research has succeeded in delineating a variety of conditions that impact children's suggestibility, experimental studies essentially have ignored a critical aspect of Ceci and Bruck's (1993) definition of suggestibility. Specifically, their emphasis on "a range of social and psychological factors" implies that characteristics of the individual also may impact eyewitness reports. To date, however, the influence of individual difference variables on susceptibility to suggestion remains largely uninvestigated (Bruck, et al., 1997; Gudjonsson, 1992). The importance of this future direction for research has been highlighted by noting that age is an index variable reflecting important individual differences (e.g., intellectual and social functioning) and an examination of such characteristics is essential in 
determining the reliability of child witnesses (Ceci, Crotteau, Smith, \& Loftus, 1994; Davies, Tarrant, \& Flin, 1989). Accordingly, the present study was designed as an initial attempt to combine the experimental and individual differences approaches to research to achieve a better understanding of children's vulnerability to suggestive questioning techniques. The following sections will provide a discussion of both the experimental and individual difference factors employed in the present investigation.

\section{Experimental Factors}

\section{Type of Question}

The increased involvement of children in the legal system has sparked renewed interest in how to elicit event memories from children. It is important to note that under certain circumstances, even very young children (i.e., preschoolers) are capable of providing accurate and useful information about witnessed events. Specifically, a consistent finding in the literature is that children's recollections are quite accurate in response to open-ended questions, that is, questions that require a multiple-word response (e.g., "Tell me about everything that happened," “Tell me about the man") (Bruck et al., 1998; Poole \& Lamb, 1998; Poole \& White, 1991). Typically, however, children provide significantly less information in response to open-ended questions than in response to a series of specific questions that ask about a particular detail and often require only a one-word response (e.g., "yes/no") (Poole \& Lamb, 1998; Poole \& White, 1991). As a result, interviewers frequently employ specific questions to elicit more detailed information from children. However, research shows that children's responses to specific questions are less accurate than their responses to open-ended questions (Bruck et al., 1997; Poole \& Lamb, 1998; Poole \& White, 1991). Furthermore, specific questions are much more 
likely to be leading in nature which can lead to the suggestibility of witnesses; that is, errors in recall stemming from exposure to false information or to an emotional atmosphere that encourages particular responses (Poole \& Lamb, 1998; Poole \& White, 1991). Given the detrimental impact of specific questions on the accuracy of children's reports, a substantial amount of research has focused on delineating the various types of specific questions and their effects on the reliability of children's recollections.

The use of specific, misleading questions in investigative interviews has a negative impact on accuracy of recall. Research has documented that subtle changes in the wording of a question can increase suggestibility. Dale, Loftus, and Rathbun (1978) examined the influence of the form of the question on preschoolers' (4-5-year-olds) eyewitness recollections. Results indicated that changing the article used in a question from "a" to "the" (i.e., "Did you see a" vs. "Did you see the") for questions about non-occurring events increased inaccurate responding. In addition, questions containing quantifiers such as "some" and "any" (i.e., "Did you see some," "Did you see any") were found to increase suggestibility. Other research conducted with adults has demonstrated the detrimental impact of using a negative term in the question (e.g., "Didn't you see" vs. "Did you see”) on accuracy of recall (Loftus \& Zanni, 1975).

Forced-choice questions also have been found to compromise the reliability of children's eyewitness reports. Such questions typically take one of two forms: (1) correct response embedded within the question, and (2) correct response not embedded within the question (i.e., neither option is correct). The problem with forced-choice questions appears to be the development of a response set favoring the selection of the second option (Walker, Lunning, \& Eilts, 1996, as cited in Poole \& Lamb, 1998). This seems to be especially true for young children 
(5-year-olds) who are less likely than older children (7-and-9-year-olds) to provide a response of "neither" when the correct option is not embedded within the question (Walker et al., 1996, as cited in Poole \& Lamb, 1998). To date, however, research examining the use of forced-choice questions is rather limited. Thus, future research is clearly warranted to obtain a better understanding of the impact of this type of question on the accuracy of children's eyewitness reports.

Child witnesses typically are interviewed by numerous individuals, each of whom may have different agendas (e.g., police officers, prosecutors, defense attorneys, social workers). For example, whereas police officers are interested in gathering information that is consistent with a particular suspect, defense attorneys aim to discover information that would disprove the guilt of their client. Accordingly, interviewers may use different strategies to elicit information from children that is consistent with their goals and beliefs (Bruck et al., 1997). Thus, the extent to which children can be lead to provide "correct" and "incorrect" responses is of critical importance in assessing the reliability of child witnesses. Cassel and Bjorklund (1995) examined this issue by randomly assigning children (6-and 8-year-olds) to either a positive-leading interview (i.e., questions suggested correct responses about the witnessed event) or a negativeleading interview (i.e., questions suggested incorrect answers about the event). Results indicated that children provided more correct responses to the positive-leading questions than the negativeleading questions. Conversely, incorrect responses were higher in the negative-leading interview condition than the positive-leading condition. Thus, the pattern of results appears to suggest that children in the positive-leading condition were "lead" to accept the correct answers, whereas exposure to the negative-leading questions had a detrimental impact on accuracy of recall. 
A significant amount of recent research has focused on investigating young children's (i.e., preschoolers) vulnerability to suggestion. Developmental studies of suggestibility have documented reliable age differences in suggestibility with very young children (3-6-year-olds) being most vulnerable to suggestive questioning techniques (see Bruck et al., 1997; Ceci \& Bruck, 1993, for reviews). However, as noted by Ceci and Bruck (1993), it is unwise to conclude that susceptibility to suggestion is limited to young children for several different reasons. First, due to issues of task equivalence, developmental studies may underestimate the suggestibility of children older than six years of age. Specifically, the questions and tasks employed in such studies must be geared toward the lowest common denominator, or preschoolers, and thus, may be easier for children ages seven and older. Additionally, research has shown that children older than six years of age and even adults demonstrate impairments in memory performance when leading questions were employed in investigative-style interviews (e.g., Ackil \& Zaragoza, 1995; Loftus \& Pickrell, 1995; Warren \& Lane, 1995). Thus, a critical task for future research involves examining susceptibility to suggestion for child age groups that have been neglected in the past, such as middle childhood (see Bruck et al., 1998). Furthermore, such research efforts must include the development of age-relevant tasks and paradigms to gain a better understanding of the degree of suggestibility of children in this age range (e.g., exposure to multiple suggestive questions as opposed to the use of only one as is the case with many studies involving preschoolers) (Bruck et al., 1998). Accordingly, the present study aimed to address this issue by investigating vulnerability to suggestive questioning techniques in 9-12-year-old children. 


\section{Gender of the Interviewer}

As previously noted, significant advances in understanding the conditions under which children are most susceptible to suggestion have been made. However, research in this area has yet to examine the impact of interviewer gender on children's eyewitness performance. To date, studies investigating children's eyewitness memory and suggestibility consistently have employed only female interviewers (e.g., Cassel \& Bjorklund, 1995; Davies, et al., 1989; Goodman \& Reed, 1986; Memon \& Vartoukian, 1996; Poole \& White, 1991; Portwood \& Reppucci, 1996). Thus, an important factor that might influence the reliability of the child witness remains uninvestigated.

Children involved in legal proceedings generally are asked to disclose personal information (e.g., physical/sexual abuse events, family functioning in custody evaluations) to authority figures (e.g., doctors, therapists, police officers, lawyers, etc.). Thus, an examination of interviewer characteristics that might influence the ability to elicit such personal information is of critical importance. One factor that may affect the disclosure of personal information is the gender of the interviewer. A consistent finding in the adult literature is that both men and women tend to disclose more personal information about psychological problems to female interviewers than to male interviewers (Dindia \& Allen, 1992; Pollner, 1998). However, research examining the effects of interviewer gender on eliciting sexual information (e.g., sexual abuse and offenses) has yielded equivocal results. Specifically, Fry, Rozewicz, and Crisp (1996) had male and female interviewers administer a sexual abuse interview to women with chronic pelvic pain. Results indicated that gender of the interviewer did not affect the number of abuse incidents described by the women. Kaplan, Becker, and Tenke (1991) surveyed adolescent male 
sex offenders (11-19-years-old) about their preference and comfort in talking about sexual issues with a male or female interviewer. Whereas non-abused males indicated no preference for a male versus a female interviewer, males who themselves were victims of physical and/or sexual abuse reported more comfort and a preference for talking with a female interviewer. Clearly, more systematic research regarding the effects of interviewer gender on the disclosure of personal information is warranted. Given that the majority of research in this area has been performed with adult populations, future efforts should be aimed at investigating such issues in childhood. Furthermore, future studies should examine the impact of interviewer gender on the reporting of information in investigative style interviews as opposed to focusing on clinical interviews.

Type of Information to be Recalled

Eyewitnesses typically are asked to provide descriptions of various types of information including physical appearances, actions, and the setting or environment. Accordingly, research in the area of children's eyewitness memory has examined the reliability of children's reports for different types of information. A consistent finding is that children's (range 3-11-years-of-age) recollections are more accurate for descriptions about actions than for details about persons and the setting or environment (Davies et al., 1989; Goodman, Hirschman, Hepps, \& Rudy, 1991; Memon \& Vartoukian, 1996).

Research with adult populations also has examined accuracy of reporting for different types of information and yielded interesting results. Specifically, interactions between gender and the type of information to be recalled have been found. In general, it appears that females are more accurate than males in recollections of female-oriented details (e.g., what the woman was 
wearing, what she did), whereas males are more accurate than females on questions concerning male-actor characteristics and surroundings (Christiaansen, Ochalek, \& Sweeney, 1984; Powers et al., 1979).

To date, gender differences in accuracy of recall for different types of information have not been found in research with children. Goodman and Reed (1986) and Davies, Tarrant, and Flin (1989) examined the impact of both child age and child gender on the accuracy of children's eyewitness reports. The studies were similar in that younger and older children engaged in an interaction with a male research assistant and were questioned regarding their recollections of the event several days later. Older children were more accurate in their eyewitness reports than younger children, however no gender differences in accuracy were found. Based on the results of research with adult populations, one might have expected the male children in these studies to have been more accurate in their recollections than females given that the questions were centered on male-oriented details (i.e., the questions were based on the interaction with the male research assistant). Perhaps better memory for same-gender details is the result of learning via increased exposure across the life-span. At this point, however, it appears that more systematic research examining the reliability of children's reports for same-gender details is needed to achieve a more complete understanding of this issue.

\section{$\underline{\text { Individual Difference Variables }}$}

The conditions of the interview clearly play a major role in accounting for children's suggestibility. However, not all children are influenced by suggestive questioning techniques. Accordingly, researchers in the area of children's eyewitness memory are beginning to emphasize the importance of examining individual factors that might account for differences in children's 
vulnerability to suggestive questions (Bruck et al., 1997). To date, little research on this topic with child populations exists. Thus, guided by a review of the adult literature as well as a conceptual understanding of the cognitive and socio-emotional processes involved in investigative interview situations, the following individual factors were selected for examination in the present study: (1) attention, (2) social anxiety, (3) temperament, and (4) assertiveness. The remainder of this section will provide a discussion of the relevance of these factors as predictor variables in children's vulnerability to suggestion. It is important to note that while these factors may have an independent influence on children's suggestibility, they also may interact in a variety of ways to influence suggestibility. Accordingly, relations between attention, temperament, social anxiety, and assertiveness also will be discussed.

\section{$\underline{\text { Attention }}$}

Attentional processes are fundamental to the reporting of witnessed events on several different levels. First, attention is required for the transfer of information into memory. Thus, accurate recollections of a particular event are contingent on an individual attending to important elements of the event (Poole \& Lamb, 1998). Additionally, attentional processes are required during subsequent interviews about the witnessed event. Specifically, individuals must attend to the questions being asked by the interviewers (Poole \& Lamb, 1998).

Research shows that while general alertness does not change much throughout the lifespan, the ability to focus attention on tasks at hand does increase with age (Gibson \& Radner, 1979). However, differences in attentional abilities may play a role in susceptibility to suggestive questioning techniques. Furthermore, attentional abilities may be affected by other factors including anxiety and self-preoccupation (Crozier, 1979; Sattler, 1992) (interactions 
among these variables are discussed below). Accordingly, the present study was designed to examine the role attentional processes may play in influencing children's vulnerability to suggestion.

\section{$\underline{\text { Social Anxiety }}$}

Feelings of anxiety and discomfort in social situations are quite common. In fact, it is likely that most everyone will experience anxiety in a social setting at some point in their lives, such as when giving a public speech or being interviewed for a job. However, individuals differ greatly in the frequency and intensity with which they experience anxiety in social situations as well as in the impact such feelings have on their daily functioning (Leary \& Kowalski, 1995). For some individuals, feelings of extreme anxiety and distress occur in response to "the prospect or presence of interpersonal evaluation in real or imagined social settings" (Schlenker \& Leary, 1982, p. 642). Thus, social-evaluative concerns function as the defining aspect of social anxiety and often such apprehensions lead socially-anxious individuals to withdrawal from or, at the extreme, avoidance of social situations (Leary \& Kowalski, 1995).

While socially-anxious individuals may experience anxiety in a wide variety of social situations, four particular types of situations appear to be extremely problematic including those involving: (a) formal speaking and interactions (e.g., presenting a speech in class or a meeting), (b) informal speaking and interactions (e.g., talking at a party or dance), (c) assertive interactions (e.g., standing up for oneself, talking to authority figures), and (d) observations of behavior or actions (e.g., eating or writing while others are present) (Holt, Heimberg, Hope, \& Liebowitz, 1992). Within each of these social situations, interactions with members of the opposite sex appear to heighten feelings of anxiety for socially-anxious individuals (Galassi \& Bruch, 1992; 
Leary \& Kowalski, 1995). Consistent with Schlenker and Leary's (1982) conceptualization of social anxiety, each of these particular types of situations involves a social-evaluative component. Specifically, socially-anxious individuals often exhibit a range of social-evaluative concerns including fears of negative evaluations or criticism from others as well as fears of their own limitations and incompetencies (Beidel \& Morris, 1993; Gilbert \& Trower, 1990; Leary \& Kowalski, 1995). Additionally, socially-anxious individuals generally have concerns about selfpresentation and consequently, often demonstrate a strong desire to please others to avoid embarrassment and humiliation (Gilbert \& Trower, 1990; Leary \& Kowalski, 1995).

Given the types of situations that are problematic for socially-anxious individuals and the social-evaluative concerns they exhibit, social anxiety may be expected to have important implications regarding the accuracy and effectiveness of an eyewitness. Generally, eyewitnesses' reporting of events take place in several of the types of social situations known to precipitate social anxiety including formal speaking and assertive interactions (e.g., talking to police personnel and lawyers), situations involving direct observations of behavior, and interactions with members of the opposite sex. This, in combination with socially-anxious individuals' fears of negative evaluation and desire to please others, may have a detrimental impact on the accuracy of their recollections and also render them more vulnerable to suggestive lines of questioning. Working primarily with adult populations, Gudjonsson and colleagues have examined relations between suggestibility and social-evaluative anxiety (see Gudjonsson, 1992, for a review). Results demonstrated positive associations between social-evaluative anxiety and suggestibility. Other studies conducted with adult populations have examined the influence of general anxiety on eyewitness performance. Siegel and Loftus (1978) examined relations 
between an individual's level of anxiety and self-preoccupation at the time of testing and their subsequent eyewitness performance. Both anxiety and self-preoccupation were negatively correlated with accuracy of recall. In a related study, Ward and Loftus (1985) examined the impact of different personality factors, namely introversion and extroversion, on eyewitness performance. As the researchers noted, introverts and extroverts are posited to differ in their basal levels of arousal which is related to anxiety. Specifically, introverts are thought to display increased levels of arousal as compared to extroverts. Results indicated that introverts were more susceptible to the impact of leading, post-event information than extroverts.

In sum, the types of situations known to precipitate social anxiety, the social-evaluative concerns of anxious individuals, and previous research examining the impact of anxiety on memory with adult populations provide a basis for expecting differences in eyewitness performance based on this variable. However, to date this issue remains largely uninvestigated, particularly in the field of children's eyewitness memory (Bruck et al., 1997). Accordingly, a primary aim of the present study was to examine the influence of social anxiety on children's susceptibility to suggestion.

\section{Temperament}

In examining the etiology of social anxiety, researchers have identified child temperament as an important developmental precursor (Asendorpf, 1993; Rubin, 1993; Stevenson-Hinde \& Shouldice, 1993). Specifically, when confronted with unfamiliarity in both social and non-social situations (e.g., strangers, environmental changes), some children respond with increased arousal, irritability, and inhibited behavior patterns characterized primarily by social withdrawal (Asendorpf, 1993; Rubin, 1993). Results of an ambitious longitudinal investigation indicated 
that social withdrawal in children at age five was related to internalizing problems in early adolescence (age 11) (Rubin, 1993). Accordingly, temperamental differences also may be related to susceptibility to suggestion.

To date, no studies have examined relations between temperamental characteristics and suggestibility, per se. However, research investigating relations between temperament and obedience provide support for the notion that temperamental factors may be linked with vulnerability to suggestion. Specifically, in a study by Kagan (as cited in Schacter, Kagan, and Leichtman, 1995), low-reactive-uninhibited and high-reactive-inhibited 4-year-old children were asked to perform a variety of actions by a research assistant. The actions children were asked to perform differed as a function of whether they would be approved by their parents (e.g., pouring water from one cup to another vs. throwing a ball at the experimenter's face or pouring juice on the table). Results indicated that compared to low-reactive-uninhibited children, high-reactiveinhibited children demonstrated more obedience to the experimenter's requests. That is, highreactive-inhibited children were less likely to refuse the experimenter's request and less likely to question why they should perform the act than low-reactive-uninhibited children. Thus, inhibited children (who are at increased risk for the development of internalizing disorders, such as social anxiety; Asendorpf, 1993) may be less likely to resist suggestive questions due to their willingness to please adults. The present study aimed to address this question by examining aspects of child temperament proffered to be related to the construct of social anxiety (e.g., approach/withdrawal, flexibility/rigidity). 


\section{$\underline{\text { Assertiveness }}$}

As noted by Ceci and Bruck (1993), a potential underlying mechanism of children's suggestibility involves their compliance and willingness to please adults and authority figures. That is, through the process of socialization, children come to view adults as honest and consequently, trust that they are asking credible questions. Research examining the effects of repeated questioning on children's eyewitness memory lends support to this notion by documenting that children typically change their answers presumably to please the adult who is questioning them (e.g., Siegal, Waters, \& Dinwiddy, 1988). As previously noted, however, not all children are influenced by suggestive questioning techniques (e.g., repetition), thereby suggesting that other factors may be correlated with or independent of compliance. One such factor may be assertiveness.

In a study conducted with adults, Gudjonsson (1988) found a negative association between assertiveness and eyewitness suggestibility. To date, research has yet to examine the relationship between assertiveness and children's susceptibility to suggestion. Accordingly, the present study was designed to address this issue.

\section{Relations among Attention, Social Anxiety, Assertiveness, and Suggestibility}

As previously noted, Ceci and Bruck's (1993) definition of suggestibility emphasizes the impact of social and psychological factors not only on children's reporting of events, but also on the processes of encoding, storage, and retrieval. The notion that increases in emotional arousal are linked with reductions in attention which, in turn, adversely affect the encoding of information is not new (Easterbrook, 1959). Recent research examining the impact of socialevaluative anxiety on memory lends support to the notion that such processes (e.g., attention, 
encoding, storage, retrieval) might be compromised in individuals experiencing extreme social anxiety. Specifically, Kimble and Zehr (1982) had college-aged females who differed in trait self-consciousness (e.g., embarrassment, anxiety, concern, etc.) briefly meet five other women. Results indicated that highly self-conscious females recalled less information about characteristics of the women they had met (e.g., hair color, color of their sweaters, objects they carried) than females who were low in self-consciousness. In explaining the results, the investigators noted that self-consciousness may have limited the attentional processes needed for encoding information and thus, negatively impacted recall for external information. This negative impact on memory processes coupled with the socially-anxious individual's desire to please others and to avoid embarrassment may render them more susceptible to suggestive questioning techniques when it comes to the reporting of events in investigative interview situations.

One of the situational domains known to precipitate social anxiety involves interactions requiring assertive behavior such as when talking to an authority figure or resisting high-pressure tactics (Holt et al., 1992). Clearly, interrogative situations can be conceptualized as a social situation that requires assertive behavior as eyewitnesses must report to a variety of authority figures (e.g., police personnel, lawyers, judges) as well as to resist suggestive questioning techniques. Consistent with the social-evaluative concerns of socially-anxious individuals, fears of negative evaluation may decrease the likelihood of assertive behavior in interrogative situations, thereby increasing susceptibility to suggestion. Gudjonsson (1988) has found support for this notion. Specifically, results demonstrated a negative association between adults' assertiveness and social-evaluative anxiety. Furthermore, whereas social-evaluative anxiety was 
positively associated with suggestibility scores, assertiveness was negatively correlated with eyewitness suggestibility.

Taken together, the results of research examining relations among attention, social anxiety, assertiveness, and memory suggest that these individual factors may interact in meaningful ways to create a psychological profile of a "suggestible" eyewitness.

\section{Statement of the Problem}

To date, research examining the influence of individual differences on children's reporting of witnessed events is extremely limited. Accordingly, the present study was designed to combine the experimental and individual differences approaches to research in an attempt to address this critical void in the literature. Given that individual factors typically are assessed via self-report measures which often require a minimum third grade reading level, this study included children nine to twelve years of age. In addition to facilitating the assessment of individual differences, the selection of children in this age range is of critical importance as previous research primarily has emphasized the examination of suggestibility of very young children (i.e., preschoolers) (see Bruck et al., 1998).

Children viewed a brief videotaped anger scenario between male and female adult actors. Following a 20-minute delay, children were interviewed regarding their recollections of the adult interaction. This investigative interview included a: (1) free recall task (i.e., "tell me everything you can remember about what you saw and what happened on the videotape), (2) prompted recall task (i.e., series of open-ended questions about the man, woman, room), and (3) series of specific questions (i.e., questions that require a one-word response) phrased in either a non-leading or leading format. The interviews were conducted by either a male or female research assistant. 
Prior to and following the interview, children completed self-report measures and tasks aimed at assessing attention, social anxiety, and assertiveness. In addition, parents completed questionnaires designed to assess their perceptions of their child's social anxiety and temperament.

\section{$\underline{\text { Research Questions }}$}

(1) Do children's free and prompted recall reports of accurate and inaccurate information differ as a function of general type of information (i.e., appearance, actions, statements, setting), child gender, and interviewer gender?

Based on previous research in the area of children's eyewitness memory (e.g., Cassel \& Bjorklund, 1995; Memon \& Vartoukian, 1996; Poole \& White, 1991), children's free and prompted recall reports were hypothesized to be highly accurate. In addition, children's recollections were hypothesized to be more accurate for certain types of information including the actions and statements made by the actors (as opposed to details about the appearance of the actors and the room/setting). In the absence of pertinent data, no formal hypotheses were proffered regarding the effects of child and interviewer gender on accuracy of recall for general information.

(2) Do children's free and prompted recall reports of accurate and inaccurate information differ as a function of gender-specific information (i.e., man/woman appearance, man/woman actions, man/woman statements), child gender, and interviewer gender?

As previously noted, gender differences in the accuracy of recall for gender-specific information have emerged in the adult literature. Specifically, females tend to be more accurate than males for recollections of female-oriented details, whereas males typically are more accurate 
than females for information regarding male-oriented characteristics (Christiaansen et al., 1984; Powers et al., 1979). To date, the examination of children's recollections for gender-specific details remains largely uninvestigated in the area of eyewitness memory. Based on the results of research with adult populations, children may be expected to be more accurate in their recollections for same-gender details. In the absence of pertinent data, however, this notion was regarded as exploratory.

(3) Do children's accurate responses to specific questions differ as a function of type of information (i.e., man/woman characteristics, room characteristics, argument-content characteristics), type of interview (i.e., non-leading or leading), type of question (i.e., non$\underline{\text { leading, correctly, and incorrectly leading), child gender, and interviewer gender? }}$

Consistent with previous research (see Cassel \& Bjorklund, 1995; Ceci \& Bruck, 1993), children's responses to specific interview questions were hypothesized to differ as a function of type of interview and type of question. Children exposed to the non-leading interview condition (who were asked only non-leading questions) were hypothesized to be highly accurate in their recollections. Accuracy of responding of children assigned to the leading interview condition, however, was hypothesized to differ depending on the type of question (i.e., non-leading, correctly leading, incorrectly leading). Specifically, for the leading interview condition, children's responses to both the non-leading and correctly leading questions were hypothesized to be more accurate than their responses to the incorrectly leading questions. That is, the inclusion of incorrectly leading questions was hypothesized to have a negative impact on accuracy of recall. 
Children's responses to specific interview questions also were hypothesized to differ as a function of type of interview, type of question, and type of information. Previous research has demonstrated that children tend to be more vulnerable to suggestive questions that center on peripheral (e.g., setting/environment) as opposed to central (e.g., actions, dialogue) details (Goodman et al., 1991). Accordingly, accuracy of responding to incorrectly leading questions for children in the leading interview condition was hypothesized to differ as a function of type of information. Specifically, the inclusion of incorrectly leading questions was hypothesized to have a more negative impact on accuracy of responding for details about the room/setting (i.e., peripheral information) as opposed to questions about the content of the argument (i.e., central information).

(4) Do meaningful relations exist among the individual difference variables as assessed by both parent- and child-report?

As previously noted, anxiety and self-preoccupation have been proffered to negatively impact attentional processes (Crozier, 1979; Easterbrook, 1959; Sattler, 1992). Furthermore, research examining the impact of social-evaluative anxiety on memory lends support to the notion that attentional processes are compromised in individuals experiencing social anxiety and self-consciousness (Kimble \& Zehr, 1982). Accordingly, a negative association between child social anxiety and attention was hypothesized.

Given the social-evaluative concerns of socially-anxious individuals and research conducted by Gudjonsson (1988) with adults, children's reports of social anxiety were hypothesized to be negatively related to their reports of assertiveness. 
Child temperament has been identified as an important developmental precursor to social anxiety (Asendorpf, 1993; Rubin, 1993). Thus, parental perceptions of child social anxiety were hypothesized to relate to aspects of child temperament. Specifically, parental perceptions of child social anxiety were hypothesized to be related to perceptions of the child's tendency (1) to withdraw from novel persons and situations, and (2) to resist changes in the environment and behavioral routines.

\section{(5) Do individual differences predict susceptibility to suggestion?}

Based on previous research with adult populations (e.g., Gudjonsson, 1988) as well as an understanding of the social-evaluative concerns displayed by socially-anxious individuals (e.g., fears of negative evaluation, desire to please others) (Leary \& Kowalski, 1995), child social anxiety was hypothesized to be a significant predictor of suggestibility. Specifically, children with increased levels of social anxiety were hypothesized to be more susceptible to leading questions.

Assertiveness and attention also were hypothesized to predict vulnerability to suggestive questions. Based on research conducted with adults (Gudjonsson, 1988), children reporting less assertiveness were hypothesized to be more vulnerable to leading questions. Given that attentional processes are fundamental to eyewitness memory performance (Poole \& Lamb, 1998), children with reduced attentional abilities were hypothesized to display increased suggestibility. 
Method

\section{$\underline{\text { Participants }}$}

Ninety-six (48 boys and 48 girls) 9-12-year-old children $(\underline{\mathrm{M}}=10.5$-years; $\underline{\mathrm{SD}}=1.12)$ and a parent participated (95\% mothers, $5 \%$ fathers). Participants were predominantly EuropeanAmerican (96\%), with the remainder of participants being Asian-American (2\%), AfricanAmerican (1\%), and Indian (1\%). Socioeconomic status (SES), as determined by the Hollingshead Four-Factor Index (Hollingshead, 1975), ranged from Class 1 to Class 3 with a mean of $51.6(\underline{\mathrm{SD}}=10.06)$, representative of middle-class status. The majority of children were from intact, two-parent homes (90\%), with the remainder being from either divorced (5\%), separated $(3 \%)$, or single-parent $(2 \%)$ households.

The 96 child participants came from 72 families who agreed to participate in the study ( $84 \%$ of the 86 families contacted). While siblings were permitted to participate, no more than two children were included from any one family. Families were recruited through: (a) files of previous participants who indicated a desire to be involved in additional research (58\%), (b) fliers posted in the community, newspaper ads, announcements in church bulletins (16\%), and (c) referrals from other participants (10\%). Parents and children received a total of $\$ 15$ for participating.

$\underline{\text { Measures }}$

Wechsler Intelligence Scale for Children-Revised (WISC-R): Digit Span Subtest. The Digit Span subtest of the WISC-R was administered to children to provide an assessment of short-term memory and global attention (Sattler, 1992). The Digit Span subtest includes two parts, administered respectively: Digits Forward and Digits Backward (Sattler, 1992). For both 
tasks, a series of numbers were read to children at the rate of one per second. For the Digits Forward, children were instructed to repeat the numbers in the order that they were read, whereas for the Digits Backward task, children were instructed to repeat the numbers in the reverse order of which they were read. Raw scores were converted to normative scaled scores ranging from 119 with higher scores reflecting better concentration and attention (normative $\underline{\mathrm{M}}=10.00, \underline{\mathrm{SD}}=$ 3.00; Wechsler, 1991).

The Digit Span subtest of the WISC-R has demonstrated high split-half reliability for the age range of children included in the present study: $\underline{r}=.82$, for 9 -year-olds; $\underline{r}=.84$, for 10 -yearolds; $\underline{\mathrm{r}}=.84$, for 11 -year-olds; and $\underline{\mathrm{r}}=.87$, for 12-year-olds (Wechsler, 1991). In addition, the Digit Span subtest has documented adequate test-retest reliability for children ages 10- and 11years-old at a median interval of 23 days (range $=12-63$ days), $\underline{r}=.75$ (Wechsler, 1991). Finally, the WISC-R has demonstrated adequate concurrent validity with instruments designed to assess intelligence in childhood (Wechsler, 1991) and scores on the Digit Span subtest contribute to the "Freedom from Distractibility" factor score of the WISC-R which reflects the ability to attend or concentrate (Sattler, 1992).

Social Phobia and Anxiety Inventory for Children (SPAI-C). Children's self-reports of social anxiety were obtained via the Social Phobia and Anxiety Inventory for Children (Beidel, Turner, \& Morris, 1995). This 26-item questionnaire assesses children's behavioral, cognitive, and physiological responses to a variety of situations known to be problematic for children with extreme social anxiety (e.g., meeting new kids, reading/asking questions in class, going to parties, being in a large group, etc.). Children were instructed to rate "how often" they would feel nervous or scared for each item using a 3-point scale: (0) never or hardly ever, (1) 
sometimes, and (2) most of the time or always. Scores range from 0-52 with higher scores reflecting greater social anxiety. Initial normative data from a community sample of 9-11-yearold children $(\underline{\mathrm{n}}=277)$ are as follows: $\underline{\mathrm{M}}=14.00, \underline{\mathrm{SD}}=8.78$ (Morris \& Masia, 1998).

The SPAI-C has demonstrated high internal consistency (Cronbach's alpha $=.95)$ and high test-retest reliability (at 2 weeks, $\underline{r}=.86$; at 10 months, $\underline{r}=.63$ ) (Beidel et al., 1995). The SPAI-C also has demonstrated adequate concurrent validity with other instruments designed to assess general fear and anxiety (Beidel et al., 1995). Finally, the SPAI-C has sufficient ability to discriminate children diagnosed with social phobia from those with non-anxiety disorders (i.e., externalizing disorders) and normal controls (Beidel, Turner, \& Fink, 1996).

\section{Children's Action Tendency Scale (CATS). The Children's Action Tendency Scale was} developed as a measure of assertive versus unassertive behaviors in children (Deluty, 1979). Children were presented with a series of 13 scenarios and asked to indicate what they would (not should) do in each situation by selecting one response alternative from each of three groups. The CATS yields scores for three subscales including: (1) Aggressiveness (i.e., employing hostility when expressing one's thoughts and feelings), (2) Assertiveness (i.e., expressing one's ideas and feelings in a non-hostile manner), and (3) Submissiveness (i.e., non-hostile behavior that involves deferring to others). Scores on any subscale range from 0-26 with higher scores reflecting greater endorsement of the behavior represented in the particular subscale. The total sum score for the three subscales is 39 (Note: normative data for the 13-item version are not available). For purposes of the present study, only the assertiveness and submissiveness subscales were of conceptual interest in terms of analyses. 
Initial tests of the CATS documented adequate internal consistency for the three subscales: Aggressiveness, $\underline{\mathrm{r}}=.77$; Assertiveness, $\underline{\mathrm{r}}=.63$; and Submissiveness, $\underline{\mathrm{r}}=.72$ (Deluty, 1979). In addition, the CATS has demonstrated moderate test-retest reliability over a 4-month interval: Aggressiveness, $\underline{r}=.48$; Assertiveness, $\underline{r}=.60$; and Submissiveness, $\underline{r}=.57$ (Deluty, 1979). Finally, the CATS has demonstrated adequate concurrent validity with other measures related to assertive and nonassertive behaviors (e.g., self-esteem) (Deluty, 1979).

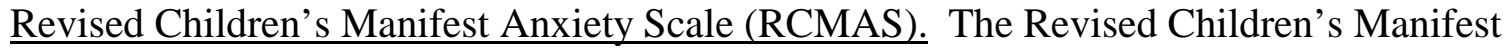
Anxiety Scale is a 37-item questionnaire designed to assess children's chronic manifest anxiety across behavioral, cognitive, and physiological domains (Reynolds \& Richmond, 1978). Children were instructed to read each item and indicate whether they think the statement is "true" or "not true" about them by circling "yes" or "no." The RCMAS yields scores for five factors including: (1) physiological anxiety, (2) concentration anxiety, (3) worry and oversensitivity, (4) total anxiety, and (5) lie scale. Raw scores were converted to normative t-scores with higher scores reflecting greater anxiety. T-scores of 50 reflect the mean for the normative sample, with each t-score increase of 10 indicative of one standard deviation. T-scores of 70 and greater are considered to be in the clinically elevated range. For purposes of the present study, the lie scale was employed to gauge the reliability of children's responses to the self-report measures. In addition, the total anxiety subscale was examined in the analyses on the basis of its conceptual contribution to the study (i.e., relation with social anxiety and attention).

The RCMAS has demonstrated adequate internal consistency (alpha $=.83)$ as well as concurrent and construct validity with other instruments designed to assess general anxiety in children (Reynolds, 1980; Reynolds \& Richmond, 1978). 
Social Phobia and Anxiety Inventory for Children (SPAI-C), Parent-version. To assess parental perceptions of child social anxiety, parents completed the parent-version of the SPAI-C. The SPAI-C parent-version consists of the same 26-items that appear on the child-version and differs from the child-version only with regard to whom the question refers (i.e., "My child feels scared" vs. "I feel scared"). Accordingly, parents were instructed to rate "how often" their child would feel nervous or scared for each item using a 3-point scale: (0) never or hardly ever, (1) sometimes, and (2) most of the time or always. Scores range from 0-52 with higher scores reflecting greater perceptions of child social anxiety.

Revised Dimensions of Temperament Survey (DOTS-R). The parent-report version of the Revised Dimensions of Temperament Survey yields a nine factor model of temperament including: (1) Activity Level-General, (2) Activity Level-Sleep, (3) Approach/Withdrawal, (4) Flexibility/Rigidity, (5) Mood, (6) Rhythmicity-Sleep, (7) Rhythmicity-Eating, (8) RhythmicityDaily Habits, and (9) Task Orientation (Windle \& Lerner, 1986). Theoretically, several of these factors appear to be related to the construct of social anxiety and thus, important in the present study including: (1) Approach/Withdrawal (i.e., the tendency to move towards or away from novel persons and/or situations), (2) Flexibility/Rigidity (i.e., the tendency to respond flexibly or inflexibly to environmental changes), and (3) Task Orientation (i.e., the tendency to concentrate and maintain focus in the presence of extraneous stimuli and the tendency to stay on task for extended periods of time). Parents were asked to indicate, on a 4-point scale, how "true" or typical each item is of their child: (1) usually FALSE, (2) more FALSE then true, (3) more TRUE than false, and (4) usually TRUE (Windle \& Lerner, 1986). Scores on the Approach/Withdrawal factor range from 7-28 with higher scores indicating a greater tendency to approach new people 
and situations. Flexibility/Rigidity factor scores range from 5-20 with higher scores reflecting a more flexible behavioral style. Finally, scores on the Task Orientation factor range from 8-32 with higher scores reflecting greater persistence and lower distractibility. Normative data for the DOTS-R, parent-report version are not available.

The previously noted temperament factors of the DOTS-R have moderate internal consistency as determined by Cronbach's alpha: (1) Approach/Withdrawal = .84; (2) Flexibility/ Rigidity $=.79$; and (3) Task Orientation $=.79$ (Windle \& Lerner, 1986). The adult-version of the DOTS-R has demonstrated concurrent validity with other instruments measuring both temperament and personality factors (Windle et al., 1986).

Design and Procedure

A 2 (type of interview: non-leading vs. leading) x 2 (child gender) x 2 (interviewer gender) design was employed. Prior to arrival, participants were randomly assigned to an interview condition and a male or female interviewer. Both the type of interview and the gender of the interviewer were distributed evenly across child gender cells.

Testing took place in a room equipped with a TV monitor, videocassette recorder, and a tape recorder. Upon arrival, parent and child were greeted by a female experimenter, and children were informed that they would be watching a videotaped discussion between an adult couple. After obtaining parental consent and child assent, children were escorted into the testing room by the experimenter. Parents were asked to remain in the waiting area and complete several forms including: (1) a background form for demographic information (see Appendix A), (2) the SPAI-C, parent-version, and (3) the DOTS-R. 
Next, children viewed a brief videotaped interaction between male and female adult actors. The experimenter simply informed children that the "first thing that we are going to do is to watch a short videotape." No other instructions were given. The interaction followed a threestep process in which the actors: (1) engaged in a one-minute verbal conflict centered on cooking dinner (i.e., man comes home from work and dinner is not ready), (2) left the room for fiveseconds, and (3) returned and engaged in a 30-second conflict ending revolving around an issue unrelated to the original conflict (i.e., who should clean-up the messy house) (see Appendix B, for the simulated conflict script). After viewing the videotape, a 20-minute delay was imposed during which the experimenter administered the Digit Span task and instructed children to complete the SPAI-C. Puzzles were available for children to play with in the event that they completed these tasks before the 20-minutes had expired. The decision to impose a delay between viewing the videotape and interviewing children about the conflict scenario was made to simulate the experiences of witnesses in the "real-world." Specifically, witnesses rarely are interviewed immediately after observing an event. In fact, investigative interviews generally occur hours, days, months, and sometimes even years after the occurrence of the event. Thus, while the 20-minute delay is both artificial and arbitrary, its use is consistent with previous research (e.g., Cassel \& Bjorklund, 1995; Goodman \& Reed, 1986; Marin, Holmes, Guth, \& Kovac, 1979).

Following the delay, the experimenter exited the room and, depending on the random assignment, a male or female research assistant entered and administered the investigative memory interview which included a: (1) free recall task, (2) prompted recall task (i.e., openended questions regarding characteristics of the man, woman, and room), and (3) series of 
specific questions phrased in either a non-leading or leading format (depending on the random assignment). To control for interviewer effects, multiple male and female interviewers were employed throughout data collection. Specifically, three different male interviewers and five different female interviewers were involved in the project. The percentage of interviews conducted by each interviewer were as follows: male $\# 1=25 \%$, male $\# 2=21 \%$, male $\# 3=4 \%$, female $\# 1=23 \%$, female $\# 2=15 \%$, female \#3= $6 \%$, female $\# 4=3 \%$, and female $\# 5=3 \%$. Preliminary repeated measures ANOVA analyses were conducted to examine the role of the interviewer in responding for the primary variables in the study (e.g., accurate and inaccurate information for free, prompted recall, and specific questions). No interactions involving the interviewer were found for children's memory interview responses.

The investigative interview began with a free recall task. Specifically, children were asked to report everything they could remember about the videotaped conflict interaction they witnessed earlier. To aid responding, children were given the following prompt: "A few minutes ago, you watched a videotape. I want you to tell me everything you can remember about what you saw and what happened on the videotape." (see Appendix C, for the free recall interview).

Following the free recall task, a prompted recall interview was administered in which children were asked a series of open-ended questions regarding characteristics of the actors, setting, and events that occurred (see Appendix D, for the prompted recall interview). Prompted recall questions have been criticized as they often introduce information that was not mentioned by children in free recall, and therefore can be considered leading (White \& Quinn, 1988). Consequently, the first question on the prompted recall interview, "Tell me about everything and everybody that was in the room on the videotape," was designed to avoid the presupposition of 
information by establishing that there was a man and a woman on the videotape. All children mentioned "a man and woman" in their responses to this initial question and thus, the remaining questions (e.g, "What did the man/woman look like?," "What was the man/woman wearing?,") should not be considered as leading in nature.

Following the prompted recall interview, children were asked a series of specific questions in either a non-leading or leading format (see Appendix E, for the non-leading and leading interviews). The non-leading and leading interviews consisted of 32 questions distributed evenly across four categories of information including: (1) man characteristics, (2) woman characteristics, (3) room characteristics, and (4) argument-content characteristics. To prevent the development of a response set, a balance of "yes" and "no" responses to the questions within each category was employed. In the leading interview condition, half of the questions from each category (i.e., man, woman, room, argument-content characteristics) were phrased in a parallel leading form. Specifically, each category of information contained two correctly leading and two incorrectly leading questions. That is, while the leading questions focused on the same information as their non-leading counterparts, these questions contained or implied both "correct" and "incorrect" information. For example, if children in the non-leading condition were asked, "Was the man wearing a tie?," then children in the leading interview condition were asked, "Wasn't the man wearing a tie?" (correctly leading). If children in the non-leading condition were asked, "Were there pots and pans sitting on the stove?," then children in the leading condition were asked, "There were pots and pans sitting on the stove, weren't there?" (incorrectly leading). Children's responses to the investigative interview were written down as 
well as audiotaped for subsequent coding. Upon completion of the memory interview, children completed the remaining self-report measures including the CATS and the RCMAS.

\section{$\underline{\text { Coding }}$}

Prior to coding the actual interviews, data from four pilot participants were scored as part of training. The training criterion was set at $85 \%$. In general, interobserver agreement exceeded criterion. Specifically, overall training percent agreements for free and prompted recall as well as the non-leading and leading interviews ranged from $93-100 \%$.

Free and prompted recall: Accurate information. Consistent with previous coding procedures (e.g., Cassel \& Bjorklund, 1995), the videotape was examined by four undergraduate research assistants who were responsible for identifying the stimuli that were present, including the: (1) man's appearance (i.e., physical, clothing, accessories) and actions, (2) woman's appearance (i.e., physical, clothing, accessories) and actions, (3) man and woman's statements, and (4) contents of the room. This procedure was employed to achieve a "gold standard" of accuracy of recall. A total of 104 items of information initially were identified as being present in the videotaped stimulus. Coding sheets were developed that included these units of information as possible accurate responses for both the free and prompted recall tasks (see Appendix F, for accuracy coding sheets).

One undergraduate research assistant coded the interviews for all 96 participants. The research assistant was instructed to listen to the audiotaped interviews and place a check-mark in the appropriate column when an item of information was mentioned (i.e., an "initial" response or response to the follow-up prompt, "what else can you remember"). Information that was repeated within the free and prompted recall interviews was only counted once. If a child 
mentioned information that was not listed on the coding sheets, but was verified as being accurate upon examining the videotape, the information was added to the coding sheets and scored as accurate. This occurred several times throughout the coding process. The items of information that were added are represented on the coding sheets with an asterisk (see Appendix F), yielding a total of 111 possible accurate items of information.

Children's "initial" responses to the questions and their responses to the prompt, "what else can you remember," were coded separately in the event that the follow-up prompt might influence accuracy of reporting. Preliminary paired samples t-test analyses indicated that while children generally provided the greatest amount of accurate information in response to the initial question (as compared to the follow-up prompt) (see Tables 1 and 2), the total amount of accurate information provided by children increased when their initial and follow-up responses were combined (see Tables 3 and 4). Consequently, children's responses to the "initial" and "what else can you remember" questions were combined into sum scores for both the free and prompted recall interviews, thereby yielding a total score for accurate information (i.e., "initial" plus "follow-up" responses). (Note: if an item of information was mentioned in response to both the initial and follow-up questions, children received only one accuracy point for the item).

To assess interobserver agreement, the responses of 19 participants (20\% of the sample) were selected and independently scored by the experimenter. Specifically, every fifth participant was chosen. While kappa is typically the preferred method of calculating interobserver agreement as it accounts for both agreement and disagreement and corrects for chance (Howell, 1992), this statistic could not be employed in the present study. Specifically, a two-way contingency table must be available to calculate kappa. Because of the low-base rates of some 
items of information in the present study and the high percentage of agreement on other items, the presence of a two-way table was extremely rare. Thus, percent agreement was employed. To address the overinflation of agreement due to the low base rates of a substantial number of items (particularly in free recall), percent agreement was calculated for only those items that were coded as accurate by either the research assistant or the experimenter. Percent agreements across the different categories of information (e.g., man/woman appearance and actions, man/woman statements, room characteristics) ranged from $95-100 \%$ for both the free and prompted recall interviews. Overall agreements (i.e., collapsed across the different categories of information) for free and prompted recall ranged from $99-100 \%$.

Free and prompted recall: Inaccurate information. Children's inaccurate responses also were coded. Similar to the coding procedure for accurate information, raters were instructed to indicate whether the inaccurate information was made in response to the "initial" question or the follow-up prompt, "what else can you remember," for both the free and prompted recall interviews. In addition, inaccurate information was recorded within the appropriate category including: (1) man characteristics (i.e., appearance and actions), (2) woman characteristics (i.e., appearance and actions), (3) man and woman's statements, and (4) room characteristics (i.e., description and content of room) (see Appendix G, for summary of inaccurate responses). Inaccurate information that was repeated within the free and prompted recall interviews was only counted once.

Consistent with previous research (e.g., Goodman, Rudy, Bottoms, \& Aman, 1990; Quas et al., 1999), the types of errors children made were coded for both the free and prompted recall interviews. Specifically, errors of "commission" and "omission" were coded. A commission 
error is defined as recalling that something occurred when it actually did not (Goodman et al., 1990). That is, information is provided that was not present in the videotaped stimulus. Two types of commission errors were examined: (1) factually-incorrect, and (2) intrusions. Consistent with past research (Cassel \& Bjorklund, 1995), factually-incorrect errors included the misreporting of information that was present in the videotaped stimulus and clearly $\underline{\text { could }}$ be discerned. That is, information was provided that was a factual misrepresentation of what actually occurred. Examples of factually-incorrect errors included misreporting of the actors' age, height, weight, hair color, primary clothing, etc (see Appendix $\mathrm{H}$, for a complete list of factually incorrect errors). Intrusions were defined as the reporting of information that was not present in the videotaped stimulus or could not be discerned (Cassel \& Bjorklund, 1995). That is, information was provided that was not included or could not be verified as present in the videotaped stimulus. Examples of intrusion errors included the actors' eye color, socks, underwear, actions they did not perform, statements they did not make, items in the room, etc. (see Appendix H, for a complete list of intrusion errors). An omission error occurred when something that did occur was not reported in recall (Goodman et al., 1990). Omission errors were calculated for both free and prompted recall by dividing the total amount of information that was not reported in accurate recall by the total possible accurate items of information across the different categories of information (i.e., man/woman appearance and actions, man/woman statements, room characteristics).

Preliminary paired samples t-test analyses performed for both the free and prompted recall interviews indicated that children typically reported more factually-incorrect and intrusion commission errors in response to the "initial" question versus the "follow-up" prompt (i.e., "what 
else can you remember") (see Tables 5-8). However, the total amount of commission errors provided by children generally increased when their initial and follow-up responses were combined (see Tables 9-12). Thus, children's responses to the "initial" and "what else can you remember" questions were combined into sum scores for both the free and prompted recall interviews, thereby yielding a total score for both factually-incorrect and intrusion errors (i.e., “initial" plus "follow-up" responses). (Note: if an item of information was mentioned in response to both the initial and follow-up questions, children received only one inaccuracy point for the item).

The responses of 19 participants (20\% of the sample) were selected and independently scored by the experimenter to assess interobserver agreement. For the reasons outlined above in the "free and prompted recall: accurate information" section, percent agreement was employed. Percent agreement was calculated for only those items that were coded as inaccurate (i.e., factually-incorrect or intrusion) by either the research assistant or the experimenter. Factuallyincorrect commission error agreements across the different categories of information (e.g., man/woman appearance and actions, man/woman statements, room characteristics) ranged from 94-100\% for the prompted recall interview. Overall agreements (i.e., collapsed across the different categories of information) for both free and prompted recall ranged from 97-100\% (Note: only one factually-incorrect commission error was present for free recall-man's actions and percent agreement was $100 \%$ ). Intrusion commission error agreements across the different categories of information (e.g., man/woman appearance and actions, man/woman statements, room characteristics) ranged from $80-100 \%$ for both the free and prompted recall interviews (Note: lower percent agreement was attributed to the low occurrence of intrusions for some 
categories of information). Overall percent agreements (i.e., collapsed across the different categories of information) for intrusion commission errors for both free and prompted recall ranged from $98-100 \%$.

Specific questions: Non-leading and leading. Children's responses to the specific questions in both the non-leading and leading interview conditions were coded as: accurate, inaccurate, or not recalled (i.e., “don't know/remember"). In addition, children's responses to the specific correctly and incorrectly leading questions were coded according to how they corresponded to the suggestion. That is, children's responses were scored as being consistent or inconsistent with the leading question or not recalled (i.e., "don't know/remember). For example, given that the male actor was wearing a tie, responses to the correctly leading question, "Wasn't the man wearing a tie?," were coded as consistent with the suggestion if the child responded "yes" and inconsistent with the suggestion if the child stated "no." Given that the male actor did not have a briefcase, responses to the incorrectly leading question, "Did the man set his briefcase on the table or by the door when he came home?," were coded as consistent with the suggestion if the child stated "on the table or by the door" and inconsistent with the suggestion if the child responded "neither, no, or he didn't have a briefcase."

The responses of 19 participants (20\% of the sample) were selected and independently scored by the experimenter, yielding nine participants in the non-leading interview condition and ten in the leading interview condition. Percent agreement for all eight questions within each category of information (i.e., man/woman characteristics, room characteristics, argument-content characteristics) was calculated. Interobserver agreement was $100 \%$ for coding of responses as accurate, inaccurate or not recalled as well as how the responses corresponded to the suggestion. 


\section{Results}

$\underline{\text { Strategy for Data Analysis }}$

Consistent with the research questions, the primary analyses are presented in five sections. The first section examines children's reports of accurate information for both the free and prompted recall interviews. Analyses in the second section examine children's reports of inaccurate information for both the free and prompted recall tasks. The third section examines children's accurate responses to the specific questions (i.e., non-leading and leading interviews). The fourth section describes interrelations among the individual difference variables as assessed by both parent- and child-report. Finally, the fifth section examines the role of individual differences in predicting susceptibility to suggestion.

\section{$\underline{\text { Free and Prompted Recall: Accurate Information }}$}

Prior to conducting the analyses, children's accurate responses were converted to proportions for both the free and prompted recall interviews. Specifically, proportion scores were calculated for the following general categories of information, collapsed across gender of the actor: (1) appearance (32 possible items), (2) actions (25 possible items), (3) statements (23 possible items), and (4) the room (31 possible items). In addition, proportions were calculated for the: (1) man's appearance (14 possible items), (2) man's actions (14 possible items), (3) man's statements (13 possible items), (4) woman's appearance (18 possible items), (5) woman's actions (11 possible items), and (6) woman's statements (10 possible items).

Children's responses to both the free and prompted recall interviews were analyzed in a series of repeated measures ANOVAs. Specifically, a 2 (child gender) x 2 (interviewer gender) x 4 (type of information: appearance, actions, statements, room) repeated measures ANOVA was 
performed to examine children's accurate recall for general information. Type of information served as the within-subjects factor and child gender and interviewer gender served as the between-subjects factors. In addition, a 2 (child gender) x 2 (interviewer gender) x 2 (actor gender) x 3 (type of information: appearance, actions, statements) repeated measures ANOVA was performed to examine children's accurate recall for same-gender details. Actor gender and type of information served as the within-subjects factors and child gender and interviewer gender were the between-subjects factors.

Free Recall

General information. Children's accurate recollections differed only as a function of type of information, Wilks' $\Lambda=.09, \underline{F}(3,90)=313.62, \underline{p}<.001, \eta^{2}=.91$. In general, children recalled the greatest amount of accurate information about the actors' statements $(\underline{\mathrm{M}}=0.32, \underline{\mathrm{SD}}$ $=0.14)$, followed by their actions $(\underline{\mathrm{M}}=0.20, \underline{\mathrm{SD}}=0.08)$, appearance $(\underline{\mathrm{M}}=0.06, \underline{\mathrm{SD}}=0.01)$, and the room $(\underline{\mathrm{M}}=0.00, \underline{\mathrm{SD}}=0.03)$. All pairwise comparisons were significant $(\underline{\mathrm{p}}<.001)$.

Gender-specific information. Children's reports differed as a function of actor gender, Wilks' $\Lambda=.39, \underline{\mathrm{F}}(1,92)=143.44, \underline{\mathrm{p}}<.001, \eta^{2}=.61$, type of information, Wilks' $\Lambda=.17, \underline{\mathrm{F}}(2$, $91)=225.65, \underline{p}<.001, \eta^{2}=.83$, and Actor gender $X$ Type of information, Wilks' $\Lambda=.53, \underline{\mathrm{F}}(2$, $91)=40.50, \underline{p}<.001, \eta^{2}=.47$.

In general, children's recollections were more accurate for details about the male actor ( $\underline{\mathrm{M}}$ $=0.23, \underline{\mathrm{SD}}=0.07)$ than the female actor $(\underline{\mathrm{M}}=0.14, \underline{\mathrm{SD}}=0.05)$. In addition, children recalled the greatest amount of accurate information about the actors' statements $(\underline{\mathrm{M}}=0.32, \underline{\mathrm{SD}}=0.14)$, followed by their actions $(\underline{\mathrm{M}}=0.20, \underline{\mathrm{SD}}=0.08)$, and appearance $(\underline{\mathrm{M}}=0.06, \underline{\mathrm{SD}}=0.01)$ (Note: all pairwise comparisons were significant, $\mathrm{p}<.001$ ). Simple main effects tests revealed a similar 
pattern of results with respect to the type of information for both the male, $\underline{F}(2,94)=259.21$, $\underline{p}<$ .001 , and female actors, $\underline{\mathrm{F}}(2,94)=103.27, \underline{\mathrm{p}}<.001$. In addition, simple main effects tests indicated that children's recollections were more accurate for details about the male actor than the female actor with respect to appearance, $\underline{F}(1,95)=26.29, \underline{p}<.001$, actions, $\underline{F}(1,95)=$ $81.43, \underline{\mathrm{p}}<.001$, and statements, $\underline{\mathrm{F}}(1,95)=54.18, \underline{\mathrm{p}}<.001($ see Table 13$)$.

Prompted Recall

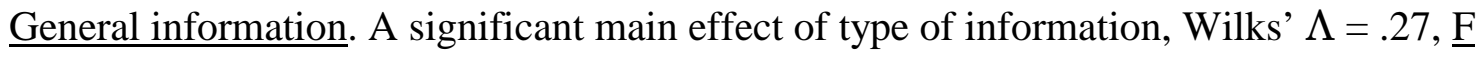
$(3,90)=81.89, \underline{p}<.001, \eta^{2}=.73$, was found. In general, children recalled the greatest amount of accurate information about the actors' statements $(\underline{\mathrm{M}}=0.40, \underline{\mathrm{SD}}=0.15)$, followed by their appearance $(\underline{\mathrm{M}}=0.35, \underline{\mathrm{SD}}=0.09)$, actions $(\underline{\mathrm{M}}=0.28, \underline{\mathrm{SD}}=0.12)$, and the room $(\underline{\mathrm{M}}=0.24, \underline{\mathrm{SD}}=$ 0.11). All pairwise comparisons were significant $(\underline{p} \leq .005)$.

Gender-specific information. Children's recollections were more accurate for details about the male actor $(\underline{\mathrm{M}}=0.37, \underline{\mathrm{SD}}=0.11)$ than the female actor $(\underline{\mathrm{M}}=0.32, \underline{\mathrm{SD}}=0.10)$, Wilks' $\Lambda=.65, \underline{\mathrm{F}}(1,92)=50.15, \underline{\mathrm{p}}<.001, \eta^{2}=.35$. In addition, children's reports differed as a function of type of information, Wilks' $\Lambda=.44, \underline{F}(2,91)=58.84, \underline{p}<.001, \eta^{2}=.56$. Children recalled the greatest amount of accurate information about the actors' statements $(\underline{\mathrm{M}}=0.40, \underline{\mathrm{SD}}$ $=0.15)$, followed by their appearance $(\underline{\mathrm{M}}=0.35, \underline{\mathrm{SD}}=0.09)$, and actions $(\underline{\mathrm{M}}=0.28, \underline{\mathrm{SD}}=0.12)$. All pairwise comparisons were significant $(\underline{p} \leq .005)$.

Interestingly, a Child gender X Actor gender interaction approached significance, Wilks' $\Lambda=.96, \underline{F}(1,92)=3.45, \underline{p}=.06, \eta^{2}=.04$. Simple main effects tests suggested that both boys, $\underline{F}$ $(1,47)=37.25, \underline{\mathrm{p}}<.001$, and girls, $\underline{\mathrm{F}}(1,47)=12.84, \underline{\mathrm{p}}=.001$, recalled more accurate details about the male actor as opposed to the female actor. In addition, girls $(\underline{\mathrm{M}}=0.34, \underline{\mathrm{SD}}=0.09)$ 
were more accurate than boys $(\underline{\mathrm{M}}=0.29, \underline{\mathrm{SD}}=0.09)$ in their recollections for female-oriented details, $\underline{\mathrm{F}}(1,95)=4.82, \underline{\mathrm{p}}=.03($ see Table 14$)$.

\section{$\underline{\text { Free and Prompted Recall: Inaccurate Information }}$}

Table 15 displays the means and standard deviations for children's inaccurate responses (i.e., omission errors, factually-incorrect, and intrusion commission errors) regarding general categories of information (i.e., collapsed across gender of the actor). Similarly, means and standard deviations for children's inaccurate responses regarding gender-specific information are presented in Tables 16 and 17. As can be seen in Tables 15-17, commission errors (i.e., factually-incorrect and intrusions) were extremely rare and thus, were not included in subsequent analyses.

Prior to examining children's omission errors, children's raw omission scores were converted to proportions for both the free and prompted recall interviews. Specifically, proportion scores were calculated for the following general categories of information, collapsed across gender of the actor: (1) appearance, (2) actions, (3) statements, and (4) the room. In addition, proportions were calculated for the: (1) man's appearance, (2) man's actions, (3) man's statements, (4) woman's appearance, (5) woman's actions, and (6) woman's statements.

Children's omission errors for both the free and prompted recall interviews were analyzed in a series of repeated measures ANOVAs. Specifically, a 2 (child gender) x 2 (interviewer gender) x 4 (type of information: appearance, actions, statements, room) repeated measures ANOVA was performed to examine children's omission errors regarding general information. Type of information served as the within-subjects factor and child gender and interviewer gender served as the between-subjects factors. In addition, a 2 (child gender) x 2 (interviewer gender) $\mathrm{x}$ 
2 (actor gender) x 3 (type of information: appearance, actions, statements) repeated measures ANOVA was performed to examine children's omission errors for same-gender details. Actor gender and type of information served as the within-subjects factors and child gender and interviewer gender were the between-subjects factors.

$\underline{\text { Free recall }}$

General information. Omission errors made by children differed as a function of type of information, Wilks' $\Lambda=.09, \underline{\mathrm{F}}(3,90)=313.62, \underline{\mathrm{p}}<.001, \eta^{2}=.91$. Specifically, omission errors were greatest for information regarding the room/setting $(\underline{\mathrm{M}}=0.99, \underline{\mathrm{SD}}=0.04)$, followed by information about the actors' appearance $(\underline{\mathrm{M}}=0.94, \underline{\mathrm{SD}}=0.01)$, their actions $(\underline{\mathrm{M}}=0.80, \underline{\mathrm{SD}}=$ $0.08)$, and statements $(\underline{\mathrm{M}}=0.68, \underline{\mathrm{SD}}=0.14)$. All pairwise comparisons were significant $(\underline{\mathrm{p}}<$ $.001)$.

Gender-specific information. Children's omission errors for gender-specific details differed as a function of actor gender, Wilks' $\Lambda=.39, \underline{\mathrm{F}}(1,92)=143.44, \underline{\mathrm{p}}<.001, \eta^{2}=.61$, type of information, Wilks' $\Lambda=.17, \underline{F}(2,91)=225.65, \underline{p}<.001, \eta^{2}=.83$, and Actor gender X Type of information, Wilks' $\Lambda=.53, \underline{F}(2,91)=40.50, \underline{p}<.001, \eta^{2}=.47$.

In general, omission errors were greatest for details about the female actor $(\underline{M}=0.86, \underline{S D}$ $=0.05)$ than the male actor $(\underline{\mathrm{M}}=0.77, \underline{\mathrm{SD}}=0.07)$. Simple main effects tests indicated that omission errors were greatest for information about the actors' appearance, followed by their actions, and statements for both the male, $\underline{\mathrm{F}}(2,94)=259.21, \underline{\mathrm{p}}<.001$, and female actors, $\underline{\mathrm{F}}(2$, $94)=103.27, \underline{p}<.001$. In addition, simple main effects tests indicated that children made more omission errors regarding details about the female actor than the male actor with respect to 
appearance, $\underline{\mathrm{F}}(1,95)=26.29, \underline{\mathrm{p}}<.001$, actions, $\underline{\mathrm{F}}(1,95)=81.43, \underline{\mathrm{p}}<.001$, and statements, $\underline{\mathrm{F}}(1$, $95)=54.18, \underline{p}<.001($ see Table 18$)$.

\section{Prompted recall}

General information. Children's omission errors for general information differed only as a function of type of information, Wilks' $\Lambda=.27, \underline{\mathrm{F}}(3,90)=81.89, \underline{\mathrm{p}}<.001, \eta^{2}=.73$. Omission errors were greatest for information regarding the room $(\underline{\mathrm{M}}=0.76, \underline{\mathrm{SD}}=0.11)$, followed by the actors' actions $(\underline{\mathrm{M}}=0.72, \underline{\mathrm{SD}}=0.12)$, their appearance $(\underline{\mathrm{M}}=0.65, \underline{\mathrm{SD}}=0.09)$, and statements $(\underline{\mathrm{M}}=0.60, \underline{\mathrm{SD}}=0.15)$. All pairwise comparisons were significant $(\underline{\mathrm{p}} \leq .005)$.

Gender-specific information. Omission errors were greatest for details about the female actor $(\underline{\mathrm{M}}=0.68, \underline{\mathrm{SD}}=0.10)$ as opposed to the male actor $(\underline{\mathrm{M}}=0.63,0.11)$, Wilks' $\Lambda=.65, \underline{\mathrm{F}}(1$, $92)=50.15, \underline{p}<.001, \eta^{2}=.35$. In addition, omission errors differed as a function of type of information, Wilks' $\Lambda=.44, \underline{\mathrm{F}}(2,91)=58.84, \underline{\mathrm{p}}<.001, \eta^{2}=.56$. Omission errors were greatest for information about the actors' actions $(\underline{\mathrm{M}}=0.72, \underline{\mathrm{SD}}=0.12)$, followed by their appearance $(\underline{\mathrm{M}}$ $=0.65, \underline{\mathrm{SD}}=0.09)$, and statements $(\underline{\mathrm{M}}=0.60, \underline{\mathrm{SD}}=0.15)$. All pairwise comparisons were significant $(\underline{\mathrm{p}}<.005)$.

A Child gender X Actor gender interaction approached significance, Wilks' $\Lambda=.96, \underline{\mathrm{F}}$ (1, $92)=3.45, \underline{p}=.06, \eta^{2}=.04$. Simple main effects tests suggested that omission errors were greater for details about the female actor than the male actor for both boys, $\underline{\mathrm{F}}(1,47)=37.25, \underline{\mathrm{p}}<$ .001 , and girls, $\underline{\mathrm{F}}(1,47)=12.84, \underline{\mathrm{p}}=.001$. In addition, girls $(\underline{\mathrm{M}}=0.66, \underline{\mathrm{SD}}=0.09)$ made less omission errors than boys $(\underline{\mathrm{M}}=0.71, \underline{\mathrm{SD}}=0.09)$ for female-oriented details, $\underline{\mathrm{F}}(1,95)=4.82, \underline{\mathrm{p}}=$ .03 (see Table 19). 


\section{Specific Questions: Non-Leading and Leading Interviews}

While several strategies for analyzing children's responses to the specific questions exist, only one strategy was deemed as appropriate for the following reasons. First, an examination of children's responses as a function of the type of interview only (i.e., non-leading vs. leading), does not permit a clear interpretation of the results as the responses of children assigned to the leading interview condition are based on three different types of questions including: (1) nonleading, (2) correctly leading, and (3) incorrectly leading. Thus, by examining children's responses solely as a function of type of interview, important issues are not addressed, such as the fact that children in the leading interview condition may be just as accurate as those in the non-leading condition when responding to non-leading questions. Furthermore, comparisons between children's responses to the correctly and incorrectly leading questions in the leading interview condition and their non-leading parallel forms in the non-leading interview condition are not possible when only examining the type of interview. Accordingly, children's responses to the specific questions were analyzed in a repeated measures ANOVA that included both the type of interview and type of question. Specifically, a 2 (child gender) x 2 (interviewer gender) $x$ 2 (type of interview: non-leading vs. leading) x 3 (type of question: non-leading, "correctly" leading, "incorrectly" leading) x 4 (type of information: man, woman, room, argument-content characteristics) was performed. Type of question and type of information served as the withinsubjects factors and child gender, interviewer gender, and type of interview served as the between-subjects factors.

Prior to conducting the analyses, children's accurate and "don't know/remember" responses were converted to proportions. Specifically, for each general category of information 
(i.e., man, woman, room, argument-content characteristics), proportion scores were calculated for the three different types of questions (i.e., non-leading, "correctly" leading, "incorrectly" leading), collapsed across type of interview. The non-leading question proportion score was comprised of the non-leading questions that were present on both the non-leading and leading interviews. The "correctly" leading question proportion score consisted of the: (1) correctly leading questions for the leading interview, and (2) non-leading parallel question versions for the non-leading interview. The "incorrectly" leading question proportion score was comprised of the: (1) incorrectly leading questions for the leading interview, and (2) non-leading parallel question versions for the non-leading interview (see Table 20).

As can be seen in Table 20, scores for the "correctly" and "incorrectly" leading questions are not "pure" scores as the non-leading parallel forms of the questions are included. Thus, on an a priori basis, only effects that included an interaction between type of interview and type of question were expected to reveal meaningful information and thus, interpreted.

\section{$\underline{\text { Accurate Responses }}$}

Children's accurate responses to the specific questions differed as a function of Type of interview X Type of question, Wilks' $\Lambda=.81, \underline{F}(2,87)=9.93, \underline{p}<.001, \eta^{2}=.19$. Follow-up tests revealed a simple main effect of type of question for the leading interview condition, $\underline{\mathrm{F}}(2$, $46)=28.47, \underline{p}<.001$, but not the non-leading interview condition, $\underline{\mathrm{F}}(2,46)=2.23, \underline{\mathrm{p}}=.12$. Pairwise comparisons indicated that for the leading interview condition, children's recollections were more accurate in response to the non-leading questions $(\underline{\mathrm{M}}=0.70, \underline{\mathrm{SD}}=0.10)$ than the incorrectly leading questions $(\underline{\mathrm{M}}=0.50, \underline{\mathrm{SD}}=0.18), \underline{\mathrm{p}}<.001$. In addition, accuracy of responding was greater for the correctly leading questions $(\underline{\mathrm{M}}=0.71, \underline{\mathrm{SD}}=0.12)$ as opposed to 
the incorrectly leading questions $(\underline{\mathrm{M}}=0.50, \underline{\mathrm{SD}}=0.18), \underline{\mathrm{p}}<.001$. Follow-up univariate tests revealed a simple main effect of type of interview only for the "incorrectly" leading questions, $\underline{\mathrm{F}}$ $(1,95)=19.21, \underline{p}<.001$. Specifically, children in the non-leading interview condition (who were responding to the non-leading parallel question versions $)$ were more accurate $(\underline{M}=0.65$, $\underline{\mathrm{SD}}=0.15$ ) than children in the leading interview condition (who were responding to the incorrectly leading questions) $(\underline{\mathrm{M}}=0.50, \underline{\mathrm{SD}}=0.18)($ see Table 21$)$.

Consistency of Responses with the Suggestion: Correctly and Incorrectly Leading Questions

Given that children's accurate responses in the leading interview condition differed as a function of type of question (i.e., correctly and incorrectly leading), a planned follow-up analysis was conducted to examine whether the difference was due to consistency of responding with the lead or suggestion. Specifically, a 2 (child gender) x 2 (interviewer gender) x 2 (type of response: accurate vs. consistent) x 2 (type of question: correctly leading vs. incorrectly leading) x 4 (type of information: man, woman, room, argument-content characteristics) repeated measures ANOVA was performed for only those participants assigned to the leading interview condition. Type of response, type of question, and type of information served as within-subjects factors, whereas child gender and interviewer gender were the between-subjects factors.

Prior to conducting the analysis, children's consistent responses were converted to proportions. Specifically, for each general category of information (i.e., man, woman, room, argument-content characteristics), proportions scores were calculated for the two different types of questions (i.e., correctly leading and incorrectly leading).

Results revealed a main effect of type of question, Wilks' $\Lambda=.20, \underline{F}(1,44)=172.53, \underline{p}<$ $.001, \eta^{2}=.80$, and type of information, Wilks' $\Lambda=.16, \underline{F}(3,42)=75.97, \underline{p}<.001, \eta^{2}=.84$. In 
addition, children's reports differed as a function of Type of response X Type of information, Wilks' $\Lambda=.39, \underline{\mathrm{F}}(3,42)=21.64, \underline{\mathrm{p}}<.001, \eta^{2}=.61$, and Type of question X Type of information, Wilks' $\Lambda=.13, \underline{\mathrm{F}}(3,42)=93.39, \underline{\mathrm{p}}<.001, \eta^{2}=.87$. However, these effects were qualified by a significant Type of response $X$ Type of question X Type of information interaction, Wilks' $\Lambda=.39, \underline{\mathrm{F}}(3,42)=21.64, \underline{\mathrm{p}}<.001, \eta^{2}=.61$.

Planned simple interaction tests revealed a significant Type of response X Type of information interaction for incorrectly leading questions, $\underline{F}(3,45)=22.40, \underline{p}<.001$. Simple main effects of type of response were found for information about the man, $\underline{F}(1,47)=17.20, \underline{p}<$ .001 , woman, $\underline{\mathrm{F}}(1,47)=32.42, \underline{\mathrm{p}}<.001$, room, $\underline{\mathrm{F}}(1,47)=12.13, \mathrm{p}=.001$, and the content of the argument, $\underline{\mathrm{F}}(1,47)=5.29, \underline{\mathrm{p}}<.05$ (see Table 22$)$. The results indicated that whereas children's responses to the incorrectly leading questions were more consistent with the suggestion (and thus, less accurate) for details about the man and room, their responses were less consistent with the suggestion (and thus, more accurate) for details about the woman and content of the argument.

Not Recalled (i.e.. “don’t know/remember) Responses

Table 23 displays the mean proportion scores and standard deviations for children's "don't know/remember" responses to the specific questions as a function of type of question, type of interview, and type of information. As seen in Table 23, "don't know/remember" responses were extremely rare and thus, were not analyzed. 


\section{Interrelations among the Individual Difference Variables}

Preliminary Analyses

To gauge the reliability of children's self-reports, children with RCMAS-Lie scale scores in the clinically elevated range $(\geq 70 ; \underline{n}=5)$ were identified and compared to children with low or non-clinical Lie scale scores $(<70)$ on the child report measures of interest including the: SPAI-C, CATS-assertiveness and submissiveness subscales, and the RCMAS-total anxiety subscale. Preliminary ANOVA analyses indicated no differences between the two groups on any of the previously named child-report measures. Furthermore, RCMAS-Lie scale scores did not correlate with any of the child-report measures (see Table 26).

Table 24 displays the means and standard deviations for both the parent- and child-report measures. For purposes of analyses and clarity of understanding, scores on the DOTS-R: Approach/Withdrawal and Flexibility/Rigidity subscales were converted so that higher scores reflected a greater tendency to: (1) avoid and withdraw from new people and situations, and (2) display rigidity in responding to environmental changes in routines. Consequently, reference to these scales has been changed to the DOTS-R: Withdrawal/Approach and Rigidity/Flexibility. Pearson product-moment correlations were used to examine interrelations among the individual difference variables.

Relations between the Individual Difference Variables as assessed by both Parent- and Child$\underline{\text { Report }}$

Parent-report. As seen in Table 25, parental perceptions of child social anxiety were associated with aspects of child temperament including the child's tendency to: (1) withdraw from new situations or meeting new people, $\underline{\mathrm{r}}(95)=.48, \underline{\mathrm{p}}<.001$, and (2) display more rigidity 
in behavioral routines, $\underline{\mathrm{r}}(95)=.43, \underline{\mathrm{p}}<.001$. In addition, parental perceptions of their child's tendency to withdraw from new people and situations were associated with perceptions of: (1) more rigidity in child behavioral styles, $\underline{\mathrm{r}}(95)=.44, \underline{\mathrm{p}}<.001$, and $(2)$ increased task persistence/reduced distractibility, $\underline{\mathrm{r}}(95)=.22, \underline{\mathrm{p}}<.05$.

Child-report. Table 26 illustrates the interrelations between the child-report measures designed to assess individual differences. A negative relation between child social anxiety and attention was found, $\underline{\mathrm{r}}(96)=-.21, \underline{\mathrm{p}}<.05$. That is, child social anxiety was associated with decreases in attentional processes. Child social anxiety also was positively related to assertiveness, $\underline{\mathrm{r}}(96)=.21, \underline{\mathrm{p}}<.05$, and general anxiety, $\underline{\mathrm{r}}(96)=.47, \underline{\mathrm{p}}<.001$.

Parent- and child-report. As seen in Table 27, several significant relations were found between parents' and children's reports of individual differences (3 out of 32; 9\%). Specifically, parental perceptions of child social anxiety were associated with children's decreased attentional performance on the Digit Span task, $\underline{\mathrm{r}}(95)=-.22, \underline{\mathrm{p}}<.05$. In addition, parents' perceptions of their child's ability to persist at a task and ignore distractions were associated with children's: (1) increased concentration and attention (Digit Span), $\underline{\mathrm{r}}(95)=.22$, and $(2)$ reduced levels of general anxiety $(\mathrm{RCMAS}), \underline{\mathrm{r}}(95)=-.21, \underline{\mathrm{ps}}<.05$.

\section{$\underline{\text { Factor Analysis }}$}

A series of regression analyses were planned to examine whether individual characteristics predict susceptibility to suggestion. To facilitate these analyses, a principalcomponents factor analysis with a varimax rotation was performed that included the four parentreport and six child-report measures. Prior to conducting the factor analysis, parent- and childreport scores were standardized. Results of the factor analysis identified four factors with 
eigenvalues greater than one. Taken together, these factors accounted for $61 \%$ of the variance.

Consistent with recommendations for factor analysis (e.g., Tabachnick \& Fidell, 1989), individual measures with factor loadings of .50 or greater were retained for inclusion in each factor (see Table 28). Factor scores were computed for use in the regression analyses.

The first factor, Parental Perceptions of Child Anxiety, accounted for $20 \%$ of the variance and included the parent-report measures designed to assess both child social anxiety and temperamental constructs related to social anxiety. The second factor, Child Anxiety, accounted for $16 \%$ of the variance, and included the child-report measures designed to assess both general and social anxiety. The third factor, Attention, accounted for $13 \%$ of the variance and included both the child- and parent-report measures designed to assess attentional differences. The fourth and final factor, Social Desirability, accounted for $12 \%$ of the variance and consisted of the children's reports of assertive, submissive, and lying behaviors (see "Discussion" section for a complete explanation of why these factors are believed to reflect social desirability).

\section{Individual Differences as Predictors of Susceptibility to Suggestion}

The primary focus of the present study was to investigate whether individual differences predicted susceptibility to suggestion. Accordingly, only those children assigned to the leading interview condition were included in the analyses. A series of standard multiple regressions were performed separately for children's consistent and accurate responses to the correctly and incorrectly leading questions. That is, outcome variables included: consistency and accuracy of response for correctly leading questions, and consistency and accuracy of response for incorrectly leading questions. Predictor variables for analyses examining the consistency of children's responses to the correctly and incorrectly leading questions included: (1) age, (2) child gender, 
(3) parental perceptions of child anxiety (Factor 1), (4) child anxiety (Factor 2), (5) attention (Factor 3), and (6) social desirability (Factor 4). Predictor variables for analyses examining the accuracy of children's responses to the correctly and incorrectly leading questions included the previously named variables and the addition of consistency of response. Pearson productmoment correlations among the variable included in the standard multiple regression are displayed in Table 29.

Prior to performing the regression analyses, Pearson product-moment correlations were calculated separately for children's consistent and accurate responses to the correctly and incorrectly leading questions. Accuracy and consistency were perfectly correlated for the correctly leading questions, $\underline{\mathrm{r}}(48)=1.00, \underline{\mathrm{p}}=.000$, and thus, only accuracy was employed as the outcome variable for the regression analysis examining children's responses to the correctly leading questions. For the incorrectly leading questions, accuracy and consistency were negatively correlated, $\underline{\mathrm{r}}(48)=-.94, \underline{\mathrm{p}}<.001$. Consequently, consistency was included as a predictor variable for the analysis examining the accuracy of children's responding for the incorrectly leading questions.

Results indicated that the individual difference variables did not predict accuracy of children's responses to the correctly leading questions $(\underline{p}=.17)$ or consistency of children's responses to the incorrectly leading questions $(\mathrm{p}=.49)$. For children's accurate responses to the incorrectly leading questions, both child gender $(\beta=.16)$ and consistency of response $(\beta=-.94)$ were significant predictors of accuracy, $\underline{\mathrm{R}}^{2}=.91, \underline{\mathrm{F}}(7,46)=54.38, \underline{\mathrm{p}}<.001$ (see Table 30). However, when consistency was excluded as a predictor, individual differences did not predict accuracy of children's responses to the incorrectly leading questions $(\mathrm{p}=.44)$. 


\section{Discussion}

By including both free and prompted recall interviews as well as non-leading and leading interviews, this study was designed to simulate elements of a "real-world" eyewitness experience under controlled conditions.

As hypothesized, the information children reported during free recall was highly accurate. However, given the "gold standard" of accuracy, their free recall reports were far from complete as evidenced by the high occurrence of omission errors. Children's recollections were more accurate for certain types of information including details about what was said and actions. This finding is consistent with previous research (e.g., Cassel \& Bjorklund, 1995; Goodman \& Reed, 1986) and suggests that some aspects of witnessed events are more salient or central than others (e.g., appearances and setting/environment) and thus, more likely to be remembered. Gender differences in recall for gender-specific information were not found. Instead, children's recollections were more accurate for details about the man than the woman, thereby suggesting that the statements made and actions performed by the man were more salient than those of the woman.

Commission errors made by children were virtually non-existent during the free recall interview. However, consistent with previous research (e.g., Cassel \& Bjorklund, 1995; Goodman et al., 1991), the information children provided during free recall was extremely limited as evidenced by the high occurrence of omission errors. Omission errors made by children were greatest for details about the room and appearances followed by actions and statements, thereby suggesting that these types of details are more peripheral and thus, less likely to be remembered. 
Given the "gold standard" of accuracy, children's responses to the prompted recall interview also were incomplete as evidenced by the high occurrence of omission errors. However, the prompted recall interview yielded more detailed information than the free recall interview. Consistent with the hypotheses, children's prompted recall reports were more accurate for certain types of information including what was said, followed by details about the actors' appearances, actions, and the room environment. This finding is somewhat inconsistent with the results of the free recall interview as well as previous research in that children typically have been found to provide significantly more information about actions than appearance details (Cassel \& Bjorklund, 1995; Goodman \& Reed, 1986). While this result seems to suggest that the use of prompted questions may function to elicit more detailed information regarding a person's appearance, caution should be exercised in making such a conclusion as the result may be due to an artifact of the design. Specifically, two questions were employed to elicit details about the actors' appearances (i.e., "What did the man/woman look like?" and "What was the man/woman wearing?"), whereas only one question was designed to elicit information about the actors' actions (i.e., "What did the man/woman do?"). Furthermore, children's responses to the questions, "What did the man/woman do?," appeared to center more on what the actors said to each other (e.g., "the man came home and said he had a busy day at work") than what they actually did (e.g., man knocked over the chair, woman was cooking dinner, etc.). Thus, children may not have fully comprehended the intent of the question which, in turn, could explain why fewer details were recalled regarding the actors' actions.

In general, and consistent with the results of the free recall interview, children's prompted recall reports were more accurate for details about the man than the woman. Interestingly, 
however, a trend reflecting gender differences in accuracy of recall for gender-specific information was found. Specifically, whereas both boys and girls recalled more accurate information about the man as opposed to the woman, girls recalled significantly more accurate information than boys regarding characteristics of the woman. Given that this finding only approached significance and was found only for the prompted recall interview, more research clearly is warranted before firm conclusions regarding children's recall for gender-specific details can be reached. However, it may be the case that better memory for same-gender details is related to issues of sex-role development and thus, is an effect that becomes more pronounced over the course of the life-span (i.e., adolescence and adulthood).

Similar to free recall, commission errors made by children were rare during the prompted recall interview. While children did provide more detailed information during the prompted recall interview, omission errors were still quite high. Consistent with the results of the free recall interview, omission errors made by children were greatest for details about the room, again suggesting that such information can be considered more peripheral and thus, less likely to be remembered.

The fact that commission errors made by children were extremely rare during the free and prompted recall interviews adds support to the notion that children are quite capable of providing accurate information when employing open-ended questions (Bruck et al., 1998; Poole \& Lamb, 1998). Furthermore, as noted by Goodman and colleagues (1991), errors of commission may be worse than errors of omission from a legal perspective as commission errors involve the addition of factually-incorrect or false information to recall as opposed to the mere omission of 
information. Thus, questioning techniques that function to reduce the occurrence of commission errors are of critical importance.

The results of both the free and prompted recall interviews indicated that children's recollections were more accurate for the statements that were made by the actors than for their actions or appearances. Previous research (e.g., Davies et al., 1989; Memon \& Vartoukian, 1996) has documented that young children's (i.e., 5-7-year-olds) free and prompted recall reports typically are more accurate for action than appearance details. While the present findings may suggest that developmental differences exist regarding the types of information (i.e., actions vs. statements) younger and older children are more likely to attend to and thus recall, firm conclusions are precluded as previous research does not appear to have examined the statements and actions made by actors separately, as in the present study. Rather, it seems that the "action" information of past research has included both details about what the actors did and what they said.

As hypothesized, both the type of interview and type of question impacted children's accuracy of recall for specific questions. Specifically, children's recollections were highly accurate in the non-leading interview condition. It is important to note, however, that children in the leading interview condition were just as accurate as those in the non-leading condition in response to non-leading questions. Consistent with previous research (Cassel \& Bjorklund, 1995; Goodman \& Reed, 1986) and the hypotheses, the inclusion of incorrectly leading questions had a negative impact on children's accuracy of recall, thereby supporting the notion that such questions lead to errors and distortions in memory. Taken together, the results emphasize the 
importance of employing non-suggestive questions when interviewing children about witnessed events.

Consistent with previous research (Cassel \& Bjorklund, 1995), children's recollections were more accurate for correctly leading as opposed to incorrectly leading questions for the leading interview condition. However, an examination of children's responses for correctly leading questions across the two interview conditions (i.e., non-leading and leading) suggests that the inclusion of correctly leading questions did not affect accuracy of recall. Specifically, children in the non-leading interview condition responded to the non-leading parallel forms of the correctly leading questions with similar levels of accuracy as those in the leading condition.

The hypothesis that children would be more suggestible for certain types of information, such as peripheral details (e.g., the room/setting), was not supported in the analysis of children's accurate responses to the specific questions. An examination of the consistency of children's responses for the incorrectly leading questions, however, does lend some support to this notion. Specifically, for the leading interview condition, children responded with increased consistency to the incorrectly leading questions for details about the room and thus, were less accurate in their recollections. Conversely, for questions centering on more salient information, such as the content of the argument, children appeared to resist the incorrect suggestions, as evidenced by their increased accuracy of recall. With respect to incorrectly leading questions about the man and woman, children's responses were more consistent with the suggestions (and thus, less accurate) for details about the man as opposed to the woman. This finding is inconsistent with the results of the free and prompted recall interviews which demonstrated that children's recollections were more accurate for details about the man than the woman. A possible 
explanation for this discrepancy may center on the fact that the incorrectly leading questions for the woman tapped information that was more salient (e.g., length of hair, actions) and thus, easier to accurately recall than the questions for the man (e.g., what he did with his briefcase).

The present study was designed to examine the impact of interviewer gender on children's eyewitness performance. No effects involving gender of the interviewer were found. At this point, however, it would not be wise to eliminate interviewer gender as a factor that might influence the reliability of children's eyewitness reports for several reasons. Specifically, in the present study, children were asked to report information about a simulated witnessed event that occurred in the laboratory as opposed to one that was personally experienced (e.g., physical and/or sexual abuse). Research conducted with adults that has demonstrated an effect of interviewer gender has involved the disclosure of personal information such as reports of psychological problems and sexual abuse (see Dinidia \& Allen, 1992; Kaplan, Becker, \& Tenke, 1991). Thus, the effects of interviewer gender on eyewitness performance may be present when interviewing children about personally experienced physical and/or sexual abuse events or even abuse-related laboratory scenarios. Clearly, more research is needed before firm conclusions regarding the impact of interviewer gender on children's eyewitness performance can be made.

Consistent with the hypotheses, meaningful relations between parent-report assessments of individual differences were found. As predicted, dimensions of child temperament were related to parental perceptions of child social anxiety. Specifically, parental perceptions of inhibited behaviors (i.e., withdrawing from novel situations/meeting new people and exhibiting reduced flexibility in adapting to changes in the environment) were related to their perceptions of child social anxiety. In addition, parental perceptions of children's tendencies to withdraw from 
meeting new people and situations were related to perceptions of reduced flexibility in adapting to changes in the environment and behavioral routines. Both of these temperamental factors (i.e., withdraw and rigidity) are characteristic of inhibited children (Rubin, 1993).

The results of analyses examining interrelations between child-report assessments of individual differences partially supported the hypotheses. First, a negative association between child social anxiety and attention was found. This finding is consistent with previous research and theory that suggests social-evaluative anxiety has a detrimental impact on attentional processes (Crozier, 1979; Easterbrook, 1959). Contrary to the hypotheses, child social anxiety was positively related to assertiveness. This finding is inconsistent with research conducted by Gudjonsson (1988) that documented a negative association between adult social-evaluative anxiety and assertiveness. A possible explanation for the present finding may be found upon a closer examination of the measure employed to assess child assertiveness. Specifically, the Children's Action Tendency Scale (CATS; Deluty, 1979) presents the assertive, submissive, and aggressive response alternatives in a paired-comparisons format. Deluty (1979) argued that by pitting the response alternatives against each other (i.e., assertive alternative against the submissive, assertive alternative against the aggressive, aggressive alternative against the submissive), the opportunity for children to consistently respond with the more socially desirable "assertive" response would be eliminated. However, this is only the case for one of the three paired comparisons; that is, when the aggressive alternative is pitted against the submissive alternative. In this situation, children may opt for the submissive response as it is more socially desirable than the aggressive response. With regard to the present study, children's scores on the CATS-subscales reflected a tendency to select assertive $(\underline{\mathrm{M}}=21.72, \underline{\mathrm{SD}}=2.99)$ and submissive 
$(\underline{\mathrm{M}}=12.47, \underline{\mathrm{SD}}=3.24)$ alternatives over the aggressive alternatives $(\underline{\mathrm{M}}=4.75, \underline{\mathrm{SD}}=4.45)$

(Note: all pairwise comparisons are significant, $\underline{p}<.001$ ). Given the design of the instrument, perhaps the CATS is a better suited as a measure of social desirability than true assertive behaviors. The results of the factor analysis appear to lend further support to this notion as the CATS-assertiveness and submissiveness scales and the RCMAS-lie scale loaded on the same factor. If this is the case, then the positive association between child social anxiety and assertiveness would be easier to understand.

Several meaningful relations between parents' and children's reports of individual differences were found in the present study. Specifically, parental perceptions of child social anxiety were associated with children's decreased attention and concentration. In addition, parents' reports of task persistence and the ability to ignore distractions were associated with children's increased attentional performance and reduced levels of general anxiety. Relations between parental-reports of child temperament and child social anxiety and child-reports of social anxiety were not found. Furthermore, results of the factor analysis that included both parent-and child-report assessments of individual differences identified separate factors for the child- and parent-report measures reflecting child anxiety. To date, research examining parentchild concordance on ratings of social anxiety is limited. However, the lack of parent-child agreement in the present study is consistent with previous research examining parent-child concordance for more global internalizing problems (e.g., general anxiety, depression) (Achenbach et al., 1987; Engel et al., 1994). Several possible explanations for the low degree of parent-child correspondence on ratings of internalizing disorders exist. First, research has documented the tendency of parents to over-report internalizing symptoms as well as to rate such 
symptoms at a higher level of intensity than children (Edelbrock, Costello, Dulcan, Conover, \& Kala, 1986). Second, the assessment of social fears and anxieties relies heavily on the interpretation of subjective feeling states as opposed to the observation of behavior (Edelbrock et al., 1986). Thus, collateral informants may not have access to all of the necessary and appropriate information required to make such assessments.

The hypotheses that individual differences in attention, assertiveness, and social anxiety would predict susceptibility to suggestion was not supported. These results are inconsistent with previous research conducted with adult populations that has documented positive associations between social-evaluative anxiety and suggestibility as well as negative relations between assertiveness and suggestibility (see Gudjonsson, 1992, for a review). Several possible explanations for the lack of predictive value of individual differences in the present study exist. From a statistical perspective, the relatively low sample size $(\underline{n}=48)$ may have limited the power to detect effects. Additionally, the lack of variability in the sample may have contributed to the non-findings (i.e., restricted range of scores on the individual difference variables). Research examining relations between intelligence and suggestibility with adults also has been limited by range effects (Powers et al., 1979). Only studies that have included participants with IQs well below average have documented negative associations between intelligence and suggestibility (see Gudjonsson, 1992, for a review).

The lack of findings with respect to individual differences also may be due to the experimental design of the study. Research conducted by Gudjonsson $(1988 ; 1992)$ documenting the significance of social-evaluative anxiety and assertiveness in predicting suggestibility has employed the "Gudjonsson Suggestibility Scale" (GSS; Gudjonsson, 1984). Specifically, 
participants listened to an audiotaped narrative that describes details of a mugging and were subsequently asked to respond to a series of 20 specific questions (15 of which are incorrectly leading). Upon answering the questions, participants were given negative feedback concerning their performance. Specifically, participants were informed that they had made some errors and consequently, were required to go through the questions again and that this time they should try to be more careful. Four suggestibility scores were calculated: (1) the number of leading questions yielded to during the initial interview (Yield 1), (2) the number of leading questions yielded to after the negative feedback (Yield 2), (3) shift of any initial responses following the negative feedback (Shift), and (4) total suggestibility which consisted of the sum of Yield 1 and Shift responses. Upon closer examination of Gudjonsson's (1988) results, it appears that socialevaluative anxiety was more closely related to suggestibility scores after the negative feedback was given (i.e., Yield 2 and Shift). Consequently, the influence of social anxiety on suggestibility may only be present under certain types of conditions, namely those involving direct negative evaluations or threats to self-presentation (e.g., accusatory tone, repeated questioning, pressure tactics by legitimate authority figures, etc).

Given that the present study was an initial attempt at investigating the role individual differences play in influencing children's susceptibility to suggestion, efforts were made to maintain tight control over the experimental design and procedure. Specifically, while leading questions were employed to examine suggestibility, the emotional tone of the interview was kept neutral. Thus, while the current results may suggest otherwise, it seems premature at this point to assume that individual characteristics do not influence children's vulnerability to suggestion. 
Clearly, more research is warranted to discern the types of conditions that might interact with individual factors in influencing suggestibility.

Several limitations of the present study merit attention. First, while the present study was designed to simulate elements of a "real-world" investigative interview (e.g., free and prompted recall, non-leading and leading questions), this was done under a highly controlled and contrived situation (e.g., witnessed a benign event, 20-minute delay, etc.). Thus, a tradeoff between precision and generalizability of the results is unavoidable. In addition, the lack of findings with respect to interviewer gender and individual differences may have been due to the fact that children were bystanders of, as opposed to participants in, the witnessed event. Other factors that may have contributed to the lack of predictive value of individual differences include: (1) low sample size, (2) the use of a community sample which may have restricted the range of variability with respect to individual differences (i.e., inclusion of extreme groups may reveal different results), and (3) the fact that children may not have perceived the interviewers as legitimate authority figures. Finally, perhaps other individual characteristics, not assessed in the present study, are related to suggestibility (e.g., self-esteem, depression).

In sum, the present study adds support to the literature on children's eyewitness memory performance by the replication of results for free and prompted recall as well as non-leading and leading interviews. In addition, this study extends previous research by investigating susceptibility to suggestion in an age group that has been neglected in the past as well as providing an initial attempt at investigating relations between individual differences and suggestibility. Given that a variety of experimental conditions are known to impact susceptibility to suggestion (e.g., repeated questioning, emotional tone of interview, status of interviewer, 
stereotypes) (Ceci \& Bruck, 1993), future research should be aimed at combining the experimental and individual differences approaches in an effort to differentiate the conditions that may interact with child characteristics in influencing suggestibility. 


\section{References}

Achenbach, T. M., McConaughy, S. H., \& Howell, C. T. (1987). Child/adolescent behavioral and emotional problems: Implications of cross-informant correlations for situational specificity. Psychological Bulletin, 101, 213-232.

Ackil, J. K., \& Zaragoza, M. S. (1995). Developmental differences in eyewitness suggestibility and memory for source. Journal of Experimental Child Psychology, 60, 57-83.

Asendorpf, J. B. (1993). Beyond temperament: A two-factorial coping model of the development of inhibition during childhood. In K. H. Rubin \& J. B. Asendorpf (Eds.),

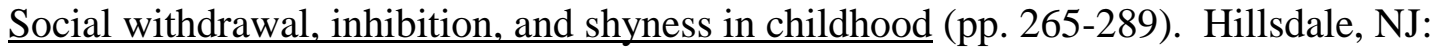
Lawrence Erlbaum Associates, Inc.

Beidel, D. C., \& Morris, T. L. (1993). Avoidant disorder of childhood and social phobia. In H. L. Leonard (Ed.), Child and Adolescent Psychiatric Clinics of North America, 2, 623-638.

Beidel, D. C., Turner, S. M., \& Fink, C. M. (1996). Assessment of childhood social phobia: Construct, convergent, and discriminative validity of the Social Phobia and Anxiety Inventory for Children (SPAI-C). Psychological Assessment, 8, 235-240.

Beidel, D. C., Turner, S. M., \& Morris, T. L., (1995). A new inventory to assess childhood social anxiety and phobia: The Social Phobia and Anxiety Inventory for Children. Psychological Assessment, 7, 73-79.

Bruck, M., Ceci, S. J., \& Hembrooke, H. (1998). Reliability and credibility of young children's reports: From research to policy and practice. American Psychologist, 53, 136-151.

Bruck, M., Ceci, S. J., \& Melnyk, L. (1997). External and internal sources of variation in the creation of false reports in children. Learning and Individual Differences, 9, 289-316. 
Cassel, W. S., \& Bjorklund, D. F. (1995). Developmental patterns of eyewitness memory and suggestibility: An ecologically based short-term longitudinal study. Law and Human Behavior, 19, 507-532.

Ceci, S. J., \& Bruck, M. (1993). Suggestibility of the child witness: A historical review and synthesis. Psychological Bulletin, 113, 403-439.

Ceci, S. J., Crotteau, M. L., Smith, E., \& Loftus, E. F. (1994). Repeatedly thinking about a nonevent: Source misattributions among preschoolers. Consciousness and Cognition, 3, 388407.

Ceci, S. J., Ross, D. F., \& Toglia, M. P. (1987). Suggestibility of children's memory: Psycholegal implications. Journal of Experimental Psychology: General, 116, 38-49.

Christiaansen, R. E., Ochalek, K., \& Sweeney, J. D. (1984). Individual differences in eyewitness memory and confidence judgments. Journal of General Psychology, 110, 47-52.

Crozier, R. (1979). Shyness as anxious self-preoccupation. Psychological Reports, 44, 959-962.

Dale, P. S., Loftus, E. F., \& Rathbun, L. (1978). The influence of the form of the question on the eyewitness testimony of preschool children. Journal of Psycholinguistic Research, 7. 269-277.

Davies, G., Tarrant, A., \& Flin, R. (1989). Close encounters of the witness kind: Children's memory for a simulated health inspection. British Journal of Psychology, 80, 415-429.

Deluty, R. H. (1979). Children's Action Tendency Scale: A self-report measure of aggressiveness, assertiveness, and submissiveness in children. Journal of Consulting and Clinical Psychology, 47, 1061-1071. 
Dindia, K., \& Allen, M. (1992). Sex differences in self-disclosure: A meta-analysis. Psychological Bulletin, 112, 106-124.

Easterbrook, J. A. (1959). The effect of emotion on cue utilization and the organization of behavior. Psychology Review, 66, 183-201.

Edelbrock, C., Costello, A. J., Dulcan, M. K., Conover, N. C., \& Kala, R. (1986). Parent-child agreement on child psychiatric symptoms assessed via structured interview. Journal of Child Psychology and Psychiatry, 27, 181-190.

Engel, N. A., Rodrigue, J. R., \& Geffken, G. R. (1994). Parent-child agreement on ratings of anxiety in children. Psychological Reports, 75, 1251-1260.

Fry, R. P. W., Rozewicz, L. M., \& Crisp, A. H. (1996). Interviewing for sexual abuse: Reliability and effect of interviewer gender. Child Abuse and Neglect, 20, 725-729.

Galassi, J. P., \& Bruch, M. A. (1992). Counseling with social interaction problems: Assertion and social anxiety. In S. D. Brown \& R. W. Lent (Eds.), Handbook of Counseling Psychology (2nd ed., pp. 757-791). New York: John Wiley \& Sons, Inc.

Gibson, E., \& Radner, N. (1979). Attention: The perceiver as performer. In G.A. Hale \& M. Lewis (Eds.), Attention and cognitive development (pp. 1-21). New York: Plenum Press.

Gilbert, P., \& Trower, P. (1990). The evolution and manifestation of social anxiety. In W. R. Crozier (Ed.), Shyness and embarrassment (pp. 144-177). New York: Cambridge University Press.

Goodman, G. S., Hirschman, J. E., Hepps, D., \& Rudy, L. (1991). Children’s memory for stressful events. Merrill-Palmer Quarterly, 37, 109-158. 
Goodman, G. S, \& Reed, R. S. (1986). Age differences in eyewitness testimony. Law and Human Behavior, 10, 317-332.

Goodman, G. S., Rudy, L., Bottoms, B. L., \& Aman, C. (1990). Children's concerns and memory: Issues of ecological validity in the study of children's eyewitness testimony. In R. Fivush \& J. Hudson (Eds.), Knowing and remembering in young children (pp. 249284). New York: Cambridge University Press.

Gudjonsson, G. H. (1984). A new scale of interrogative suggestibility. Personality and Individual Differences, 5, 303-314.

Gudjonsson, G. H. (1988). Interrogative suggestibility: Its relationship with assertiveness, socialevaluative anxiety, state anxiety and method of coping. British Journal of Clinical Psychology, 27, 159-166.

Gudjonsson, G. H. (1992). The psychology of interrogations, confessions, and testimony. New York: John Wiley \& Sons, Inc.

Hilgard, E. R., \& Loftus, E. F. (1979). Effective interrogation of the eyewitness. International Journal of Clinical and Experimental Hypnosis, 27, 342-357.

Hollingshead, A. B. (1975). Four-factor index of social status. Unpublished manuscript. Yale University, New Haven, CT.

Holt, C. S., Heimberg, R. G., Hope, D. A., \& Liebowitz, M. R. (1992). Situational domains of social phobia. Journal of Anxiety Disorders, 6, 63-77.

Howell, D. G. (1992). Statistical methods for psychology ( $3^{\text {rd }}$ ed.). Belmont, California: Duxbury Press. 
Kaplan, M. S., Becker, J. V., \& Tenke, C. E. (1991). Influence of abuse history on male adolescent self-reported comfort with interviewer gender. Journal of Interpersonal Violence, 6, 3-11.

Kimble, C. E., \& Zehr, H. D. (1982). Self-consciousness, information load, self-presentation, and memory in a social situation. Journal of Social Psychology, 118, 39-46.

Leary, M. R., \& Kowalski, R. M. (1995). Social anxiety. New York: The Guilford Press.

Leichtman, M. D., \& Ceci, S. J. (1995). The effects of stereotypes and suggestions on preschoolers' reports. Developmental Psychology, 31, 568-578.

Loftus, E. F., \& Doyle, J. M. (1992). Eyewitness testimony: Civil and criminal (2nd ed.). Charlottesville, VA: The Michie Co.

Loftus, E. F., \& Pickrell, J. (1995). The formation of false memories. Psychiatric Annals, 25, $720-725$.

Loftus, E. F., \& Zanni, G. (1975). Eyewitness testimony: The influence of the wording of a question. Bulletin of the Psychonomic Society, 5, 86-88.

Marin, B. V., Holmes, D. L., Guth, M., \& Kovac, P. (1979). The potential of children as eyewitnesses: A comparison of children and adults on eyewitness tasks. Law and Human Behavior, 3, 295-306.

Memon, A., \& Vartoukian, R. (1996). The effects of repeated questioning on young children's eyewitness testimony. British Journal of Psychology, 87, 403-415.

Morris, T. L., \& Masia, C. L. (1998). Psychometric evaluation of the Social Phobia and Anxiety Inventory for Children: Concurrent validity and normative data. Journal of Clinical Child Psychology, 27, 452-458. 
Oates, K., \& Shrimpton, S. (1991). Children's memories for stressful and non-stressful events. Medicine, Science, and the Law, 31, 4-10.

Pollner, M. (1998). The effects of interviewer gender in mental health interviews. Journal of Nervous and Mental Disease, 186, 369-373.

Poole, D. A., \& Lamb, M. E. (1998). Investigative interviews of children: A guide for helping professionals. Washington, D.C.: American Psychological Association.

Poole, D. A, \& White, L. T. (1991). Effects of question repetition on the eyewitness testimony of children and adults. Developmental Psychology, 27, 975-986.

Portwood, S. G., \& Reppucci, N. D. (1996). Adults' impact on the suggestibility of preschoolers' recollections. Journal of Applied Developmental Psychology, 17, 175-198.

Powers, P. A., Andriks, J. L., \& Loftus, E. F. (1979). Eyewitness accounts of females and males. Journal of Applied Psychology, 64, 339-347.

Quas, J. A., Goodman, G. S., Bidrose, S., Pipe, M. E., Craw, S., \& Ablin, D. S. (1999). Emotion and memory: Children's long-term remembering, forgetting, and suggestibility. Journal of Experimental Child Psychology, 72, 235-270.

Reynolds, C. R. (1980). Concurrent validity of What I Think and Feel: The Revised Children's Manifest Anxiety Scale. Journal of Consulting and Clinical Psychology, 48, 774-775.

Reynolds, C. R., \& Richmond, B. O. (1978). What I Think and Feel: A revised measure of children's manifest anxiety. Journal of Abnormal Child Psychology, 6, 271-280.

Rubin, K. H. (1993). The Waterloo Longitudinal Project: Correlates and consequences of social withdrawal from childhood to adolescence. In K. H. Rubin \& J. B. Asendorpf (Eds.), 
Social withdrawal, inhibition, and shyness in childhood (pp. 291-314). Hillsdale, NJ: Lawrence Erlbaum Associates, Inc.

Sattler, J. M. (1992). Assessment of children (3rd ed.). San Diego: Jerome M. Sattler, Publisher, Inc.

Saywitz, K., Geiselman, R., \& Bornstein, G. (1992). Effects of cognitive interviewing, practice, and interview style on children's recall performance. Journal of Applied Psychology, 77, 744-756.

Schacter, D. L., Kagan, J., \& Leichtman, M. D. (1995). True and false memories in children and adults: A cognitive neuroscience perspective. Psychology, Public Policy, and Law, 1, 411-428.

Schlenker, B. R., \& Leary, M. R., (1982). Social anxiety and self-presentation: A conceptualization and model. Psychological Bulletin, 92, 641-669.

Schooler, J. W., \& Loftus, E. F. (1986). Individual differences and experimentation: Complementary approaches to interrogative suggestibility. Social Behaviour, 1, 105-112.

Siegal, M.., Waters, L., \& Dinwiddy, L. (1988). Misleading children: Causal attributions for inconsistency under repeated questioning. Journal of Experimental Child Psychology, 45, 438-456.

Siegel, J. M., \& Loftus, E. F. (1978). Impact of anxiety and life stress upon eyewitness testimony. Bulletin of the Psychonomic Society, 12, 479-480.

Stevenson-Hinde, J., \& Shouldice, A. (1993). Wariness to strangers: A behavior systems perspective revisited. In K. H. Rubin \& J. B. Asendorpf (Eds.), Social withdrawal, 
inhibition, and shyness in childhood (pp. 101-116). Hillsdale, NJ: Lawrence Erlbaum Associates, Inc.

Tabachnick, B. G., \& Fidell, L. S. (1989). Using multivariate statistics $\left(2^{\text {nd }}\right.$ ed.). New York: HarperCollins Publishers, Inc.

Ward, R. A., \& Loftus, E. F. (1985). Eyewitness performance in different psychological types. Journal of General Psychology, 112, 191-200.

Warren, A. R., \& Lane, P. (1995). The effects of timing and type of questioning on eyewitness accuracy and suggestibility. In M. Zaragoza (Ed.), Memory and testimony in the child witness (pp. 44-60). Thousand Oaks, CA: Sage.

Wechsler, D. (1991). Wechsler Intelligence Scale for Children Manual ( $3^{\text {rd }}$ ed.). San Antonio, TX: Harcourt Brace Jovanovich, Inc.

White, S., \& Quinn, K. M. (1988). Investigatory independence in child sexual abuse evaluations: Conceptual considerations. Bulletin of the American Academy of Psychiatry and Law, 16, 269-278.

Windle, M., \& Lerner, R. M. (1986). Reassessing the dimensions of temperamental individuality across the life span: The Revised Dimensions of Temperament Survey (DOTS-R). Journal of Adolescent Research, 1, 213-230.

Windle, M., Hooker, K., Lernerz, K., East, P. I., Lerner, J. V., \& Lerner, R. M. (1986). Temperament, perceived competence, and depression in early- and late-adolescents. Developmental Psychology, 22, 384-392. 


\section{APPENDIX A}

Demographic Background Questionnaire 
Participant\#

\section{BACKGROUND INFORMATION SHEET}

TODAY'S DATE:

NAME OF CHILD:

BIRTHDATE OF CHILD: / /

SEX OF CHILD: male female

NAME OF PARENT ACCOMPANYING CHILD:

SPOUSE'S/PARTNER'S NAME (if applicable):

MARITAL STATUS (please circle):

$1=$ single

$2=$ married (for how long:

3 = separated (for how long:

4 = divorced (for how long:

5 = widowed (for how long:

$6=$ remarried (for how long:

A) IF SINGLE, SEPARATED, DIVORCED, OR WIDOWED, ARE YOU CURRENTLY INVOLVED IN A RELATIONSHIP (please circle)? yes no

B) IF YOU CIRCLED “YES,” HOW LONG HAVE YOU BEEN IN THE RELATIONSHIP?

WITH WHOM DOES THE ABOVE NAMED CHILD LIVE?

(e.g., mother or father only, mother and father, mother and stepfather, stepmother and father, mother and partner, father and partner, etc.)

HIGHEST LEVEL OF SCHOOL COMPLETED BY PERSON(S) WITH WHOM THE CHILD LIVES:

(e.g., 9th grade, high school graduate, some college, college graduate, graduate/professional degree, etc.)

person (e.g., mother, stepfather, etc.)

level

person (e.g., father, stepmother, etc.) level 
OCCUPATION OF PERSON(S) WITH WHOM THE CHILD LIVES:

person (e.g., mother, stepfather, etc.) occupation

person (e.g., father, stepmother, etc.) occupation

HIGHEST LEVEL OF SCHOOL COMPLETED BY OTHER PERSON(S) WHO PROVIDE FINANCIAL SUPPORT FOR THE CHILD (if applicable):

(e.g., 9th grade, high school graduate, some college, college graduate, graduate/professional degree, etc.)

person (e.g., mother, stepfather, etc.)

level

person (e.g., father, stepmother, etc.) level

OCCUPATION OF OTHER PERSON(S) WHO PROVIDE FINANCIAL SUPPORT FOR THE CHILD (if applicable):

person (e.g., mother, stepfather, etc.) occupation

person (e.g., father, stepmother, etc.) occupation

NAME, BIRTHDATE, AND SEX OF OTHER CHILDREN:

WOULD YOU BE INTERESTED IN PARTICIPATING IN OTHER STUDIES IN THE PSYCHOLOGY DEPARTMENT?

yes no maybe

WHERE DO YOUR CHILDREN ATTEND SCHOOL?

IF YOU WOULD LIKE TO KNOW WHAT WE FIND IN THIS STUDY, PLEASE LEAVE US YOUR ADDRESS BELOW. (NOTE -- IT MAY TAKE MANY MONTHS): 


\section{APPENDIX B}

Script for Simulated Conflict Scenario 


\section{CONFLICT SCENARIO SCRIPT}

Woman standing at kitchen counter chopping vegetables, man enters through front door carrying his suit coat...

MAN: $\quad$ Hi, honey! I'm home. How was your day today?

WOMAN: It was alright, how was yours?

MAN: Well, let's just say that I was so busy at work today that I didn't even have time to stop to eat lunch. I'm starving. What's for dinner?

WOMAN: Well, in that case, I'd better hurry dinner along.

MAN: $\quad$ WHAT? You mean dinner isn't ready yeat?

WOMAN: Not quite, but it will be ready in about a half an hour.

MAN: $\quad$ A HALF HOUR! I just told you that I haven't had anything to eat all day. Weren't you listening to me?

WOMAN: Yes, I heard you, but it takes time to prepare good food. I'm cooking as fast as I can.

MAN: $\quad$ You know what time I come home from work everyday - why don't you start cooking a little bit earlier considering you sit around here and do nothing all day long. I can't believe how lazy you are.

WOMAN: Just what is that supposed to mean? I work hard during the day too, you know and if I'm doing such a lousy job, why don't you cook your own dinner?

MAN: $\quad$ Well, maybe I'll just go somewhere else and eat!

WOMAN: Fine. Go ahead and leave!

Man stands up, knocks over the chair and exits the kitchen. Woman sits down at the table and puts her head in her hands. After a few moments, she stands up and exits the kitchen. 
Man and woman re-enter the room talking and acting angrily...

MAN: $\quad$...And just look at this place - it's a pigsty! Don't you ever clean?

WOMAN: Hey! This isn't all my mess! Those are your sneakers, I don't even eat potato chips, and you were the last one to read the paper.

MAN: Well, what about the dirty carpet and the inch of dust covering everything? You could still clean, you know?

WOMAN: Yeah, and I'd have to clean-up your mess to do it! No thank-you! 


\section{APPENDIX C}

Free Recall Interview 
Participant\#

\section{FREE RECALL INTERVIEW}

Instructions: "Hi, [state child's name], my name is [state your name] and I am going to ask you some questions. A few minutes ago, you watched a videotape. I want you to tell me everything you can remember about what you saw and what happened on the videotape."

"As you talk, I am going to write down what you say and also record your statements on this tape recorder. So, again, tell me everything you can remember about what you saw and what happened on the videotape."

WRITE DOWN - VERBATIM - EVERYTHING THE CHILD SAYS:

WHAT ELSE CAN YOU REMEMBER? 
APPENDIX D

Prompted Recall Interview 
Participant\#

\section{PROMPTED RECALL INTERVIEW (OPEN-ENDED QUESTIONS)}

Instructions: "Okay, now I am going to ask you some more specific questions about the videotape you watched earlier. I know that you already mentioned some of these things, but I want you to tell me again. Just as before, I am going to write down what you say."

A) First, tell me about everything and everybody that was in the room on the videotape:

B) Okay, now tell me more about the man in the videotape:

1) What did the man look like?

- What else can you remember about what the man looked like?

2) What was the man wearing?

- What else can you remember about what the man was wearing?

3) What did the man do?

- What else can you remember about what the man did?

4) What did the man say?

- What else can you remember about what the man said? 
B) Now tell me about the woman in the videotape:

1) What did the woman look like?

- What else can you remember about what the woman looked like?

2) What was the woman wearing?

- What else can you remember about what the woman was wearing?

3) What did the woman do?

- What else can you remember about what the woman did?

4) What did the woman say?

- What else can you remember about what the woman said?

C) And what about the room, what did the room look like?

- What else can you remember about what the room looked like? 


\section{APPENDIX E}

Non-Leading and Leading Interviews 
Participant\#

\section{SPECIFIC QUESTIONS: NON-LEADING}

\section{MALE CHARACTERISTICS:}

1) What color hair did the man have?

2) Did the man have a mustache?

3) Was the man wearing dark colored pants?

4) What color was the man's shirt?

5) Did the man put his coat on the back of a chair?

6) Did the man have a newspaper?

7) Was the man wearing a tie?

8) Did the man have a briefcase when he came home?

\section{FEMALE CHARACTERISTICS:}

1) What color was the woman's hair?

2) Did the woman have long or short hair?

3) Was the woman wearing a necklace?

4) What color was the woman's shirt?

5) What color were the woman's pants?

6) Was the woman wearing glasses?

7) Was the woman wearing an apron?

8) Was the woman washing dishes when the man came home? 


\section{SPECIFIC QUESTIONS: NON-LEADING}

\section{ROOM CHARACTERISTICS:}

1) Did you see a window in the room?

2) How many chairs were in the room?

3) Was there a toaster on the counter?

4) What was sitting on top of the refrigerator?

5) Was there a phone in the room?

6) Was there a picture hanging on the wall above the sink?

7) Was there a plant on the table?

8) Were there pots and pans sitting on the stove?

\section{CONTENT CHARACTERISTICS OF THE ARGUMENT:}

1) Did the man touch the woman?

2) Did the man say the woman was lazy?

3) Was the woman angry because the man was late for dinner?

4) Did the man leave the room before the woman did?

5) Did the man complain about the messy house when he came back into the room?

6) Did the man or the woman knock over a chair?

7) Did the woman leave the room carrying a knife?

8) Did the woman call the man a slob? 
Participant\#

\section{SPECIFIC QUESTIONS: LEADING}

\section{MALE CHARACTERISTICS:}

1) What color hair did the man have?

2) Did the man have a mustache?

3) Wasn't the man wearing dark colored pants? (correctly leading)

4) What color was the man's shirt?

5) The man put his coat on the back of a chair, didn't he? (incorrectly leading)

6) Did the man have a newspaper?

7) Wasn't the man wearing a tie? (correctly leading)

8) Did the man set his briefcase on the table or by the door when he came home? (incorrectly leading)

\section{FEMALE CHARACTERISTICS:}

1) What color was the woman's hair?

2) Didn't the woman have long hair? (incorrectly leading)

3) The woman was wearing a necklace, wasn't she? (correctly leading)

4) What color was the woman's shirt?

5) What color were the woman's pants?

6) Wasn't the woman was wearing glasses? (correctly leading)

7) Was the woman wearing an apron?

8) Was the woman washing dishes or setting the table when the man came home? (incorrectly leading) 


\section{SPECIFIC QUESTIONS: LEADING}

\section{ROOM CHARACTERISTICS:}

1) Did you see a window in the room?

2) How many chairs were in the room?

3) There was a toaster on the counter, wasn't there? (correctly leading)

4) What was sitting on top of the refrigerator?

5) Was there a phone in the room?

6) Was there a clock or a calendar hanging on the wall above the sink? (incorrectly leading)

7) Wasn't there a plant on the table? (correctly leading)

8) There were pots and pans sitting on the stove, weren't there? (incorrectly leading)

\section{CONTENT CHARACTERISTICS OF THE ARGUMENT:}

1) Did the man touch the woman?

2) Didn't the man say the woman was lazy? (correctly leading)

3) Was the woman angry because the man was late for dinner?

4) Did the man leave the room at the same time or after the woman did? (incorrectly leading)

5) The man complained about the messy house when he came back into the room, didn't he? (correctly leading)

6) Did the man or the woman knock over a chair?

7) Did the woman leave the room carrying a knife?

8) The woman called the man a slob, didn't she? (incorrectly leading) 
APPENDIX F

Free and Prompted Recall Accuracy Coding Sheets 
Participant \#

Coder's Name

\section{ACCURATE - MAN CHARACTERISTICS (APPEARANCE \& ACTIONS):}

1) Physical Description (7 points possible):

\begin{tabular}{|c|c|c|c|c|}
\hline & & & Frequency of & Occurrence \\
\hline "Initial" & "What else" & & Free Recall & $\begin{array}{l}\text { Prompted } \\
\text { Recall }\end{array}$ \\
\hline 1a1) & $1 \mathrm{a} 2)$ & white/light skin & 0 & 12 \\
\hline 1b1) & 1b2) & $\begin{array}{l}\text { average/medium height (sort of } \\
\text { tall) }\end{array}$ & 0 & 24 \\
\hline $1 \mathrm{c} 1)_{-}$ & $1 c 2)$ & average/medium weight & 0 & 6 \\
\hline 1d1) ___ & $1 \mathrm{~d} 2)$ & short hair & 0 & 9 \\
\hline 1e1) & 1e2) & dark hair (brown/dark brown/black) & 0 & 84 \\
\hline 1f1) _ـ & 1f2) & male/man & 96 & 96 \\
\hline 1g1) & 1g2) & about age 30 (young adult)* & 0 & 2 \\
\hline
\end{tabular}

2) Description of Clothing/Accessories ( 7 points possible):

\begin{tabular}{|c|c|c|c|c|}
\hline "Initial" & "What else" & & Free Recall & $\begin{array}{c}\text { Prompted } \\
\text { Recall }\end{array}$ \\
\hline 2a1) & 2a2) & shirt & 0 & 68 \\
\hline $2 b 1)$ & $2 \mathrm{~b} 2)$ & long-sleeved (shirt) & 0 & 8 \\
\hline $2 \mathrm{c} 1)$ & $2 \mathrm{c} 2)$ & solid blue/light blue (shirt) & 0 & 14 \\
\hline $2 \mathrm{~d} 1)$ & $2 \mathrm{~d} 2)$ & tie & 0 & 73 \\
\hline $2 \mathrm{e} 1)$ & $2 \mathrm{e} 2)$ & pants & 1 & 93 \\
\hline 2f1) & $2 \mathrm{f} 2)$ & dark-colored/navy/black (pants) & 0 & 40 \\
\hline $2 \mathrm{~g} 1)$ & $2 \mathrm{~g} 2)$ & $\begin{array}{l}\text { dark-colored/navy/black } \\
\text { jacket/coat* }\end{array}$ & 0 & 6 \\
\hline
\end{tabular}


Participant \#

Coder's Name

\section{ACCURATE - MAN CHARACTERISTICS (APPEARANCE \& ACTIONS):}

3) Description of Actions (14 points possible):

Frequency of Occurrence

"Initial" "What else"

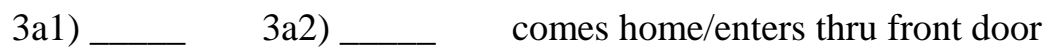

3b1)

$3 \mathrm{c} 1$

3d1)

$3 \mathrm{e} 1$

3f1)

$3 \mathrm{~g} 1$

3h1)

3i1)

$3 \mathrm{j} 1)$

$3 \mathrm{k} 1)$

311)

$3 \mathrm{~m} 1)$

3n1)
$3 \mathrm{~b} 2$

$3 \mathrm{c} 2)$

3d2)

3e2)

$3 \mathrm{f} 2$

$3 g 2)$

3h2)

3i2)

3j2)

$3 \mathrm{k} 2)$

312)

$3 \mathrm{~m} 2)$

3n2) carrying suit coat/jacket

carrying newspaper

shuts front door

hangs coat up on coat rack

picks-up paper from counter

sits down at table

opens paper/looks at or reads paper

gets angry/agitated/yells

shakes/ruffles newspaper w/hands

knocks over chair

leaves room/goes in different room

points toward floor/carpet

wipes hand on top of fridge
Prompted Recall

89

70

0

3

0

3

0

3

4

18

0

6

15

45

10

25

80

83

0

50

65

78

67

0

5

9 
Participant \#

Coder's Name

\section{ACCURATE - WOMAN CHARACTERISTICS (APPEARANCE \& ACTIONS):}

4) Physical Description (8 points possible):

\begin{tabular}{|c|c|c|c|c|}
\hline & & & Frequency of & Occurrence \\
\hline "Initial" & "What else" & & Free Recall & $\begin{array}{c}\text { Prompted } \\
\text { Recall }\end{array}$ \\
\hline 4a1) & $4 a 2)$ & white/light skin & 0 & 11 \\
\hline $4 b 1)$ & $4 b 2)$ & short (shorter than man) & 0 & 29 \\
\hline $4 c 1)$ & $4 c 2)$ & slightly overweight (heavy set) & 0 & 31 \\
\hline $4 \mathrm{~d} 1)$ & $4 \mathrm{~d} 2)$ & short hair & 0 & 23 \\
\hline $4 e 1)_{-}$ & $4 e 2)$ & blonde/sandy or light brown hair & 1 & 67 \\
\hline 4f1) & 4f2) & female/woman & 96 & 96 \\
\hline $4 \mathrm{~g} 1)_{2}$ & $4 \mathrm{~g} 2)$ & about age 30 (young adult)* & 0 & 3 \\
\hline $4 h 1)_{-}$ & $4 \mathrm{~h} 2)$ & straight hair* & 0 & 1 \\
\hline
\end{tabular}

5) Description of Clothing/Accessories (10 points possible):

\begin{tabular}{|c|c|c|c|c|}
\hline "Initial" & "Wh & & Free Recall & $\begin{array}{c}\text { Prompted } \\
\text { Recall }\end{array}$ \\
\hline 5a1) & $5 a 2)$ & shirt & 2 & 81 \\
\hline $5 b 1)_{-}$ & $5 b 2)$ & short-sleeved (shirt) & 0 & 2 \\
\hline $5 c 1)_{-}$ & $5 c 2)$ & solid green (shirt) & 1 & 34 \\
\hline $5 \mathrm{~d} 1)_{-}$ & $5 \mathrm{~d} 2)$ & pants & 1 & 81 \\
\hline $5 e 1)$ & $5 e 2)$ & jeans/blue (pants) & 0 & 37 \\
\hline $5 \mathrm{f} 1)$ & $5 f 2)$ & glasses & 1 & 44 \\
\hline $5 g 1)_{2}$ & $5 \mathrm{~g} 2)$ & gold necklace & 0 & 5 \\
\hline $5 \mathrm{~h} 1)$ & $5 \mathrm{~h} 2)$ & wristwatch & 0 & 4 \\
\hline 5i1) & $5 \mathrm{i} 2)$ & ring & 0 & 5 \\
\hline $5 \mathrm{j} 1)$ & $5 j 2)$ & pocket on shirt* & 0 & 1 \\
\hline
\end{tabular}


Participant \#

Coder's Name

\section{ACCURATE - WOMAN CHARACTERISTICS (APPEARANCE \& ACTIONS):}

6) Description of Actions (11 points possible):

\begin{tabular}{|c|c|c|c|c|}
\hline "Initial" & "What else" & & Free Recall & $\begin{array}{l}\text { Prompted } \\
\text { Recall }\end{array}$ \\
\hline $6 a 1)$ & $6 a 2)$ & cooking/making dinner/chopping & 35 & 82 \\
\hline $6 b 1)_{2}$ & $6 \mathrm{~b} 2)$ & gets food from cupboard & 1 & 14 \\
\hline $6 c 1)_{-}$ & $6 c 2)$ & gets angry/agitated/yells & 40 & 47 \\
\hline $6 \mathrm{~d} 1)_{2}$ & $6 \mathrm{~d} 2)$ & holding knife & 0 & 6 \\
\hline $6 e 1)$ & $6 e 2)$ & throws knife on counter & 0 & 3 \\
\hline $6 f 1)$ & $6 f 2)$ & puts hand on hip & 0 & 2 \\
\hline $6 g 1)_{-}$ & $6 g 2)$ & crosses arms across chest & 0 & 2 \\
\hline $6 h 1)$ & $6 h 2)$ & sits down at table & 18 & 37 \\
\hline $6 \mathrm{i1})$ & $6 \mathrm{i} 2)$ & puts head in hands at table & 11 & 22 \\
\hline $6 \mathrm{j} 1)$ & $6 j 2)$ & leaves room/goes in different room & 50 & 42 \\
\hline $6 \mathrm{k} 1)$ & $6 \mathrm{k} 2)$ & $\begin{array}{l}\text { points at "items" in room (sneakers, } \\
\text { paper, chips) }\end{array}$ & 0 & 4 \\
\hline
\end{tabular}


Participant \#

Coder's Name

\section{ACCURATE - CONTENT OF ARGUMENT:}

7) Man's Statements (13 points possible):

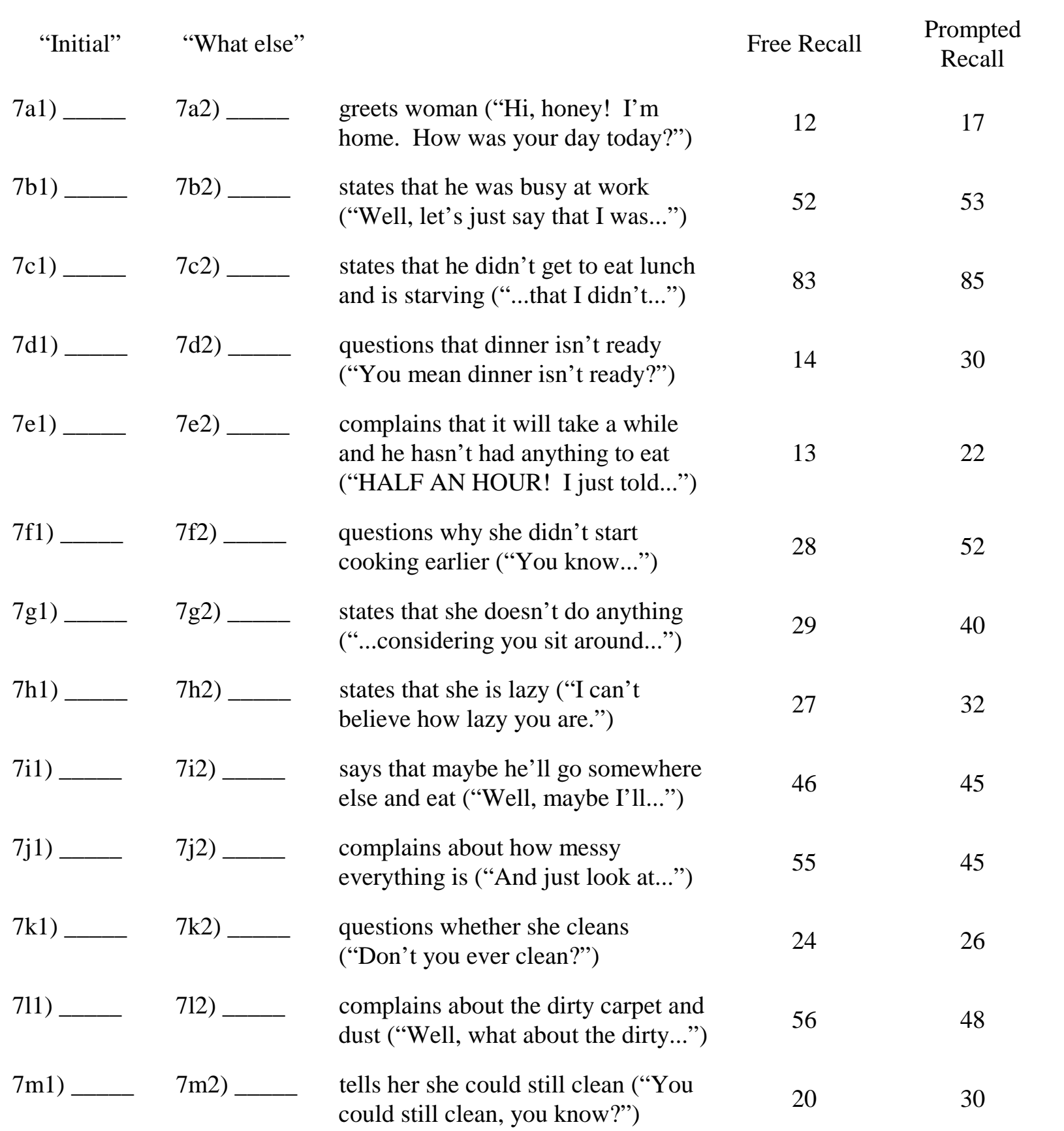

Frequency of Occurrence

greets woman ("Hi, honey! I'm how was your day today?")

tates that he was busy at work states that he didn't get to eat lunch questions that dinner isn't ready ("HALF AN HOUR! I just told...")

questions why she didn't start cooking earlier ("You know...") anything

states that she is lazy ("I can't could still clean, you know?") 
Participant \#

Coder's Name

\section{ACCURATE - CONTENT OF ARGUMENT:}

8) Woman's Statements (10 points possible):

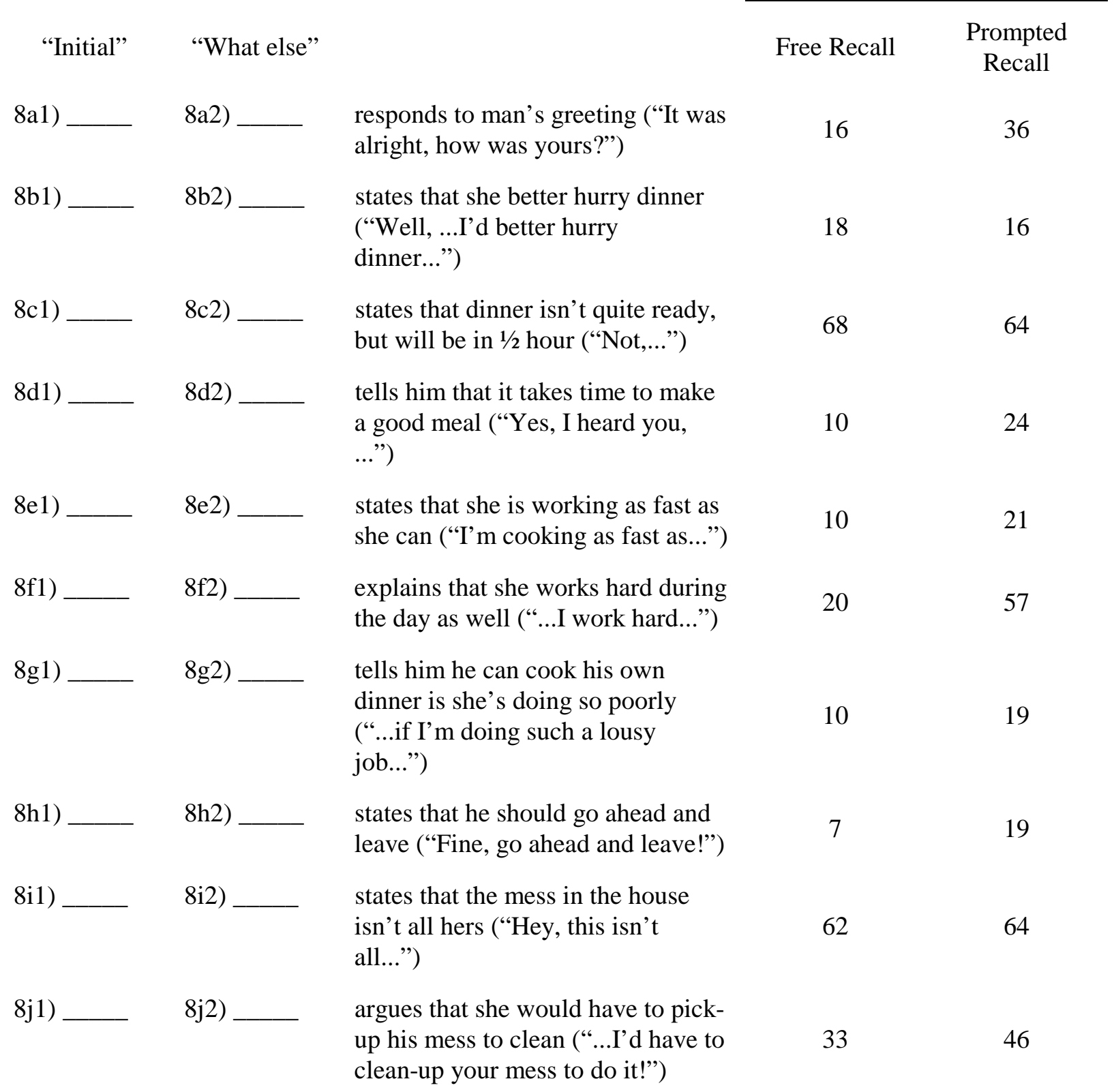

Frequency of Occurrence 
Participant \#

Coder's Name

\section{ACCURATE - ROOM CHARACTERISTICS:}

9) Description of "BIG" items (e.g., setting, appliances, furniture, etc.) (16 points possible):

\begin{tabular}{|c|c|c|c|c|}
\hline & & & Frequency of & Occurrence \\
\hline "Initial" & "What else" & & Free Recall & $\begin{array}{c}\text { Prompted } \\
\text { Recall }\end{array}$ \\
\hline $9 \mathrm{a} 1)_{-}$ & $9 a 2)$ & kitchen & 4 & 73 \\
\hline $9 b 1)$ & $9 b 2)$ & front door & 1 & 32 \\
\hline $9 \mathrm{c} 1)_{-}$ & $9 c 2)$ & wooden door/second door & 0 & 14 \\
\hline $9 \mathrm{~d} 1)_{-}$ & $9 \mathrm{~d} 2)$ & light-colored walls (white/cream) & 0 & 20 \\
\hline $9 \mathrm{e} 1)$ & $9 e 2)$ & cabinets/cupboards & 2 & 58 \\
\hline 9f1) & $9 f 2)$ & counters/countertops & 1 & 38 \\
\hline $9 \mathrm{~g} 1)_{-}$ & $9 g 2)$ & $\sin k$ & 2 & 36 \\
\hline $9 h 1)_{-}$ & $9 \mathrm{~h} 2)$ & stove/oven & 2 & 33 \\
\hline $9 \mathrm{i} 1)_{-}$ & $9 \mathrm{i} 2)$ & refrigerator & 0 & 57 \\
\hline $9 \mathrm{j} 1)$ & $9 j 2)$ & table (wooden/round) & 3 & 81 \\
\hline $9 \mathrm{k} 1)$ & $9 \mathrm{k} 2)$ & chairs at table & 2 & 65 \\
\hline 911) & $912)$ & microwave & 0 & 7 \\
\hline $9 \mathrm{~m} 1)_{-}$ & $9 \mathrm{~m} 2)$ & toaster & 0 & 1 \\
\hline $9 \mathrm{n} 1)_{-}$ & $9 \mathrm{n} 2)$ & coat rack & 0 & 24 \\
\hline $9 o 1)_{-}$ & $902)$ & coats on coat rack $*$ & 0 & 3 \\
\hline $9 \mathrm{p} 1)_{-}$ & $9 \mathrm{p} 2)$ & carpet/rug* & 0 & 14 \\
\hline
\end{tabular}


Participant \#

Coder's Name

\section{ACCURATE - ROOM CHARACTERISTICS:}

10) Description of "SMALL" items (e.g., decorations, utensils, etc.) (15 points possible):

\begin{tabular}{|c|c|c|c|c|}
\hline & & & Frequency of & Occurrence \\
\hline "Initial" & "What else" & & Free Recall & $\begin{array}{c}\text { Prompted } \\
\text { Recall }\end{array}$ \\
\hline 10a1) & $10 a 2)$ & dishes on counter & 0 & 3 \\
\hline 10b1) & $10 \mathrm{~b} 2)$ & bottle of hand-soap & 0 & 0 \\
\hline $10 \mathrm{c} 1)$ & $10 \mathrm{c} 2)$ & cutting board & 0 & 16 \\
\hline 10d1) & 10d2) & food; vegetables & 2 & 40 \\
\hline $10 \mathrm{e} 1)$ & $10 \mathrm{e} 2)$ & knife & 1 & 24 \\
\hline 10f1) & 10f2) & roll of paper towels & 0 & 1 \\
\hline $\log 1)$ & $10 \mathrm{~g} 2)$ & hand towel on stove door & 0 & 0 \\
\hline 10h1) & $10 \mathrm{~h} 2)$ & placemats on table (white) & 1 & 6 \\
\hline 10i1) & $10 \mathrm{i} 2)$ & small plant on table & 0 & 7 \\
\hline $10 \mathrm{j} 1)$ & $10 \mathrm{j} 2)$ & newspaper & 2 & 27 \\
\hline $10 \mathrm{k} 1)$ & $10 \mathrm{k} 2)$ & small picture hanging above sink & 0 & 1 \\
\hline 1011) & 1012) & wooden shelf w/knicknacks by sink & 0 & 1 \\
\hline $10 \mathrm{~m} 1)$ & $10 \mathrm{~m} 2)$ & magnets on fridge & 0 & 2 \\
\hline 10n1) & $10 \mathrm{n} 2)$ & basket of flowers/plant on fridge & 0 & 10 \\
\hline 10o1) & $10 \mathrm{o} 2)$ & sneakers by front door & 1 & 13 \\
\hline
\end{tabular}




\section{APPENDIX G}

Free and Prompted Recall Inaccuracy Coding Sheets 
Participant \#

Coder's Name

\section{INACCURATE - MAN CHARACTERISTICS (APPEARANCE \& ACTIONS):}

1) Physical Description:

\begin{tabular}{|c|c|c|c|c|}
\hline "Initial" & "What else" & & Free Recall & $\begin{array}{l}\text { Prompted } \\
\text { Recall }\end{array}$ \\
\hline 1a1) & $1 \mathrm{a} 2)$ & middle-aged & 0 & 2 \\
\hline 1b1) & $1 b 2)$ & height & 1 & 21 \\
\hline $1 \mathrm{c} 1)_{-}$ & $1 \mathrm{c} 2)$ & weight & 0 & 10 \\
\hline 1d1) & $1 \mathrm{~d} 2)$ & color of hair & 0 & 3 \\
\hline 1e1) _ & $1 \mathrm{e} 2)$ & curly hair & 0 & 1 \\
\hline 1f1) & $1 \mathrm{f} 2)$ & bald/balding & 0 & 2 \\
\hline 1g1) & 1g2) & facial hair (mustache/beard) & 0 & 4 \\
\hline 1h1) & 1h2) & eye color & 0 & 24 \\
\hline 1i1) & $1 \mathrm{i} 2)$ & size of nose & 0 & 3 \\
\hline
\end{tabular}


Participant \#

Coder's Name

\section{INACCURATE - MAN CHARACTERISTICS (APPEARANCE \& ACTIONS):}

2) Description of Clothing/Accessories:

\begin{tabular}{|c|c|c|c|c|}
\hline "Initial" & "What else" & & Free Recall & $\begin{array}{l}\text { Prompted } \\
\text { Recall }\end{array}$ \\
\hline 2a1) & $2 \mathrm{a} 2)$ & color of shirt & 0 & 42 \\
\hline 2b1) & $2 \mathrm{~b} 2)$ & short-sleeved (shirt) & 0 & 1 \\
\hline $2 \mathrm{c} 1)$ & $2 c 2)$ & color of pants & 0 & 20 \\
\hline $2 \mathrm{~d} 1)$ & $2 \mathrm{~d} 2)$ & jacket/coat & 1 & 68 \\
\hline $2 \mathrm{e} 1)$ & $2 \mathrm{e} 2)$ & color of jacket/coat & 0 & 3 \\
\hline 2f1) & $2 \mathrm{f} 2)$ & vest & 0 & 1 \\
\hline $2 g 1)_{-}$ & $2 \mathrm{~g} 2)$ & tuxedo & 0 & 4 \\
\hline 2h1) & $2 \mathrm{~h} 2)$ & hat & 0 & 2 \\
\hline 2i1) & $2 \mathrm{i} 2)$ & shoes & 0 & 44 \\
\hline $2 \mathrm{j} 1)_{-}$ & $2 \mathrm{j} 2)$ & socks & 0 & 11 \\
\hline 2k1) & $2 \mathrm{k} 2)$ & underwear & 0 & 2 \\
\hline 211) & 212) & belt & 0 & 7 \\
\hline $2 \mathrm{~m} 1)$ & $2 \mathrm{~m} 2)$ & suspenders & 0 & 1 \\
\hline $2 \mathrm{n} 1)$ & $2 \mathrm{n} 2)$ & glasses & 0 & 4 \\
\hline 2o1) & 2o2) & watch & 0 & 2 \\
\hline $2 \mathrm{p} 1)$ & $2 \mathrm{p} 2)$ & pencil behind ear & 0 & 1 \\
\hline
\end{tabular}


Participant \#

Coder's Name

INACCURATE - MAN CHARACTERISTICS (APPEARANCE \& ACTIONS):

3) Description of Actions:

\begin{tabular}{|c|c|c|c|c|}
\hline "Initial" & "What else" & & Free Recall & $\begin{array}{l}\text { Prompted } \\
\text { Recall }\end{array}$ \\
\hline $3 a 1)$ & $3 a 2)$ & takes off jacket/coat & 0 & 12 \\
\hline $3 b 1)$ & $3 b 2)$ & takes off hat & 0 & 1 \\
\hline $3 c 1)$ & $3 c 2)$ & hangs hat on coat rack & 0 & 1 \\
\hline $3 \mathrm{~d} 1)_{-}$ & $3 \mathrm{~d} 2)$ & puts hat on table & 0 & 1 \\
\hline $3 e 1)_{-}$ & $3 e 2)$ & carrying a briefcase & 0 & 5 \\
\hline $3 \mathrm{f} 1)$ & $3 \mathrm{f} 2)$ & sets down briefcase & 0 & 1 \\
\hline $3 g 1)$ & $3 g 2)$ & carrying a folder & 0 & 1 \\
\hline $3 h 1)$ & $3 \mathrm{~h} 2)$ & puts feet on table & 0 & 2 \\
\hline 3i1) & $3 i 2)$ & throws/slams/drops newspaper & 4 & 6 \\
\hline $3 \mathrm{j} 1)$ & $3 \mathrm{j} 2)$ & $\begin{array}{l}\text { wipes hand on microwave/file } \\
\text { cabinet/chest/shelf }\end{array}$ & 3 & 1 \\
\hline $3 \mathrm{k} 1)$ & $3 \mathrm{k} 2)$ & $\begin{array}{l}\text { pushes something out of the way of } \\
\text { the door }\end{array}$ & 0 & 1 \\
\hline 311) _ـ & 312) & slams the door & 2 & 7 \\
\hline $3 \mathrm{~m} 1)$ & $3 \mathrm{~m} 2)$ & starts the car & 1 & 0 \\
\hline
\end{tabular}


Participant \#

Coder's Name

INACCURATE - WOMAN CHARACTERISTICS (APPEARANCE \& ACTIONS):

4) Physical Description:

\begin{tabular}{|c|c|c|c|c|}
\hline "Initial" & "What else" & & Free Recall & $\begin{array}{c}\text { Prompted } \\
\text { Recall }\end{array}$ \\
\hline $4 \mathrm{a} 1)_{-}$ & $4 a 2)$ & middle-aged & 0 & 3 \\
\hline 4b1) & $4 b 2)$ & height & 0 & 7 \\
\hline $4 c 1)$ & $4 c 2)$ & weight & 0 & 4 \\
\hline $4 \mathrm{~d} 1)$ & $4 d 2)$ & color of hair & 0 & 19 \\
\hline $4 \mathrm{e} 1)$ & $4 \mathrm{e} 2)$ & curly hair & 0 & 10 \\
\hline $4 \mathrm{f} 1)$ & $4 f 2)$ & length of hair & 0 & 6 \\
\hline $4 \mathrm{~g} 1)$ & $4 g 2)$ & something in hair (barrette, etc.) & 0 & 6 \\
\hline 4h1) & 4h2) & eye color & 0 & 14 \\
\hline $4 \mathrm{i1})$ & $4 \mathrm{i} 2)$ & size of nose & 0 & 1 \\
\hline $4 j 1)$ & $4 j 2)$ & length of fingernails & 0 & 1 \\
\hline $4 \mathrm{k} 1)$ & $4 \mathrm{k} 2)$ & make-up & 0 & 2 \\
\hline
\end{tabular}


Participant \#

Coder's Name

\section{INACCURATE - WOMAN CHARACTERISTICS (APPEARANCE \& ACTIONS):}

5) Description of Clothing/Accessories:

\begin{tabular}{|c|c|c|c|c|}
\hline "Initial" & "What else" & & Free Recall & $\begin{array}{l}\text { Prompted } \\
\text { Recall }\end{array}$ \\
\hline 5a1) & $5 a 2)$ & color of shirt & 1 & 42 \\
\hline $5 b 1)_{2}$ & $5 b 2)$ & long-sleeved (shirt) & 0 & 7 \\
\hline $5 \mathrm{c} 1)$ & $5 c 2)$ & type of shirt (sweater, turtleneck) & 0 & 7 \\
\hline $5 \mathrm{~d} 1)$ & $5 d 2)$ & color of pants & 1 & 27 \\
\hline $5 e 1)$ & $5 e 2)$ & skirt & 0 & 3 \\
\hline $5 \mathrm{f1})$ & $5 f 2)$ & color of skirt & 0 & 1 \\
\hline $5 \mathrm{~g} 1)$ & $5 \mathrm{~g} 2)$ & dress/gown & 0 & 9 \\
\hline $5 \mathrm{~h} 1)_{-}$ & $5 h 2)$ & color of dress/gown & 0 & 3 \\
\hline 5i1) & $5 \mathrm{i} 2)$ & apron & 0 & 2 \\
\hline $5 \mathrm{j} 1)_{-}$ & $5 \mathrm{j} 2)$ & shoes & 0 & 26 \\
\hline $5 \mathrm{k} 1)$ & $5 \mathrm{k} 2)$ & socks & 0 & 11 \\
\hline 511) _ـ & 512) & belt & 0 & 1 \\
\hline $5 \mathrm{~m} 1)$ & $5 \mathrm{~m} 2)$ & earrings & 0 & 7 \\
\hline
\end{tabular}


Participant \#

Coder's Name

INACCURATE - WOMAN CHARACTERISTICS (APPEARANCE \& ACTIONS):

6) Description of Actions:

\begin{tabular}{|c|c|c|}
\hline "Initial" & "What else" & \\
\hline $6 a 1)$ & $6 a 2)$ & making something in blender \\
\hline $6 b 1)$ & $6 b 2)$ & stirring something in a pot \\
\hline $6 c 1)$ & $6 c 2)$ & reads newspaper \\
\hline $6 \mathrm{~d} 1)$ & $6 \mathrm{~d} 2)$ & puts head down on table \\
\hline $6 e 1)$ & $6 e 2)$ & starts crying \\
\hline $6 f 1)$ & $6 f 2)$ & picks up chair/stands up chair \\
\hline $6 \mathrm{~g} 1)$ & $6 g 2)$ & picks up newspaper \\
\hline $6 \mathrm{~h} 1)$ & $6 h 2)$ & slams door \\
\hline
\end{tabular}

\begin{tabular}{cc} 
Frequency of & Occurrence \\
\hline Free Recall & $\begin{array}{c}\text { Prompted } \\
\text { Recall }\end{array}$ \\
0 & 1 \\
0 & 1 \\
0 & 2 \\
0 & 1 \\
0 & 1 \\
3 & 11 \\
1 & 2 \\
1 & 1
\end{tabular}


Participant \#

Coder's Name

INACCURATE - CONTENT OF ARGUMENT:

7) Man's Statements:

\begin{tabular}{|c|c|c|}
\hline "Initial" & "What else' & \\
\hline $7 a 1)$ & $7 a 2)$ & tells her that he had a good day \\
\hline $7 b 1)$ & $7 b 2)$ & states that she is not a good cook \\
\hline $7 \mathrm{c} 1)$ & $7 c 2)$ & says he will make his own dinner \\
\hline 7d1) & $7 \mathrm{~d} 2)$ & $\begin{array}{l}\text { explains that some of the mess is } \\
\text { his }\end{array}$ \\
\hline
\end{tabular}

\begin{tabular}{cc} 
Frequency of & Occurrence \\
\hline Free Recall & $\begin{array}{c}\text { Prompted } \\
\text { Recall }\end{array}$ \\
0 & 1 \\
0 & 1 \\
1 & 1 \\
0 & 1 \\
0 & 3
\end{tabular}

8) Woman's Statements::

\begin{tabular}{|c|c|c|}
\hline "Initial" & "What else" & \\
\hline $8 \mathrm{a} 1)$ & $8 a 2)$ & apologizes that dinner is not ready \\
\hline $8 \mathrm{~b} 1)$ & $8 b 2)$ & $\begin{array}{l}\text { asks how she is supposed to know } \\
\text { that he did not eat lunch }\end{array}$ \\
\hline $8 c 1)$ & $8 c 2)$ & $\begin{array}{l}\text { says that when he cooks, he ruins } \\
\text { dinner }\end{array}$ \\
\hline $8 \mathrm{~d} 1)$ & $8 \mathrm{~d} 2)$ & $\begin{array}{l}\text { tells him that he can not have his } \\
\text { dinner here }\end{array}$ \\
\hline $8 \mathrm{e} 1)_{-}$ & $8 \mathrm{e} 2)$ & $\begin{array}{l}\text { says that he could eat somewhere } \\
\text { else quicker }\end{array}$ \\
\hline $8 \mathrm{f} 1)$ & $8 \mathrm{f} 2)$ & $\begin{array}{l}\text { states that he doesn't have a good } \\
\text { job }\end{array}$ \\
\hline $8 \mathrm{~g} 1)$ & $8 \mathrm{~g} 2)$ & $\begin{array}{l}\text { tells him that he is the one who is } \\
\text { lazy }\end{array}$ \\
\hline $8 \mathrm{~h} 1)$ & $8 \mathrm{~h} 2)$ & $\begin{array}{l}\text { states that he should clean-up after } \\
\text { himself and help with the work }\end{array}$ \\
\hline
\end{tabular}

\begin{tabular}{cc} 
Frequency of & Occurrence \\
\hline Free Recall & $\begin{array}{c}\text { Prompted } \\
\text { Recall }\end{array}$ \\
0 & 3 \\
0 & 1 \\
1 & 0 \\
0 & 1 \\
0 & 1 \\
1 & 1 \\
0 & 3
\end{tabular}


Participant \#

Coder's Name

\section{INACCURATE - ROOM CHARACTERISTICS:}

9) Description of "BIG" items (e.g., setting, appliances, furniture, etc.):

\begin{tabular}{|c|c|c|c|c|}
\hline "Initial" & "What else" & & Free Recall & $\begin{array}{c}\text { Prompted } \\
\text { Recall }\end{array}$ \\
\hline $9 \mathrm{a} 1)_{\ldots}$ & $9 \mathrm{a} 2)$ & color of walls/wallpaper & 0 & 3 \\
\hline $9 b 1)$ & $9 b 2)$ & tile/linoleum floor & 0 & 20 \\
\hline $9 \mathrm{c} 1)_{-}$ & $9 \mathrm{c} 2)$ & ceiling & 0 & 5 \\
\hline $9 \mathrm{~d} 1)_{-}$ & $9 \mathrm{~d} 2)$ & lights & 0 & 4 \\
\hline $9 \mathrm{e} 1)$ & $9 e 2)$ & window(s) & 0 & 10 \\
\hline 9f1) & $9 f 2)$ & curtains & 0 & 1 \\
\hline $9 g 1)_{-}$ & $9 \mathrm{~g} 2)$ & living room & 0 & 5 \\
\hline $9 \mathrm{~h} 1)_{-}$ & $9 \mathrm{~h} 2)$ & TV & 1 & 5 \\
\hline 9i1) & $9 \mathrm{i} 2)$ & TV stand & 0 & 2 \\
\hline $9 \mathrm{j} 1)$ & $9 \mathrm{j} 2)$ & coffee table & 0 & 4 \\
\hline $9 \mathrm{k} 1)_{-}$ & $9 \mathrm{k} 2)$ & couch & 0 & 9 \\
\hline 911) & 912) & bedroom & 0 & 1 \\
\hline $9 \mathrm{~m} 1)$ & $9 \mathrm{~m} 2)$ & chest of drawers/dresser & 0 & 4 \\
\hline $9 \mathrm{n} 1)$ & $9 \mathrm{n} 2)$ & bookcase & 0 & 1 \\
\hline 901$)$ & $902)$ & file cabinet & 0 & 1 \\
\hline $9 \mathrm{p} 1)$ & 9p2) & laundry room & 0 & 3 \\
\hline $9 q 1)$ & $9 q 2)$ & washer & 0 & 2 \\
\hline 9r1) & $9 r 2)$ & dryer & 0 & 2 \\
\hline
\end{tabular}

Frequency of Occurrence Free Recall $\quad \begin{gathered}\text { Prompted } \\ \text { Recall }\end{gathered}$ 
Participant \#

Coder's Name

INACCURATE - ROOM CHARACTERISTICS:

10) Description of "SMALL" items (e.g., decorations, utensils, etc.):

\begin{tabular}{|c|c|c|c|c|}
\hline "Initial" & "What else" & & Free Recall & $\begin{array}{c}\text { Prompted } \\
\text { Recall }\end{array}$ \\
\hline 10a1) & $10 \mathrm{a} 2)$ & dust & 0 & 3 \\
\hline 10b1) & $10 b 2)$ & blender & 0 & 2 \\
\hline $10 \mathrm{c} 1)$ & $10 c 2)$ & pots on stove & 0 & 1 \\
\hline 10d1) & $10 \mathrm{~d} 2)$ & spatula & 0 & 1 \\
\hline $10 \mathrm{e} 1)$ & $10 \mathrm{e} 2)$ & sugar & 0 & 1 \\
\hline 10f1) & 10f2) & spices/salt \& pepper shakers & 0 & 3 \\
\hline $10 \mathrm{~g} 1)$ & $10 \mathrm{~g} 2)$ & silverware (spoons/forks) & 0 & 4 \\
\hline 10h1) & $10 \mathrm{~h} 2)$ & napkins & 0 & 1 \\
\hline 10i1) & 10i2) & tablecloth & 0 & 2 \\
\hline $10 \mathrm{j} 1)$ & $10 \mathrm{j} 2)$ & bowl/basket of fruit & 0 & 7 \\
\hline $10 \mathrm{k} 1)_{-}$ & $10 \mathrm{k} 2)$ & potato chips & 1 & 9 \\
\hline 1011) & 1012) & mirror on wall & 0 & 2 \\
\hline $10 \mathrm{~m} 1)$ & $10 \mathrm{~m} 2)$ & briefcase & 0 & 1 \\
\hline $10 \mathrm{n} 1)_{-}$ & 10n2) & paper work on table & 0 & 1 \\
\hline 10o1) & $10 \mathrm{o} 2)$ & plant on TV & 1 & 0 \\
\hline 10p1) & 10p2) & clothes/shirts & 0 & 4 \\
\hline
\end{tabular}




\section{APPENDIX H}

Types of Commission Errors 


\section{Types of Commission Errors}

$\underline{\text { A) Factually Incorrect Errors }}=\quad$ misreporting of information that was included in the videotaped stimulus and could be clearly discerned (misperceptions of what was actually there).

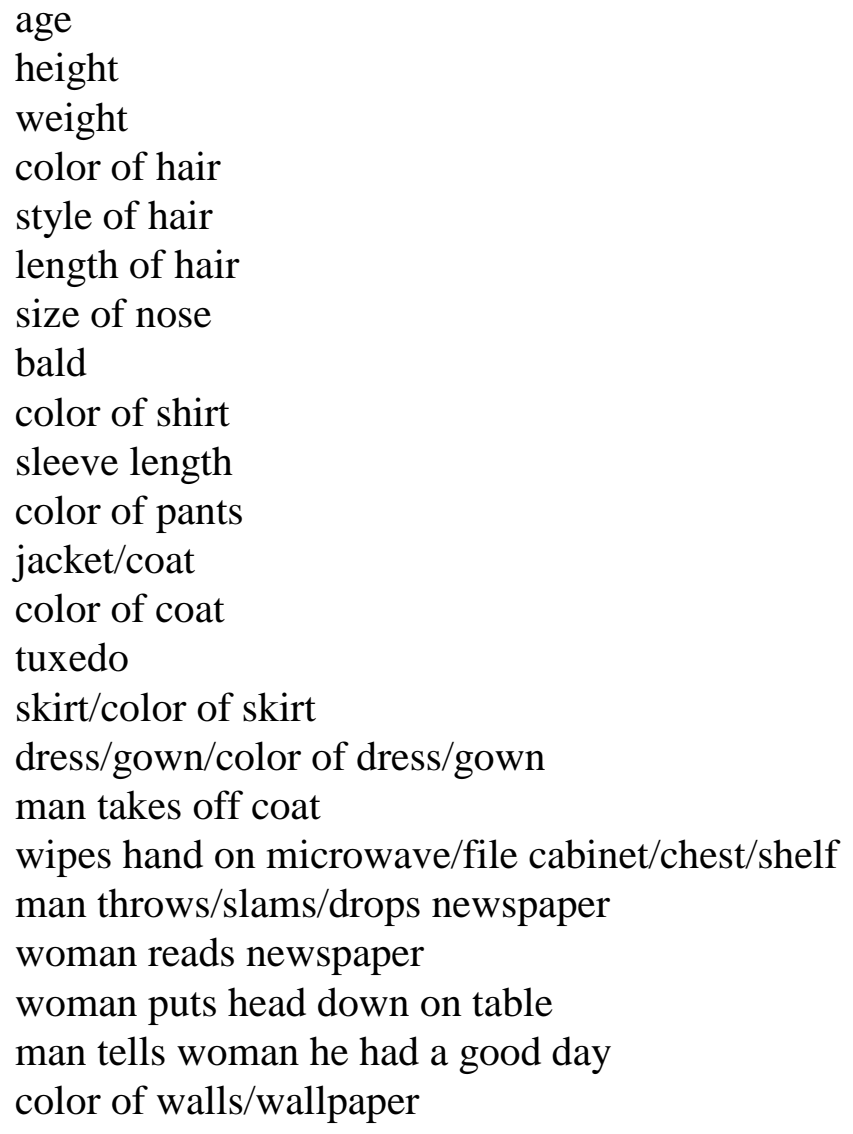


B) Intrusion Errors $=$ adding/reporting information that was not present in the videotaped stimulus or could not be discerned/verified from the videotaped stimulus.

1) Information that could not be discerned:

eye color

length of fingernails

make-up (blush, eye liner) on woman

shoes

socks

underwear

belt

man wearing a watch

earrings

tile/linoleum floor

ceiling

lights

dust

2) Added information that was not present:

facial hair

something in woman's hair (barrette, scrunchie, headband)

man wearing hat

suspenders

vest

man wearing glasses

man had pencil behind his ear

man takes off hat/hangs hat on coat rack/puts hat on table

man carrying briefcase/sets down briefcase/carrying a folder

man puts feet on table/puts hands on chest

man pushes something out of the way of the door

man/woman slams the door

man starts the car

woman making something in blender

woman stirring something in a pot

woman starts crying

woman picks up chair/newspaper

man tells woman she is not a good cook

man say he will make his own dinner

man explains that some of the mess is his

man says that it is not his mess

woman apologizes for not having dinner ready 


\section{2) Added information that was not present (continued):}

woman asks him how she is supposed to know he didn't have lunch woman says that when he cooks he ruins dinner woman tells him he can not eat at home woman says he could eat quicker somewhere else woman tells him he has a crappy job

woman tells him that he is the one who is lazy woman states that he should help with some of the work window/curtains living room/TV/TV stand/coffee table/couch bedroom/chest of drawers/bookcase/laundry room laundry room/washer/dryer potato chips blender/pots on stove/spatula sugar/spices/salt \& pepper shakers silverware/napkins/tablecloth bowl/basket of fruit

mirror on wall briefcase/paper work on table plant on TV

clothes/shirts hanging 
Table 1

Mean Proportions (and Standard Deviations) of Accurate Information Reported for Free Recall:

$\underline{\text { Initial vs. Follow-up Responses }}$

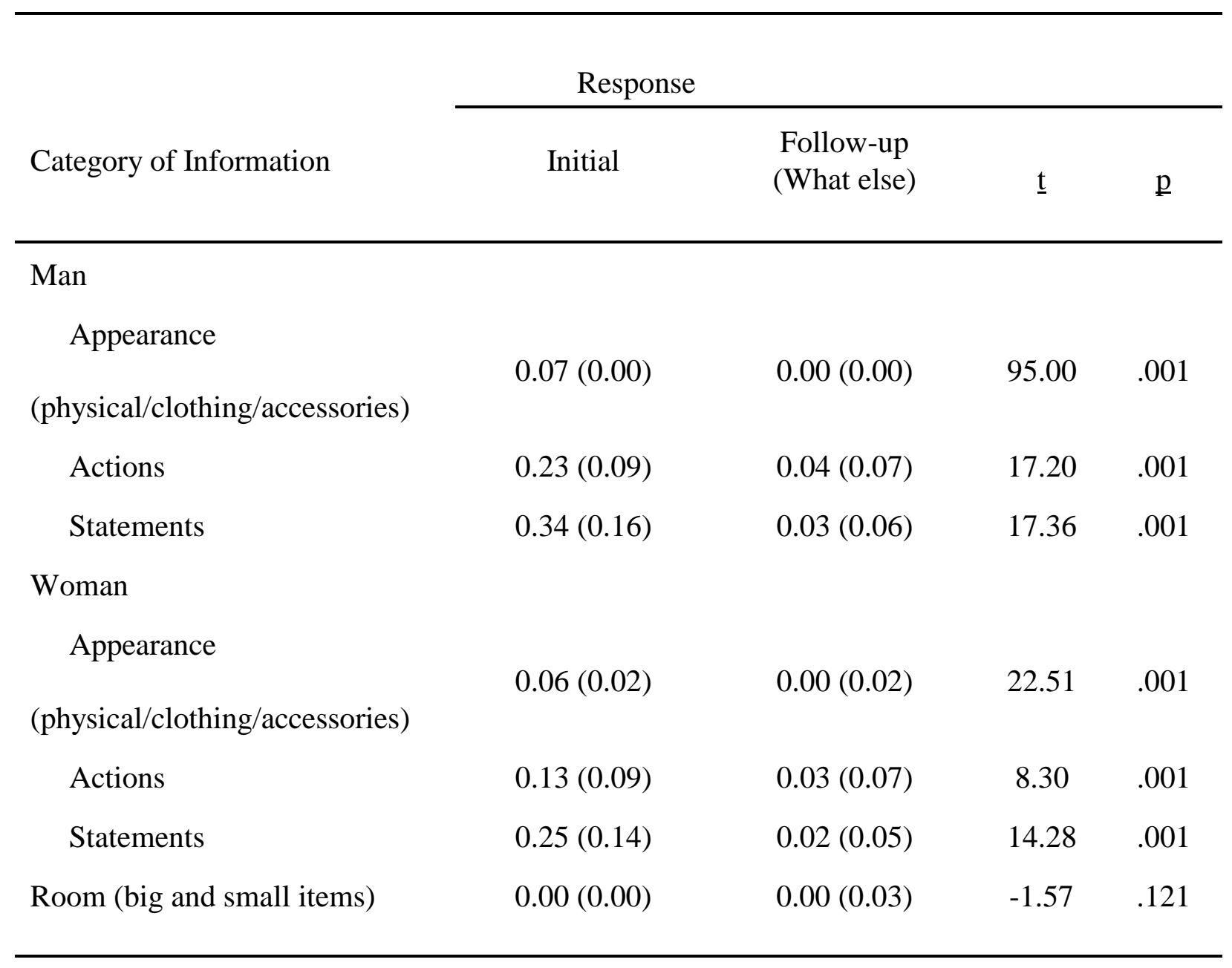


Table 2

Mean Proportions (and Standard Deviations) of Accurate Information Reported for Prompted

$\underline{\text { Recall: Initial vs. Follow-up Responses }}$

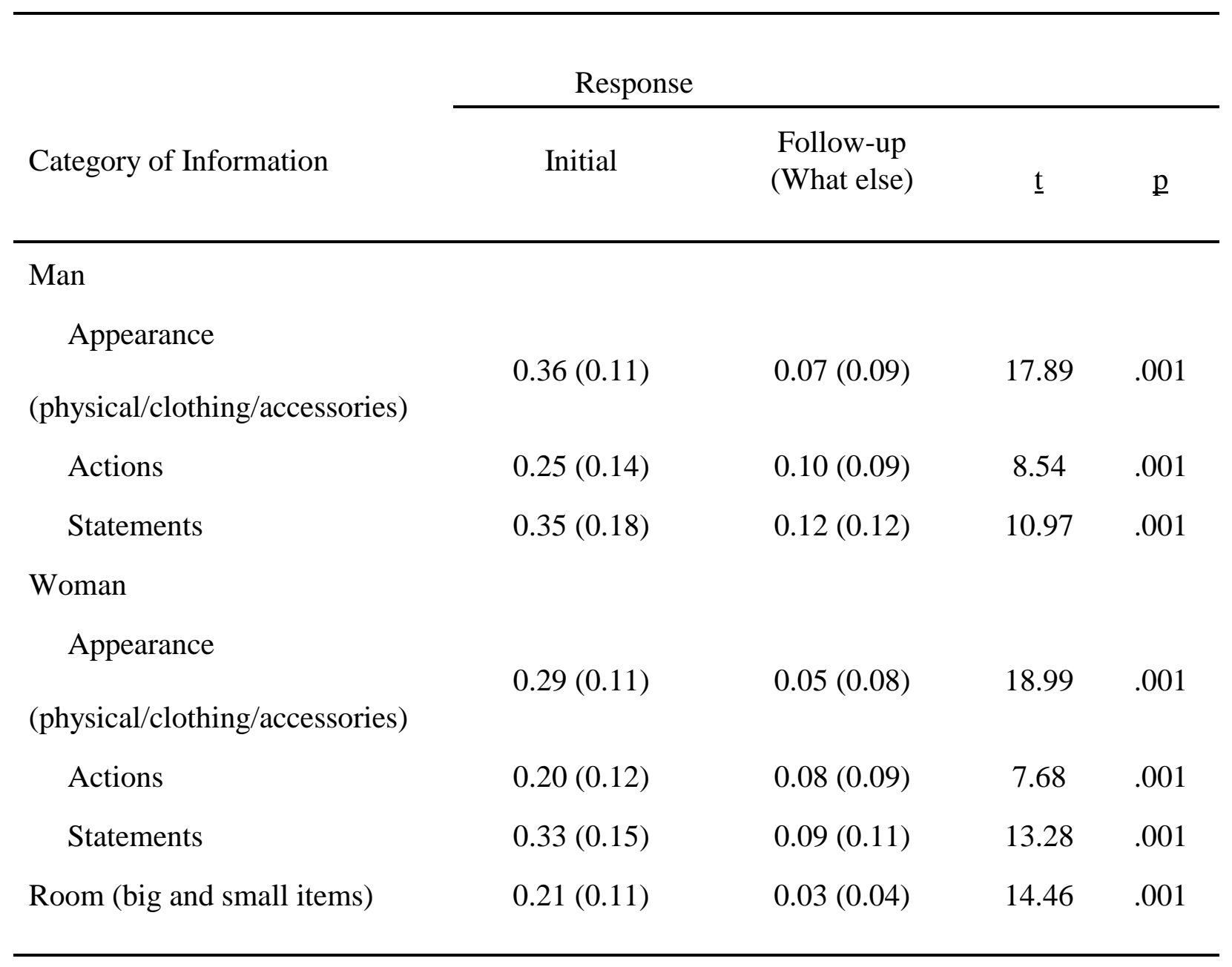


Table 3

Mean Proportions (and Standard Deviations) of Accurate Information Reported for Free Recall: $\underline{\text { Initial vs. Total (Initial + Follow-up) Responses }}$

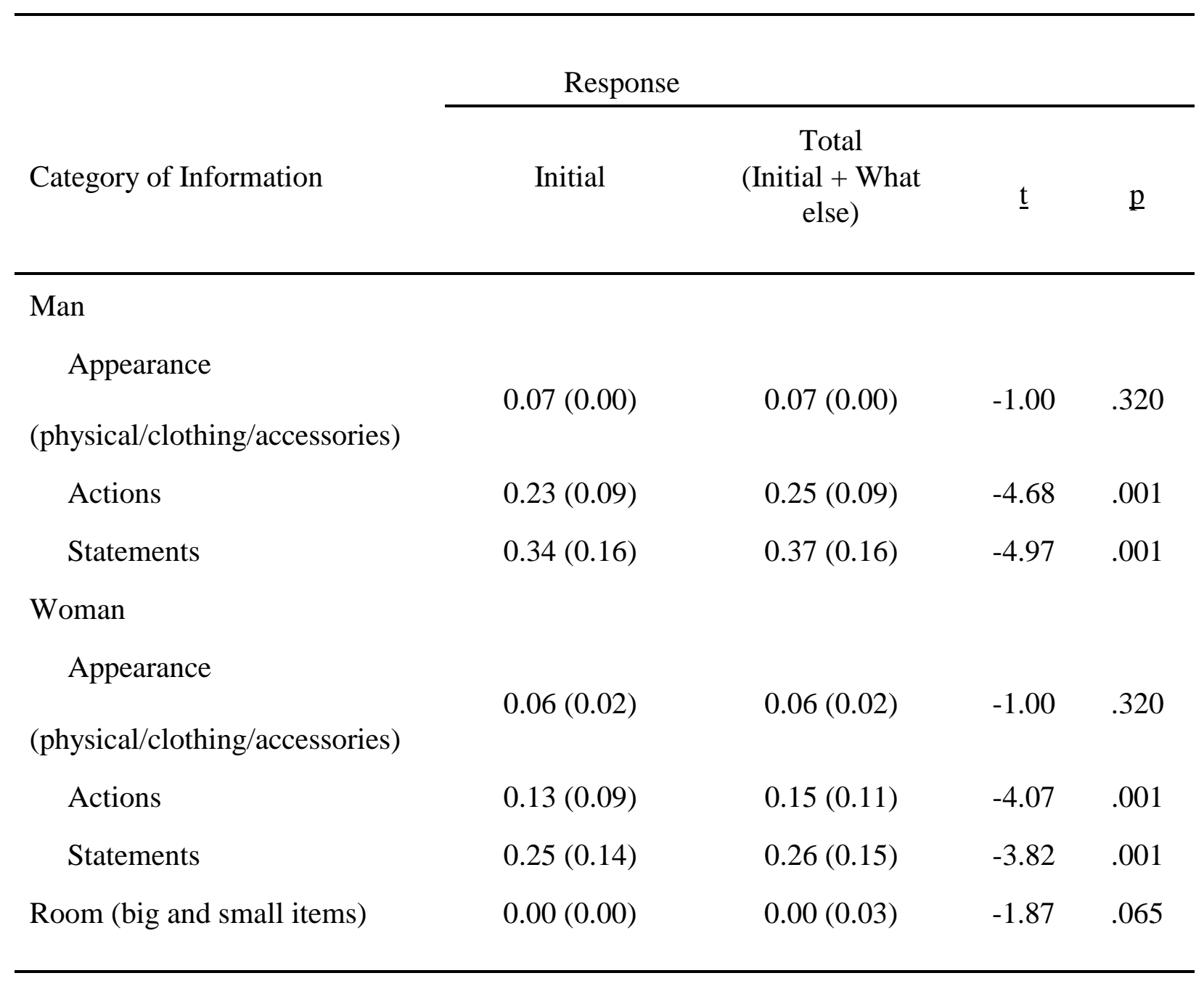


Table 4

Mean Proportions (and Standard Deviations) of Accurate Information Reported for Prompted

$\underline{\text { Recall: Initial vs. Total (Initial + Follow-up) Responses }}$

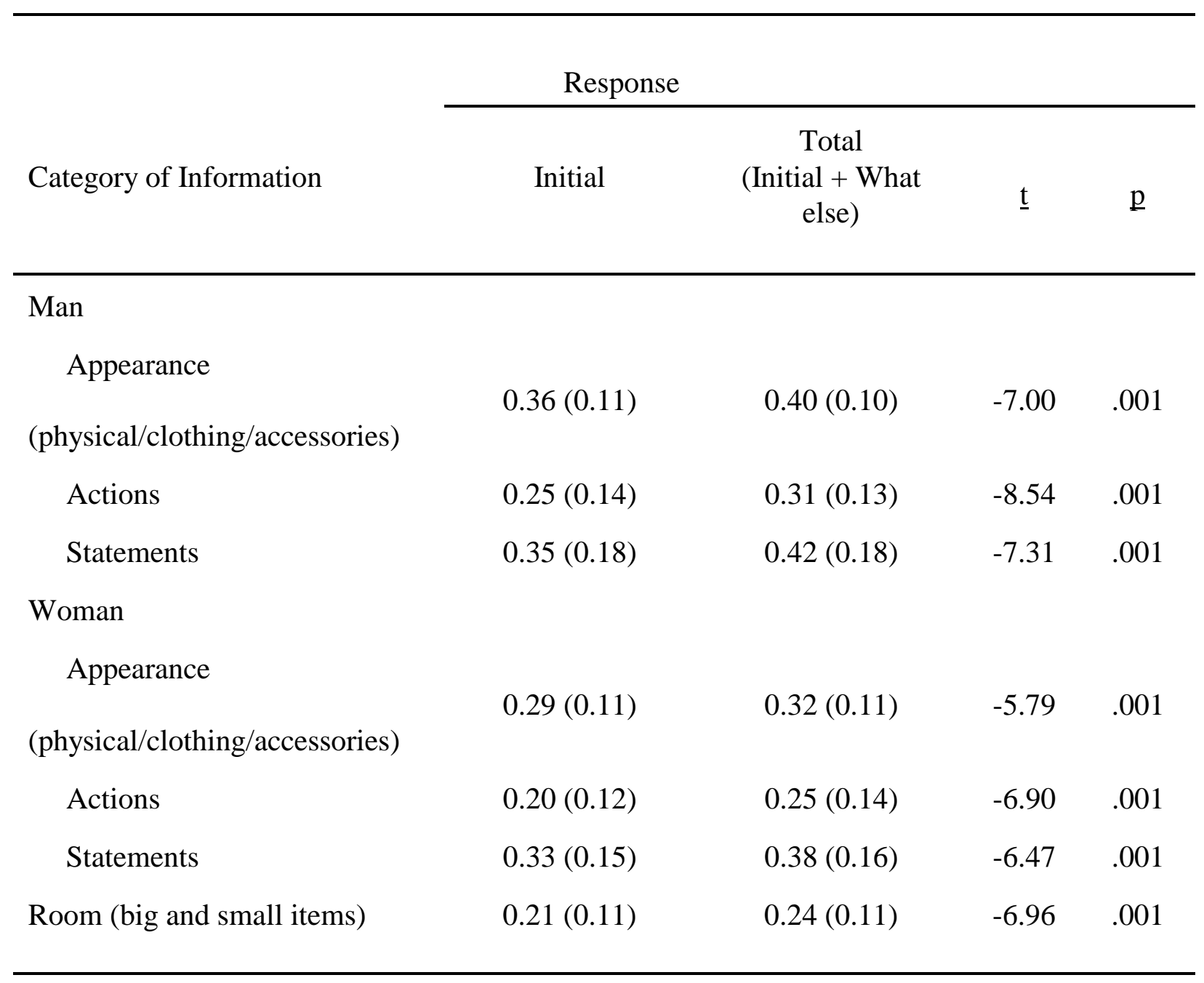




\section{Table 5}

Means (and Standard Deviations) of "Factually-Incorrect" Errors Reported for Free Recall:

$\underline{\text { Initial vs. Follow-up Responses }}$

\begin{tabular}{|c|c|c|c|c|}
\hline \multirow[b]{2}{*}{ Category of Information } & \multicolumn{2}{|c|}{ Response } & \multirow[b]{2}{*}{$\underline{\mathrm{t}}$} & \multirow[b]{2}{*}{$\underline{\mathrm{p}}$} \\
\hline & Initial & $\begin{array}{l}\text { Follow-up } \\
\text { (What else) }\end{array}$ & & \\
\hline \multicolumn{5}{|l|}{ Man } \\
\hline $\begin{array}{l}\text { Appearance } \\
\text { (physical/clothing/accessories) }\end{array}$ & $0.01(0.10)$ & $0.01(0.10)$ & 0.00 & 1.00 \\
\hline Actions & $0.05(0.22)$ & $0.02(0.14)$ & 1.14 & .259 \\
\hline Statements & $0.00(0.00)$ & $0.00(0.00)$ & ---- & ---- \\
\hline \multicolumn{5}{|l|}{ Woman } \\
\hline $\begin{array}{l}\text { Appearance } \\
\text { (physical/clothing/accessories) }\end{array}$ & $0.01(0.10)$ & $0.01(0.10)$ & 0.00 & 1.00 \\
\hline Actions & $0.00(0.00)$ & $0.00(0.00)$ & ---- & ---- \\
\hline Statements & $0.00(0.00)$ & $0.00(0.00)$ & ---- & ---- \\
\hline Room (big and small items) & $0.00(0.00)$ & $0.00(0.00)$ & ---- & ---- \\
\hline
\end{tabular}

Note. Comparisons for the man and woman's statements, the woman's actions, and the room could not be calculated as the standard error of the difference was zero. 
Table 6

Means (and Standard Deviations) of "Factually-Incorrect" Errors Reported for Prompted Recall:

$\underline{\text { Initial vs. Follow-up Responses }}$

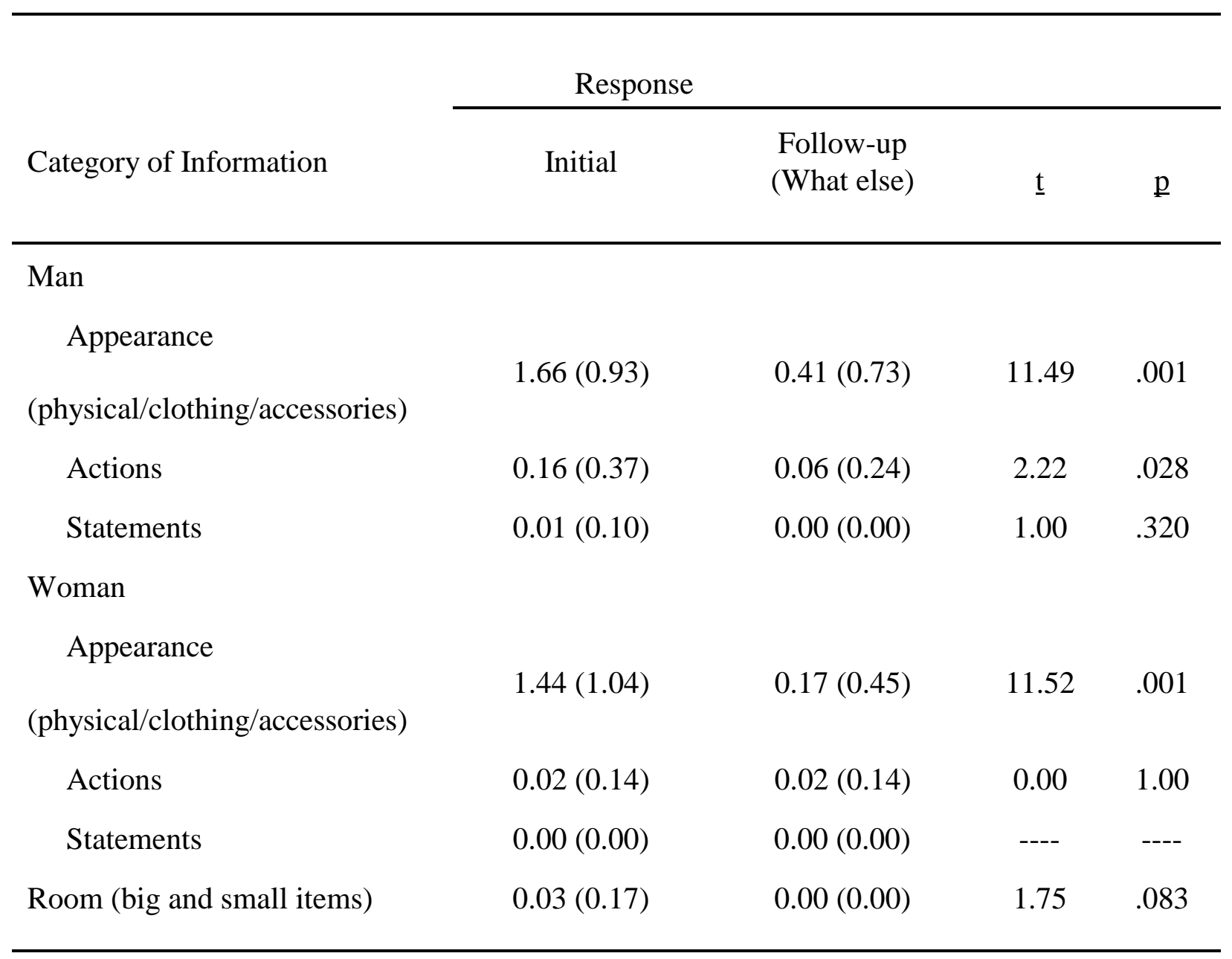

Note. Comparisons for the woman's statements could not be calculated as the standard error of the difference was zero. 
Table 7

Means (and Standard Deviations) of "Intrusion" Errors Reported for Free Recall: Initial vs.

Follow-up Responses

\begin{tabular}{|c|c|c|c|c|}
\hline \multirow[b]{2}{*}{ Category of Information } & \multicolumn{2}{|c|}{ Response } & \multirow[b]{2}{*}{$\underline{\mathrm{t}}$} & \multirow[b]{2}{*}{$\underline{p}$} \\
\hline & Initial & $\begin{array}{l}\text { Follow-up } \\
\text { (What else) }\end{array}$ & & \\
\hline \multicolumn{5}{|l|}{ Man } \\
\hline $\begin{array}{l}\text { Appearance } \\
\text { (physical/clothing/accessories) }\end{array}$ & $0.00(0.00)$ & $0.00(0.00)$ & ---- & ---- \\
\hline Actions & $0.01(0.10)$ & $0.02(0.14)$ & -0.58 & .566 \\
\hline Statements & $0.01(0.10)$ & $0.00(0.00)$ & 1.00 & .320 \\
\hline \multicolumn{5}{|l|}{ Woman } \\
\hline $\begin{array}{l}\text { Appearance } \\
\text { (physical/clothing/accessories) }\end{array}$ & $0.00(0.00)$ & $0.00(0.00)$ & ---- & ---- \\
\hline Actions & $0.01(0.10)$ & $0.05(0.27)$ & -2.03 & .045 \\
\hline Statements & $0.03(0.17)$ & $0.00(0.00)$ & 1.75 & .083 \\
\hline Room (big and small items) & $0.00(0.00)$ & $0.03(0.23)$ & -1.35 & .181 \\
\hline
\end{tabular}

Note. Comparisons for the man's appearance and the woman's statements could not be calculated as the standard error of the difference was zero. 
Table 8

Means (and Standard Deviations) of "Intrusion" Errors Reported for Prompted Recall: Initial vs.

Follow-up Responses

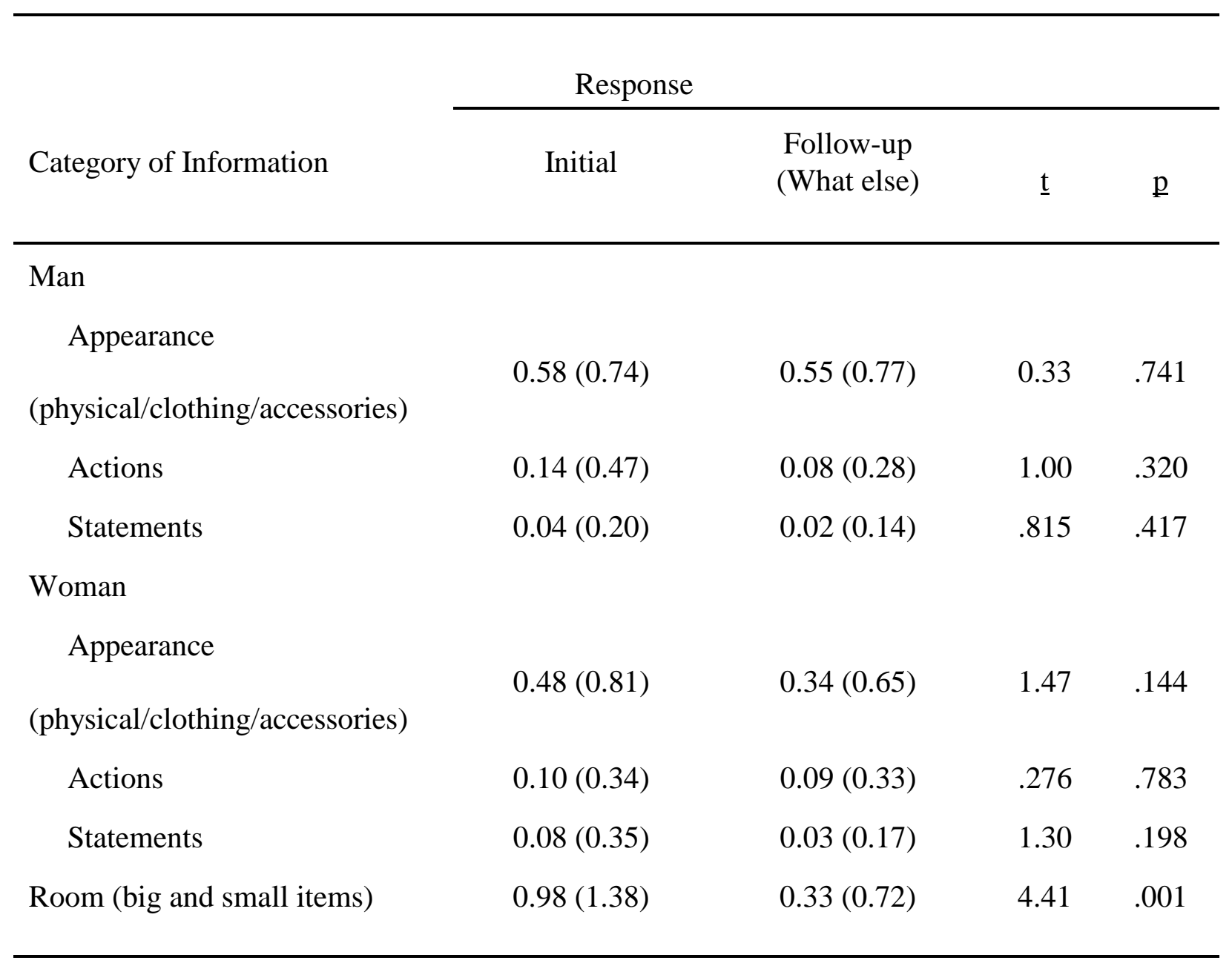


Table 9

Means (and Standard Deviations) of "Factually-Incorrect" Errors Reported for Free Recall:

$\underline{\text { Initial vs. Total (Initial + Follow-up) Responses }}$

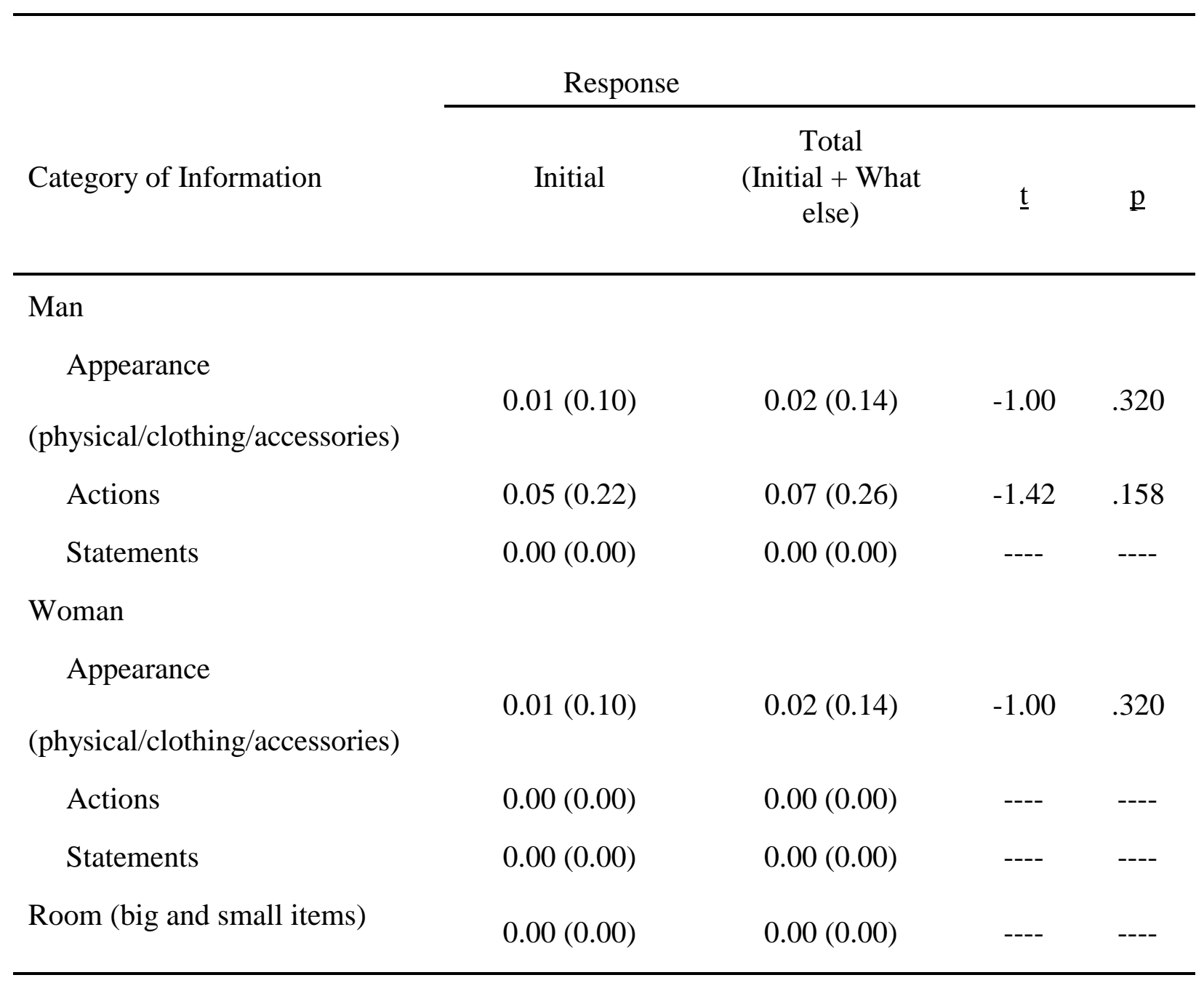

Note. Comparisons for the man and woman's statements, the woman's actions, and the room could not be calculated as the standard error of the difference was zero. 
Table 10

Means (and Standard Deviations) of "Factually-Incorrect" Errors Reported for Prompted Recall:

$\underline{\text { Initial vs. Total (Initial + Follow-up) Responses }}$

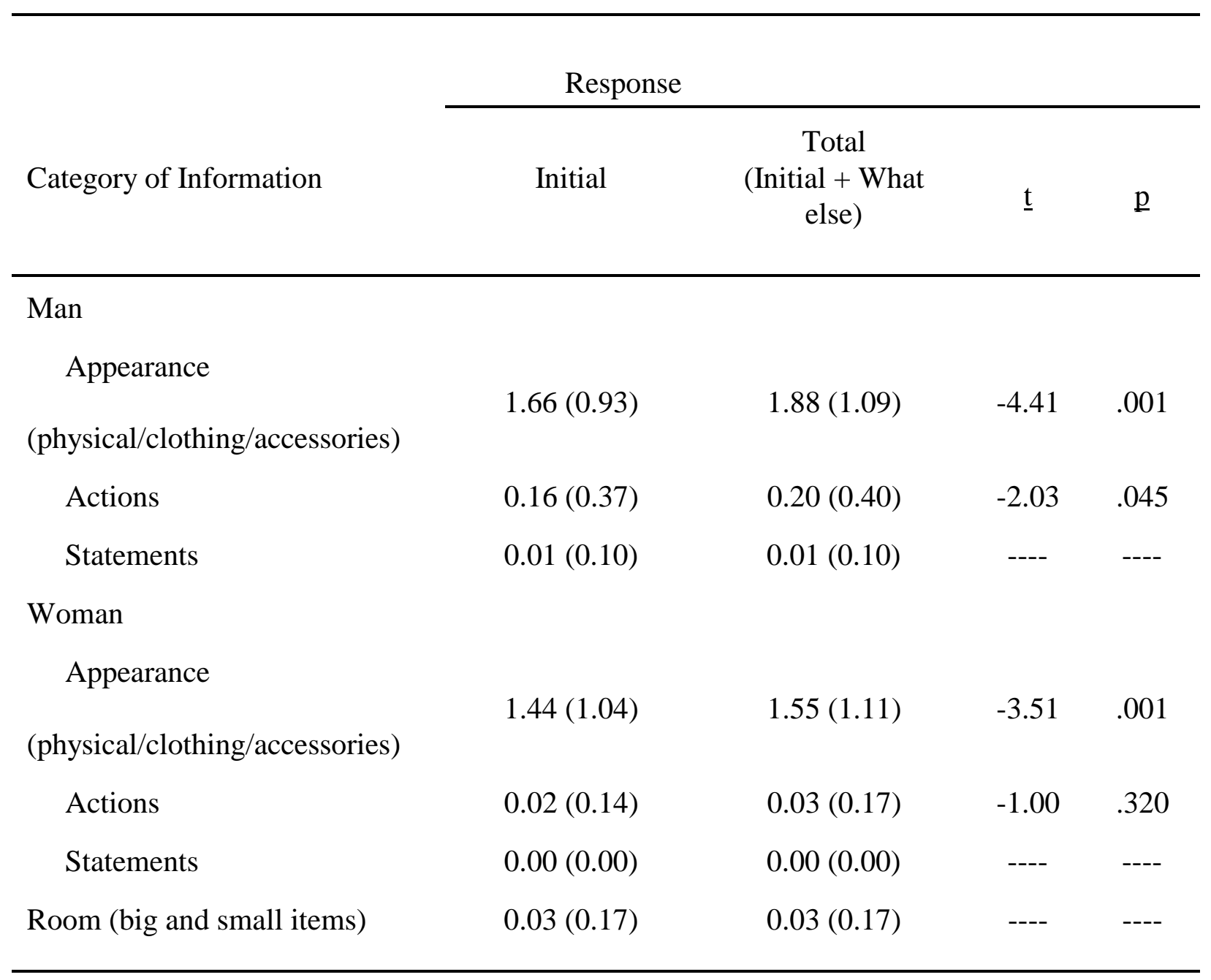

Note. Comparisons for the man and woman's statements and the room could not be calculated as the standard error of the difference was zero. 


\section{Table 11}

$\underline{\text { Means (and Standard Deviations) of "Intrusion" Errors Reported for Free Recall: Initial vs. Total }}$ $\underline{\text { (Initial + Follow-up) Responses }}$

\begin{tabular}{|c|c|c|c|c|}
\hline \multirow[b]{2}{*}{ Category of Information } & \multicolumn{2}{|c|}{ Response } & \multirow[b]{2}{*}{$\underline{\mathrm{t}}$} & \multirow[b]{2}{*}{$\mathrm{p}$} \\
\hline & Initial & $\begin{array}{c}\text { Total } \\
(\text { Initial }+ \text { What } \\
\text { else })\end{array}$ & & \\
\hline \multicolumn{5}{|l|}{ Man } \\
\hline Appearance & $0.00(0.00)$ & $0.00(0.00)$ & ---- & ---- \\
\hline Actions & $0.01(0.10)$ & $0.03(0.17)$ & -1.42 & .158 \\
\hline Statements & $0.01(0.10)$ & $0.01(0.10)$ & ---- & ---- \\
\hline \multicolumn{5}{|l|}{ Woman } \\
\hline $\begin{array}{l}\text { Appearance } \\
\text { (physical/clothing/accessories) }\end{array}$ & $0.00(0.00)$ & $0.00(0.00)$ & ---- & ---- \\
\hline Actions & $0.01(0.10)$ & $0.05(0.27)$ & -2.03 & .045 \\
\hline Statements & $0.03(0.17)$ & $0.03(0.17)$ & ---- & ---- \\
\hline Room (big and small items) & $0.00(0.00)$ & $0.03(0.23)$ & -1.35 & .181 \\
\hline
\end{tabular}

Note. Comparisons for the man and woman's appearance and the man and woman's statements could not be calculated as the standard error of the difference was zero. 
Table 12

Means (and Standard Deviations) of "Intrusion" Errors Reported for Prompted Recall: Initial vs. $\underline{\text { Total (Initial + Follow-up) Responses }}$

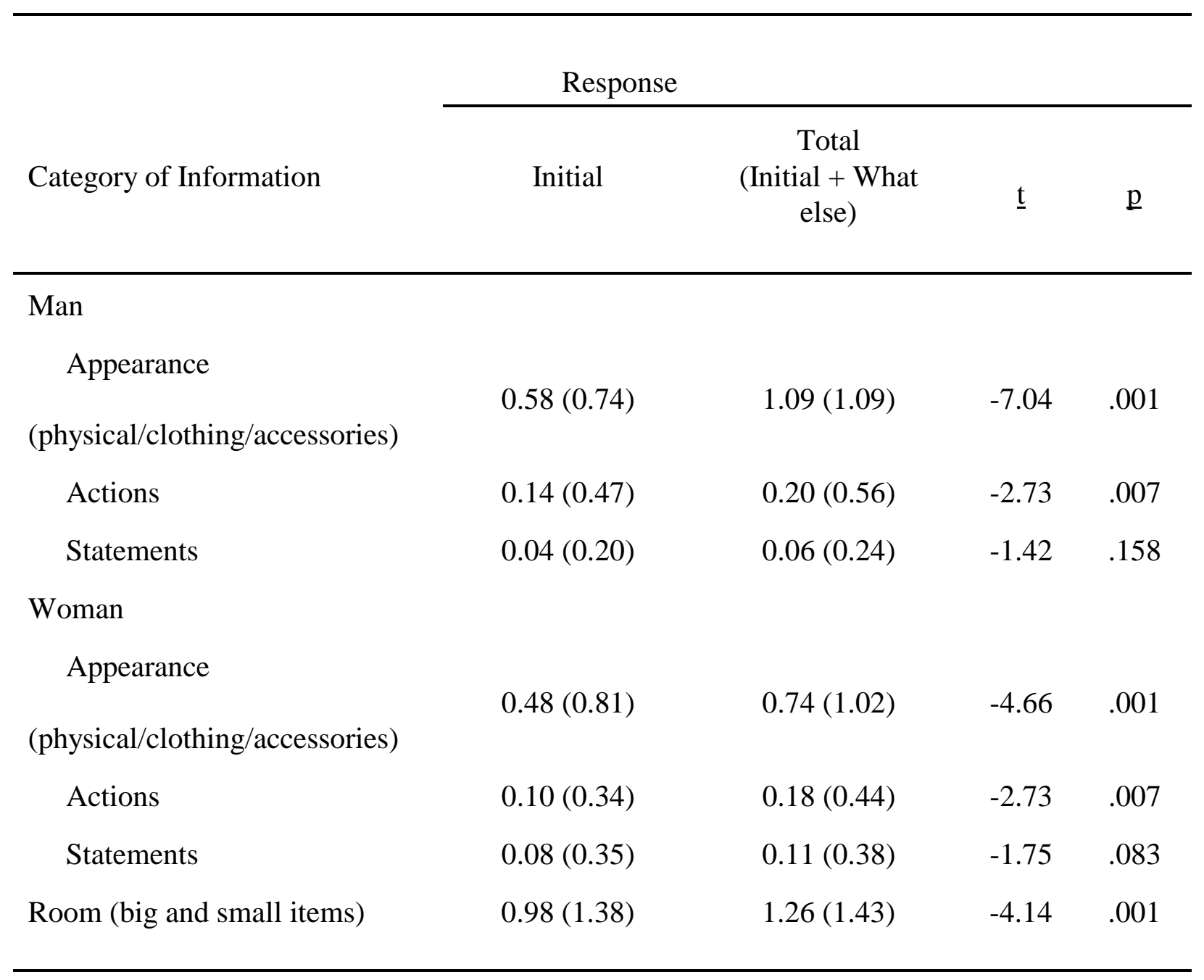




\section{Table 13}

$\underline{\text { Mean Proportions and Standard Deviations of Accurate Gender-specific Information as a }}$

Function of Type of Information: Free Recall

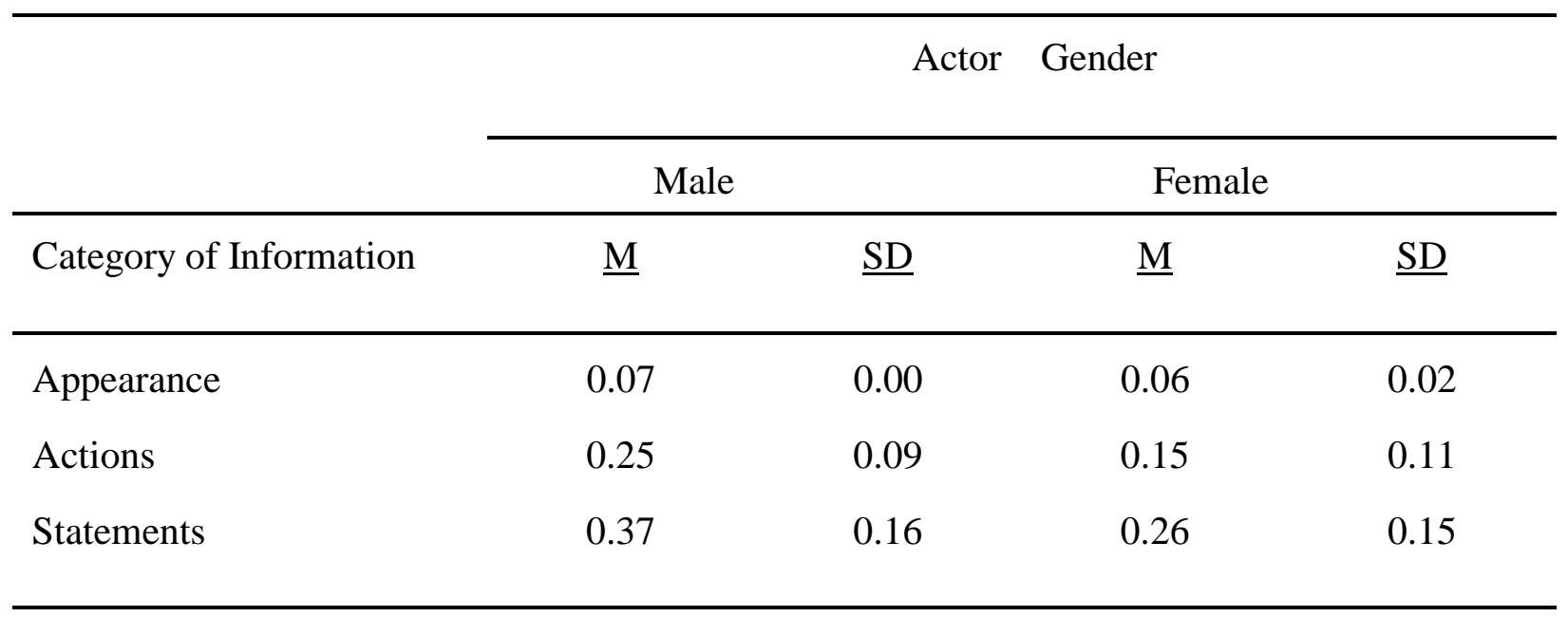

Note. All pairwise comparisons for the type of information were significant for both the male and female actors, $\underline{p}<.001$. In addition, all pairwise comparisons for actor gender were significant for the three different types of information, $\underline{p}<.001$. 
Table 14

Mean Proportions and Standard Deviations of Accurate Gender-specific Information as a

Function of Child Gender: Prompted Recall

\begin{tabular}{|c|c|c|c|c|}
\hline \multirow[b]{3}{*}{ Child Gender } & & \multicolumn{2}{|c|}{ Actor Gender } & \\
\hline & & Male & \multicolumn{2}{|c|}{ Female } \\
\hline & $\underline{\mathrm{M}}$ & $\underline{\mathrm{SD}}$ & $\underline{\mathrm{M}}$ & $\underline{\mathrm{SD}}$ \\
\hline Boys & 0.37 & 0.10 & 0.29 & 0.09 \\
\hline Girls & 0.38 & 0.11 & 0.34 & 0.09 \\
\hline
\end{tabular}

Note. Pairwise comparisons for actor gender were significant for both boys and girls, $\underline{p}<.001$. 
Table 15

Means (and Standard Deviations) of Inaccurate General Information (Raw Scores) as a Function of Type of Error: Free and Prompted Recall

\begin{tabular}{lccc}
\hline & \multicolumn{3}{c}{ Type of Error } \\
\cline { 2 - 4 } Category of Information & Omission & $\begin{array}{c}\text { Factually-Incorrect } \\
\text { Commission }\end{array}$ & $\begin{array}{c}\text { Intrusion } \\
\text { Commission }\end{array}$ \\
\hline Free Recall & $29.93(0.44)$ & $0.04(0.20)$ & $0.00(0.00)$ \\
Appearance & $19.90(2.10)$ & $0.07(0.26)$ & $0.08(0.37)$ \\
Actions & $15.57(3.23)$ & $0.00(0.00)$ & $0.04(0.20)$ \\
Statements & $30.75(1.18)$ & $0.00(0.00)$ & $0.03(0.23)$ \\
Room & & & $1.83(1.85)$ \\
Prompted Recall & $20.65(2.72)$ & $3.43(1.65)$ & $0.39(0.77)$ \\
Appearance & $17.98(2.92)$ & $0.23(0.45)$ & $0.18(0.50)$ \\
Actions & $13.72(3.41)$ & $0.01(0.10)$ & $1.26(1.43)$ \\
Statements & $23.69(3.40)$ & $0.03(0.17)$ & \\
Room & & & \\
\hline
\end{tabular}


Table 16

Means (and Standard Deviations) of Inaccurate Gender-Specific Information (Raw Scores) as a

Function of Type of Error: Free Recall

\begin{tabular}{lccc}
\hline & \multicolumn{3}{c}{ Type of Error } \\
\cline { 2 - 4 } Category of Information & Omission & $\begin{array}{c}\text { Factually-Incorrect } \\
\text { Commission }\end{array}$ & $\begin{array}{c}\text { Intrusion } \\
\text { Commission }\end{array}$ \\
\hline Man & $12.99(0.10)$ & $0.02(0.14)$ & $0.00(0.00)$ \\
Appearance & $10.51(1.32)$ & $0.07(0.26)$ & $0.03(0.17)$ \\
Actions & $8.22(2.11)$ & $0.00(0.00)$ & $0.01(0.10)$ \\
Statements & & & $0.00(0.00)$ \\
Woman & $16.94(0.43)$ & $0.02(0.14)$ & $0.05(0.27)$ \\
Appearance & $9.39(1.18)$ & $0.00(0.00)$ & $0.03(0.17)$ \\
Actions & $7.35(1.47)$ & $0.00(0.00)$ & \\
Statements & & & \\
\hline
\end{tabular}


Table 17

Means (and Standard Deviations) of Inaccurate Gender-Specific Information (Raw Scores) as a

Function of Type of Error: Prompted Recall

\begin{tabular}{lccc}
\hline & \multicolumn{3}{c}{ Type of Error } \\
\cline { 2 - 4 } Category of Information & Omission & $\begin{array}{c}\text { Factually-Incorrect } \\
\text { Commission }\end{array}$ & $\begin{array}{c}\text { Intrusion } \\
\text { Commission }\end{array}$ \\
\hline Man & & & \\
Appearance & $8.43(1.34)$ & $1.88(1.09)$ & $1.09(1.09)$ \\
Actions & $9.69(1.83)$ & $0.20(0.40)$ & $0.20(0.56)$ \\
Statements & $7.53(2.29)$ & $0.01(0.10)$ & $0.06(0.24)$ \\
Woman & & & $0.74(1.02)$ \\
Appearance & $12.22(2.06)$ & $1.55(1.11)$ & $0.18(0.44)$ \\
Actions & $8.29(1.50)$ & $0.03(0.17)$ & $0.11(0.38)$ \\
Statements & $6.19(1.56)$ & $0.00(0.00)$ & \\
\hline
\end{tabular}


Table 18

Mean Proportions and Standard Deviations of Omission Errors for Gender-specific Information as a Function of Type of Information: Free Recall

\begin{tabular}{|c|c|c|c|c|}
\hline \multirow[b]{3}{*}{ Category of Information } & \multicolumn{4}{|c|}{ Actor Gender } \\
\hline & \multicolumn{2}{|l|}{ Male } & \multicolumn{2}{|c|}{ Female } \\
\hline & $\underline{\mathrm{M}}$ & $\underline{\mathrm{SD}}$ & $\underline{\mathrm{M}}$ & $\underline{\mathrm{SD}}$ \\
\hline Appearance & 0.93 & 0.00 & 0.94 & 0.02 \\
\hline Actions & 0.75 & 0.09 & 0.85 & 0.11 \\
\hline Statements & 0.63 & 0.16 & 0.74 & 0.15 \\
\hline
\end{tabular}

Note. All pairwise comparisons for the type of information were significant for both the male and female actors, $\underline{p}<.001$. In addition, all pairwise comparisons for actor gender were significant for the three different types of information, $\underline{p}<.001$. 
Table 19

Mean Proportions and Standard Deviations of Omission Errors for Gender-specific Information as a Function of Child Gender: Prompted Recall

\begin{tabular}{|c|c|c|c|c|}
\hline \multirow[b]{3}{*}{ Child Gender } & & \multicolumn{2}{|c|}{ Actor Gender } & \\
\hline & \multicolumn{2}{|l|}{ Male } & \multicolumn{2}{|c|}{ Female } \\
\hline & $\underline{\mathrm{M}}$ & $\underline{\mathrm{SD}}$ & $\underline{\mathrm{M}}$ & $\underline{\mathrm{SD}}$ \\
\hline Boys & 0.63 & 0.10 & 0.71 & 0.09 \\
\hline Girls & 0.62 & 0.11 & 0.66 & 0.09 \\
\hline
\end{tabular}

Note. Pairwise comparisons for actor gender were significant for both boys and girls, $\underline{p} \leq .001$. 
Table 20

Non-Leading and Leading Interview Specific Questions

\begin{tabular}{|c|c|}
\hline \multicolumn{2}{|l|}{ Type of Interview } \\
\hline Non-Leading (NL) & Leading (L) \\
\hline Man & Characteristics \\
\hline What color hair did the man have? & [same as NL] \\
\hline Did the man have a mustache? & [same as NL] \\
\hline Was the man wearing dark colored pants? & $\begin{array}{l}\text { Wasn't the man wearing dark colored pants? } \\
\text { (CL) }\end{array}$ \\
\hline What color was the man's shirt? & [same as NL] \\
\hline $\begin{array}{l}\text { Did the man put his coat on the back of a } \\
\text { chair? }\end{array}$ & $\begin{array}{l}\text { The man put his coat on the back of a chair, } \\
\text { didn't he? (IL) }\end{array}$ \\
\hline Did the man have a newspaper? & [same as NL] \\
\hline Was the man wearing a tie? & Wasn't the man wearing a tie? (CL) \\
\hline $\begin{array}{l}\text { Did the man have a briefcase when he came } \\
\text { home? }\end{array}$ & $\begin{array}{l}\text { Did the man set his briefcase on the table or } \\
\text { by the door when he came home? (IL) }\end{array}$ \\
\hline Woman & Characteristics \\
\hline What color was the woman's hair? & [same as NL] \\
\hline Did the woman have long or short hair? & Didn't the woman have long hair? (IL) \\
\hline Was the woman wearing a necklace? & $\begin{array}{l}\text { The woman was wearing a necklace, wasn't } \\
\text { she? (CL) }\end{array}$ \\
\hline What color was the woman's shirt? & [same as NL] \\
\hline What color were the woman's pants? & [same as NL] \\
\hline Was the woman wearing glasses? & Wasn't the woman wearing glasses? (CL) \\
\hline Was the woman wearing an apron? & [same as NL] \\
\hline $\begin{array}{l}\text { Was the woman washing dishes when the } \\
\text { man came home? }\end{array}$ & $\begin{array}{l}\text { Was the woman washing dishes or setting the } \\
\text { table when the man came home? (IL) }\end{array}$ \\
\hline
\end{tabular}

Note. For the leading interview, correctly leading questions are denoted as "CL," whereas incorrectly leading questions are represented by "IL." 
Table 20 (continued)

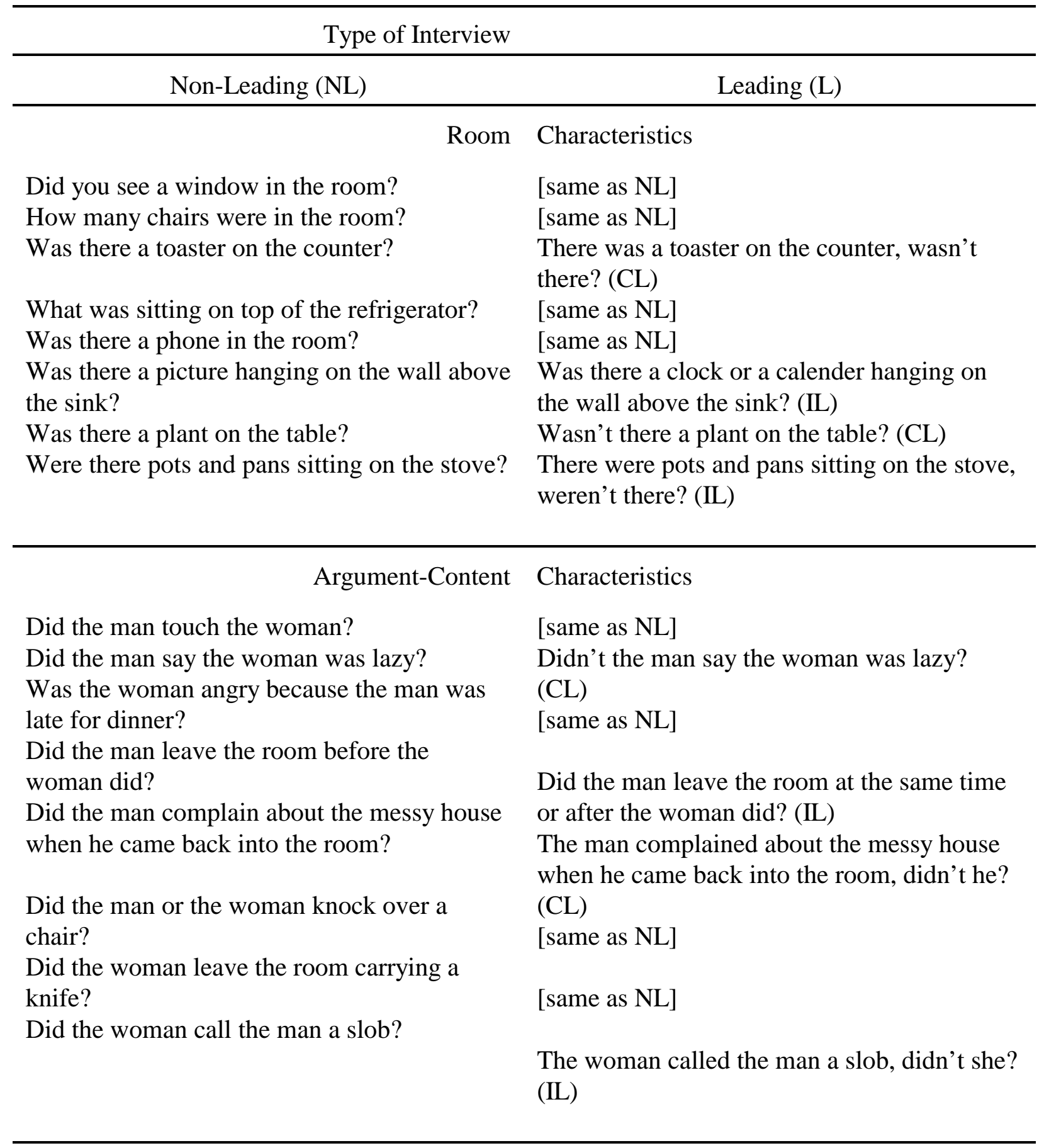

Note. For the leading interview, correctly leading questions are denoted as "CL," whereas incorrectly leading questions are represented by "IL." 
Table 21

Mean Proportions (and Standard Deviations) of Accurate Responses as a Function of

Type of Interview and Type of Question: Specific Questions

Type of Question

\begin{tabular}{lccc}
\cline { 2 - 4 } Type of Interview & Non-leading & "Correctly" leading & "Incorrectly" leading \\
\hline Non-leading & $0.70(0.10)$ & $0.66(0.16)$ & $0.65(0.15)$ \\
Leading & $0.70(0.10)$ & $0.71(0.12)$ & $0.50(0.18)$ \\
\hline
\end{tabular}


Table 22

Mean Proportions (and Standard Deviations) of Leading Interview Responses as a Function of Type of Question, Type of Response, and Type of Information

\begin{tabular}{|c|c|c|c|c|}
\hline \multirow[b]{3}{*}{ Category of Information } & \multicolumn{4}{|c|}{ Type of Question } \\
\hline & \multicolumn{2}{|c|}{ Correctly Leading } & \multicolumn{2}{|c|}{ Incorrectly Leading } \\
\hline & Accurate Responses & Consistent Response & Accurate Response & Consistent Response \\
\hline Man characteristics & $0.83(0.26)$ & $0.83(0.26)$ & $0.33(0.26)$ & $0.65(0.27)$ \\
\hline Woman characteristics & $0.48(0.31)$ & $0.48(0.31)$ & $0.74(0.29)$ & $0.26(0.29)$ \\
\hline Room characteristics & $0.52(0.36)$ & $0.52(0.36)$ & $0.30(0.34)$ & $0.64(0.35)$ \\
\hline $\begin{array}{l}\text { Argument-content } \\
\text { characteristics }\end{array}$ & $1.00(0.00)$ & $1.00(0.00)$ & $0.61(0.36)$ & $0.38(0.36)$ \\
\hline
\end{tabular}


Table 23

Mean Proportions (and Standard Deviations) of "Don't Know/Remember" Responses as a

Function of Type of Question, Type of Interview, and Type of Information: Specific Questions

\begin{tabular}{llll}
\hline & \multicolumn{3}{c}{ Type of Question } \\
\cline { 2 - 4 } Category of Information & Non-leading & "Correctly" leading & "Incorrectly" leading \\
\hline Non-Leading Interview & & & \\
Man & $0.00(0.04)$ & $0.03(0.12)$ & $0.01(0.07)$ \\
Woman & $0.04(0.12)$ & $0.06(0.17)$ & $0.00(0.00)$ \\
Room & $0.10(0.12)$ & $0.02(0.10)$ & $0.07(0.21)$ \\
Argument-content & $0.00(0.04)$ & $0.00(0.00)$ & $0.01(0.07)$ \\
Leading Interview & & & $0.01(0.07)$ \\
Man & $0.01(0.05)$ & $0.00(0.00)$ & $0.00(0.00)$ \\
Woman & $0.04(0.09)$ & $0.03(0.12)$ & $0.05(0.19)$ \\
Room & $0.10(0.13)$ & $0.06(0.17)$ & $0.01(0.07)$ \\
Argument-content & $0.00(0.00)$ & $0.00(0.00)$ & \\
\hline
\end{tabular}


Table 24

Means and Standard Deviations for Parent- and Child-Report Measures of Individual Difference

$\underline{\text { Variables }}$

\begin{tabular}{lccc}
\hline Measure & $\underline{\mathrm{M}}$ & $\underline{\underline{S D}}$ & Range \\
\hline Parent-report & & & \\
$\quad$ Social Anxiety: SPAI-C, parent & 12.31 & 6.17 & $0.67-28.67$ \\
$\quad$ Withdrawal/Approach: DOTS-R & 14.22 & 3.85 & $7-21$ \\
$\quad$ Rigidity/Flexibility: DOTS-R & 9.11 & 2.78 & $5-17$ \\
Task Orientation: DOTS-R & 20.49 & 4.41 & $10-31$ \\
Child-report & & & $5-19$ \\
$\quad$ Digit Span & 10.45 & 3.33 & $0.00-30.28$ \\
Social Anxiety: SPAI-C & 13.40 & 7.22 & $8-26$ \\
Assertiveness: CATS & 21.72 & 2.99 & $4-19$ \\
Submissiveness: CATS & 12.47 & 3.24 & $21.8-67.2$ \\
General Anxiety: RCMAS & 41.86 & 8.44 & $36.9-84.7$ \\
Lie Scale: RCMAS & 52.00 & 10.87 & \\
\hline
\end{tabular}

Note. One parent elected not to complete the parent-report measures. 
Table 25

$\underline{\text { Interrelations Between Parent-Report Assessments of Individual Difference Variables }}$

\begin{tabular}{|c|c|c|c|c|}
\hline \multirow[b]{2}{*}{ Parent-report } & \multirow[b]{2}{*}{$\begin{array}{l}\text { Social Anxiety } \\
\text { (SPAI-C) }\end{array}$} & \multicolumn{3}{|c|}{ DOTS-R } \\
\hline & & $\begin{array}{l}\text { Withdrawal/ } \\
\text { Approach }\end{array}$ & $\begin{array}{l}\text { Rigidity/ } \\
\text { Flexibility }\end{array}$ & $\begin{array}{c}\text { Task } \\
\text { Orientation }\end{array}$ \\
\hline $\begin{array}{l}\text { Social Anxiety } \\
\text { (SPAI-C, parent) }\end{array}$ & ---- & $.48 * *$ & $.43^{* *}$ & .05 \\
\hline $\begin{array}{l}\text { Withdrawal/Approach } \\
\text { (DOTS-R) }\end{array}$ & & ---- & $.44^{* *}$ & $.22 *$ \\
\hline $\begin{array}{l}\text { Rigidity/Flexibility } \\
\text { (DOTS-R) }\end{array}$ & & & ---- & .07 \\
\hline $\begin{array}{l}\text { Task Orientation } \\
\text { (DOTS-R) }\end{array}$ & & & & ---- \\
\hline
\end{tabular}

* Correlations significant at $\underline{p}<.05$ using two-tailed tests.

$* \mathrm{p}<.05, * * \mathrm{p}<.001$ 
Table 26

Interrelations Between Child-Report Assessments of Individual Difference Variables

\begin{tabular}{|c|c|c|c|c|c|c|}
\hline Child-report & Digit Span & $\begin{array}{l}\text { Social Anxiety } \\
\quad \text { (SPAI-C) }\end{array}$ & $\begin{array}{l}\text { Assertiveness } \\
\text { (CATS) }\end{array}$ & $\begin{array}{c}\text { Submissivenes } \\
\text { s } \\
\text { (CATS) }\end{array}$ & $\begin{array}{c}\text { General } \\
\text { Anxiety } \\
\text { (RCMAS) }\end{array}$ & $\begin{array}{c}\text { Lie } \\
(\mathrm{RCMAS})\end{array}$ \\
\hline Digit Span & ---- & $-.21 *$ & -.03 & .10 & -.08 & -.09 \\
\hline Social Anxiety (SPAI-C) & & ---- & $.21 *$ & .05 & $.47 *$ & -.07 \\
\hline Assertiveness (CATS) & & & ---- & .01 & .07 & .14 \\
\hline Submissiveness (CATS) & & & & ---- & -.08 & .13 \\
\hline General Anxiety (RCMAS) & & & & & ---- & -.19 \\
\hline Lie (RCMAS) & & & & & & ----- \\
\hline
\end{tabular}

* Correlations significant at $\underline{\mathrm{p}}<.05$ using two-tailed tests. 
Table 27

Interrelations Between Parent- and Child-Report Assessments of Individual Difference Variables

\begin{tabular}{|c|c|c|c|c|c|}
\hline \multirow[b]{2}{*}{ Parent-Report } & \multicolumn{5}{|c|}{ Child-Report } \\
\hline & Digit Span & $\begin{array}{l}\text { Social Anxiety } \\
\text { (SPAI-C) }\end{array}$ & $\begin{array}{c}\text { Assertiveness } \\
(\text { CATS })\end{array}$ & $\begin{array}{c}\text { Submissiveness } \\
(\text { CATS })\end{array}$ & $\begin{array}{c}\text { General Anxiety } \\
\text { (RCMAS) }\end{array}$ \\
\hline $\begin{array}{l}\text { Social Anxiety } \\
\text { (SPAI-C, parent) }\end{array}$ & $-.22 *$ & .12 & -.01 & -.06 & .01 \\
\hline $\begin{array}{l}\text { Withdrawal/Approach } \\
\text { (DOTS-R) }\end{array}$ & .04 & .12 & -.15 & -.06 & .08 \\
\hline $\begin{array}{l}\text { Rigidity/Flexibility } \\
\text { (DOTS-R) }\end{array}$ & -.04 & .04 & .02 & -.11 & .04 \\
\hline $\begin{array}{l}\text { Task Orientation } \\
\text { (DOTS-R) }\end{array}$ & $.22 *$ & -.02 & .12 & .06 & $-.21 *$ \\
\hline
\end{tabular}

* Correlations significant at $\underline{p}<.05$ using two-tailed tests. 
Table 28

$\underline{\text { Factor Analysis of Parent-and Child-Report Assessments of Individual Difference Variables }}$

\begin{tabular}{|c|c|c|c|c|}
\hline Measures & $\begin{array}{c}\text { Factor 1: } \\
\text { Parental Perceptions of } \\
\text { Anxiety } \\
\end{array}$ & $\begin{array}{c}\text { Factor 2: } \\
\text { Child Anxiety }\end{array}$ & $\begin{array}{l}\text { Factor 3: } \\
\text { Attention }\end{array}$ & $\begin{array}{c}\text { Factor 4: } \\
\text { Social Desirability }\end{array}$ \\
\hline $\begin{array}{l}\text { Social Anxiety } \\
\text { (SPAI-C, parent) }\end{array}$ & .79 & & & \\
\hline $\begin{array}{l}\text { Withdrawal/Approach } \\
\text { (DOTS-R) }\end{array}$ & .80 & & & \\
\hline $\begin{array}{l}\text { Rigidity/Flexibility } \\
\text { (DOTS-R) }\end{array}$ & .76 & & & \\
\hline $\begin{array}{l}\text { Social Anxiety } \\
\text { (SPAI-C) }\end{array}$ & & .79 & & \\
\hline $\begin{array}{l}\text { General Anxiety } \\
\text { (RCMAS) }\end{array}$ & & .82 & & \\
\hline $\begin{array}{l}\text { Task Orientation } \\
\text { (DOTS-R) }\end{array}$ & & & .76 & \\
\hline Digit-Span & & & .73 & \\
\hline Assertiveness (CATS) & & & & .69 \\
\hline Submissiveness(CATS) & & & & .53 \\
\hline Lie (RCMAS) & & & & .58 \\
\hline
\end{tabular}


Table 29

Interrelations among Variables included in the Standard Multiple Regression

\begin{tabular}{|c|c|c|c|c|c|c|c|c|c|}
\hline Variables & 1 & 2 & 3 & 4 & 5 & 6 & 7 & 8 & 9 \\
\hline 1. Age & ---- & -.04 & .09 & .05 & -.09 & -.25 & .04 & -.15 & .15 \\
\hline 2. Child Gender & & ---- & .05 & .08 & $.35^{*}$ & $.34 *$ & -.09 & -.13 & .24 \\
\hline $\begin{array}{l}\text { 3. Factor 1:Perceptions } \\
\text { of Child Anxiety }\end{array}$ & & & ---- & -.05 & -.06 & .05 & -.25 & .06 & -.11 \\
\hline $\begin{array}{l}\text { 4. Factor 2: } \\
\text { Child Anxiety }\end{array}$ & & & & ---- & .01 & -.12 & .20 & -.15 & .12 \\
\hline $\begin{array}{l}\text { 5. Factor 3: } \\
\text { Attention }\end{array}$ & & & & & ---- & -.01 & -.01 & -.19 & .17 \\
\hline $\begin{array}{l}\text { 6. Factor 4: } \\
\text { Social Desirability }\end{array}$ & & & & & & ---- & $-.34 *$ & -.14 & .16 \\
\hline $\begin{array}{l}\text { 7. Correctly Leading: } \\
\text { Accuracy }\end{array}$ & & & & & & & ---- & .17 & -.11 \\
\hline $\begin{array}{l}\text { 8. Incorrectly Leading: } \\
\text { Consistency }\end{array}$ & & & & & & & & ---- & $-.94 *$ \\
\hline $\begin{array}{l}\text { 9. Incorrectly Leading: } \\
\text { Accuracy }\end{array}$ & & & & & & & & & ---- \\
\hline
\end{tabular}

* Correlations significant at $\underline{p}<.05$ using two-tailed tests. 
Table 30

$\underline{\text { Standard Multiple Regression for Individual Difference Variables Predicting Accuracy: }}$

Incorrectly Leading Questions

\begin{tabular}{lccc}
\hline Variable & $\underline{\mathrm{B}}$ & $\underline{\mathrm{SE}} \underline{\mathrm{B}}$ & $\beta$ \\
\hline Age & 0.00 & 0.01 & 0.01 \\
Child Gender & $0.06^{*}$ & 0.02 & 0.16 \\
$\begin{array}{l}\text { Factor 1: Perceptions } \\
\text { of Child Anxiety }\end{array}$ & -0.01 & 0.01 & -0.06 \\
$\begin{array}{l}\text { Factor 2: } \\
\text { Child Anxiety }\end{array}$ & 0.00 & 0.01 & -0.04 \\
$\begin{array}{l}\text { Factor 3: } \\
\text { Attention }\end{array}$ & -0.01 & 0.01 & -0.07 \\
$\begin{array}{l}\text { Factor 4: } \\
\text { Social Desirability }\end{array}$ & 0.00 & 0.01 & -0.02 \\
$\begin{array}{l}\text { Consistency of } \\
\text { Response }\end{array}$ & $-0.87^{*}$ & 0.05 & -0.94 \\
\hline
\end{tabular}

$\underline{\mathrm{R}}=.95$

$\underline{\mathrm{R}}^{2}=.91$

Adjusted $\underline{\mathrm{R}}^{2}=.89$ 